Portland State University

PDXScholar

\title{
Understanding the Accessibility, Economic and Social Equity Impacts of Urban Greenway Infrastructure
}

Jenny Hsing-I Liu

Portland State University

Wei Shi

Portland State University

Follow this and additional works at: https://pdxscholar.library.pdx.edu/trec_reports

Part of the Transportation Commons, and the Urban Studies Commons Let us know how access to this document benefits you.

\section{Recommended Citation}

Liu, Jenny H. and Shi, Wei. Understanding the Accessibility, Economic and Social Equity Impacts of Urban Greenway Infrastructure. NITC-RR-858. Portland, OR: Transportation Research and Education Center (TREC), 2018. http://doi.org/10.15760/trec.207

This Report is brought to you for free and open access. It has been accepted for inclusion in TREC Final Reports by an authorized administrator of PDXScholar. Please contact us if we can make this document more accessible: pdxscholar@pdx.edu. 
FINAL REPORT

\section{Understanding the Accessibility, Economic and Social Equity Impacts of Urban Greenway Infrastructure}

NITC-RR-858 August 2018

NITC is a U.S. Department of Transportation national university transportation center.

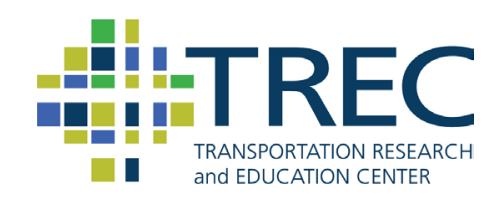





\title{
UNDERSTANDING THE ACCESSIBILITY, ECONOMIC AND SOCIAL EQUITY IMPACTS OF URBAN GREENWAY INFRASTRUCTURE
}

\author{
Final Report \\ NITC-RR-858 \\ by \\ Jenny Hsing-I Liu, Ph.D. \\ Portland State University \\ Wei Shi \\ Portland State University
}

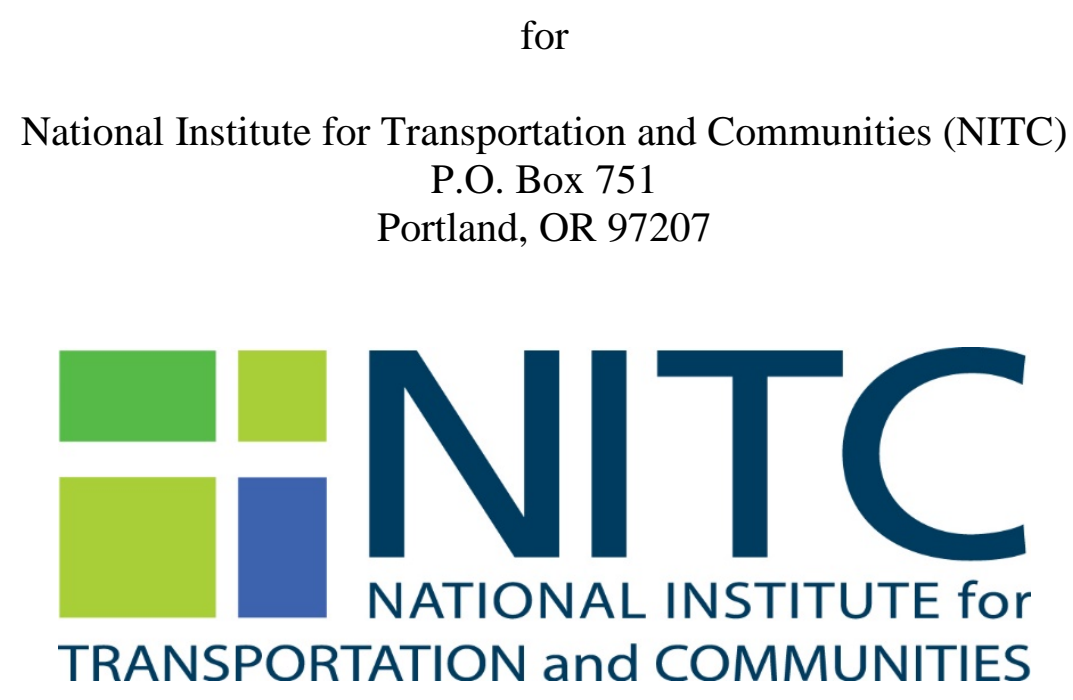

August 2018 


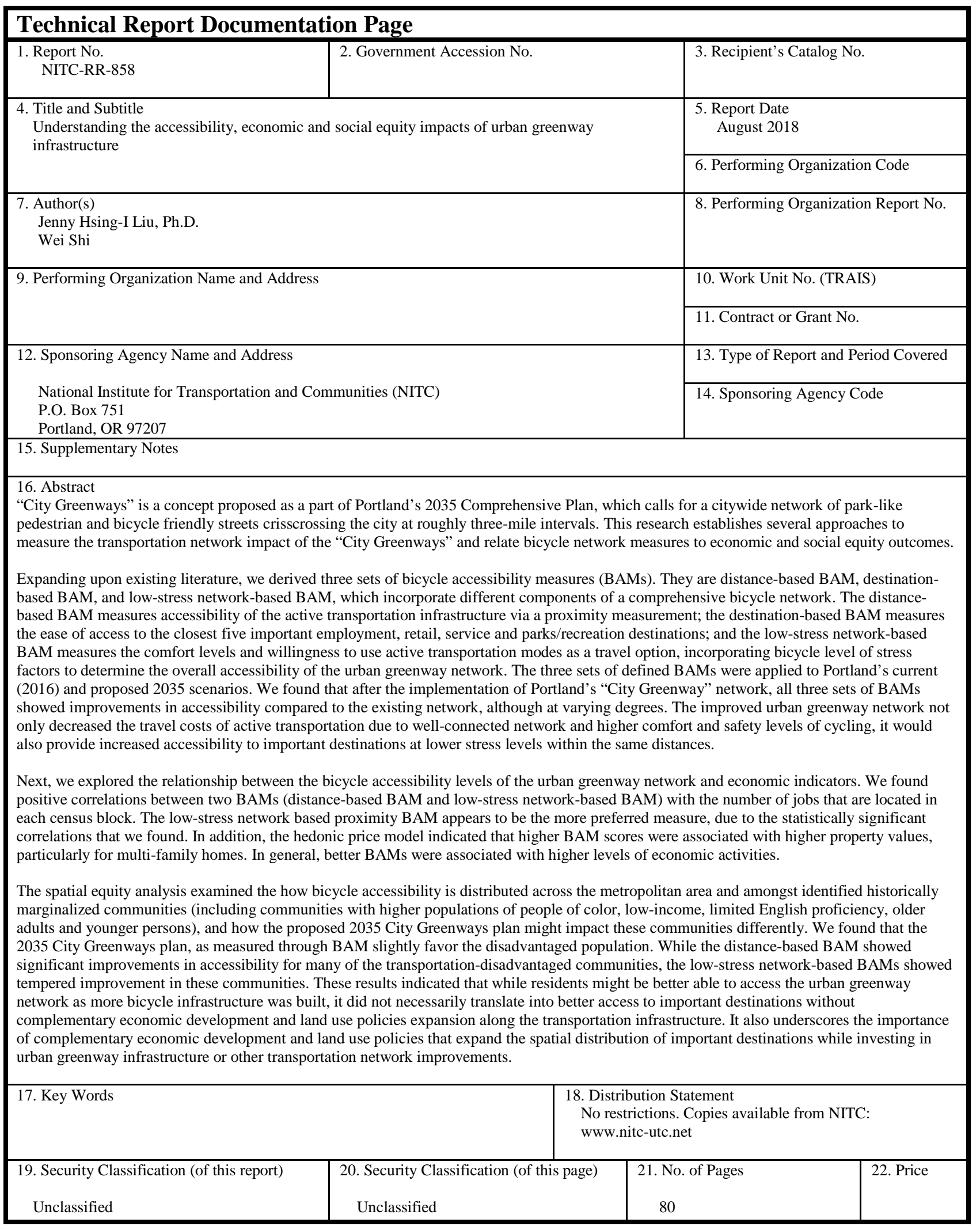




\section{ACKNOWLEDGEMENTS}

This project was funded by the National Institute for Transportation and Communities (NITC) under grant number (858). The authors would like to thank Mark Raggett and Tyler Bump at the Portland Bureau of Planning and Sustainability (BPS) for collaborating on this research effort.

\section{DISCLAIMER}

The contents of this report reflect the views of the authors, who are solely responsible for the facts and the accuracy of the material and information presented herein. This document is disseminated under the sponsorship of the U.S. Department of Transportation University Transportation Centers Program in the interest of information exchange. The U.S. Government assumes no liability for the contents or use thereof. The contents do not necessarily reflect the official views of the U.S. Government. This report does not constitute a standard, specification, or regulation.

\section{RECOMMENDED CITATION}

Liu, Jenny H. and Shi, Wei. Understanding the Accessibility, Economic and Social Equity Impacts of Urban Greenway Infrastructure. NITC-RR-858. Portland, OR: Transportation Research and Education Center (TREC), 2018. 


\section{TABLE OF CONTENTS}

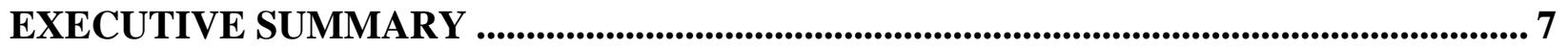

1.0 INTRODUCTION.......................................................................................................... 10

$2.0 \quad$ LITERATURE REVIEW .................................................................................................... 11

2.1 TRANSPORTATION IMPACT MEASURES ……….............................................. 11

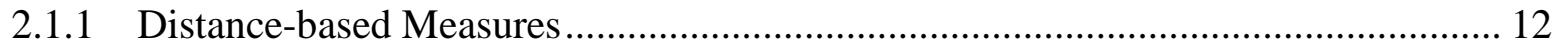

2.1.2 Destination-based Measures ........................................................................... 13

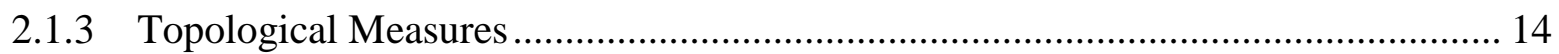

2.1.4 Walkabilty and Bikeability Measures ......................................................................... 16

2.2 ECONOMIC IMPACT MEASURES ……………......................................................... 17

2.2.1 Bicycle- and Pedestrian-related Infrastructure Investment.................................... 17

2.2.2 Business Vitality/Consumer Spending ……….................................................... 18

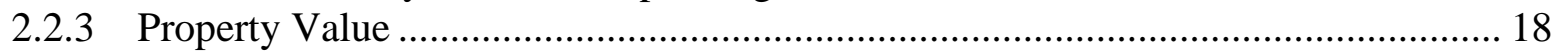

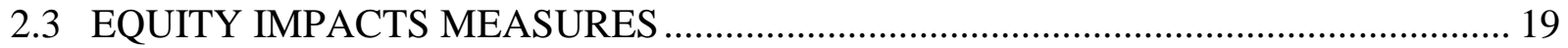

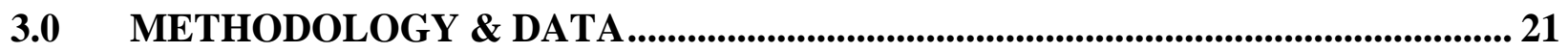

3.1 METHODS FOR TRANSPORTATION IMPACTS ………………………….............. 21

3.1.1 Distance-based BAM .................................................................................. 21

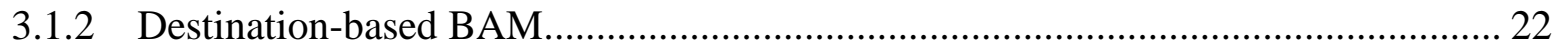

3.1.3 Low-stress Network BAM ........................................................................................ 27

3.1.4 Data for Transportation Impacts Methods ................................................................ 28

3.2 METHODS FOR ECONOMIC IMPACTS …………….............................................. 29

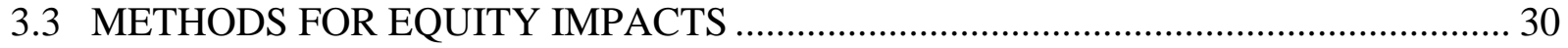

4.0 RESULTS - TRANSPORTATION IMPACTS............................................................... 35

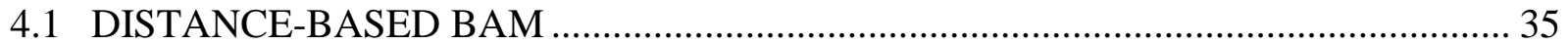

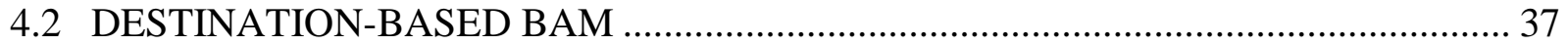

4.3 LOW-STRESS NETWORK-BASED BAMS ............................................................ 41

4.3.1 Low-Stress Network BAM - Proximity to Closest Five Important Destinations .... 43

4.3.2 Low-Stress Network BAM - Stress Level of Route to Closest Five Importation

Destinations Containing Low-Stress Segments ..................................................................... 49

4.3.3 Low-Stress Network BAM - Percentage of Important Destinations Reached through

Low-Stress Network ......................................................................................................... 54

5.0 RESULT - ECONOMIC IMPACTS.......................................................................... 57

5.1 ECONOMIC IMPACTS - EMPLOYMENT ……………………………………....... 58

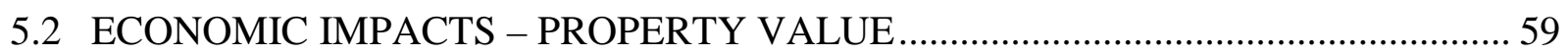

6.0 RESULTS - EQUITY IMPACTS …....................................................................65

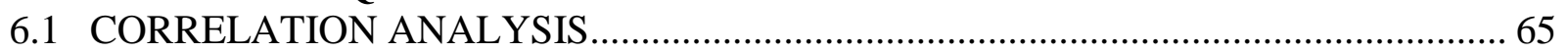

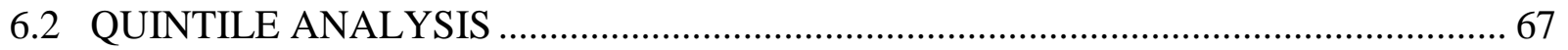

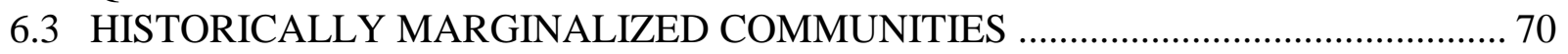

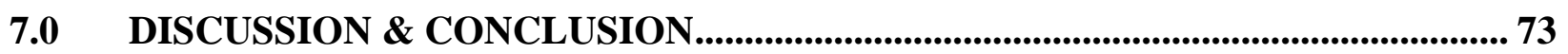

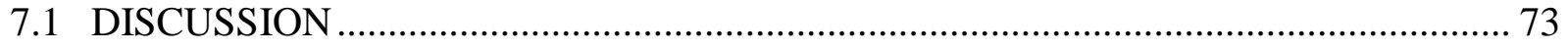

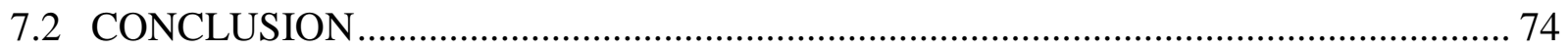

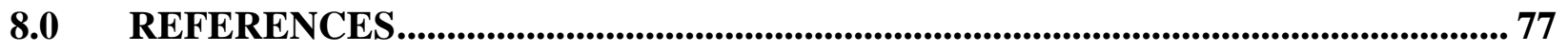




\section{LIST OF TABLES}

Table 1. Integration of Four Types of Transportation Network Measures within FHWA Six Complete Network Principles

Table 2. Urban Connectivity Parameters Summary ……………………………................. 14

Table 3. Change in the Stress Factor for Various Types of Bicycle Facility/Infrastructure on

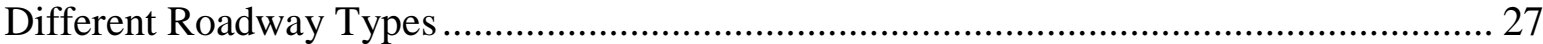

Table 4. Change in the Slope Factor for Different Slope Categories .............................................. 27

Table 5. Portland Metro Historically Marginalized Communities Criteria ..................................... 31

Table 6. Percent of Important Destinations Easily Reachable Using Urban Greenways .............. 38

Table 7. Percent of Centers Covered by Quarter Bike Network Catchment Zone (weighted destination access BAM) ……………………………………………………………..... 41

Table 8. Median Proximity (feet) to Closest Five Important Destinations Weighted by Stress

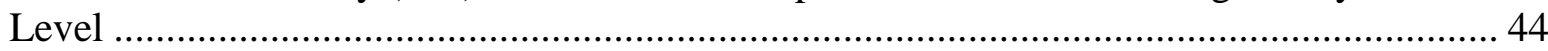

Table 9. Stress Level of Route BAM................................................................................. 49

Table 10. Percentage of Important Destination Reached by 2.5-mile Low-Stress Network........ 54

Table 11. Standardized BAM Score Summary ........................................................................... 57

Table 12. Correlation Between BAM Score and Employment at Block Level ............................. 58

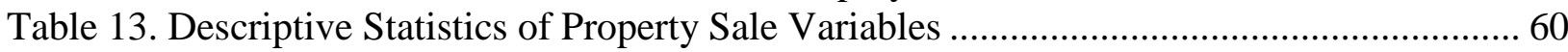

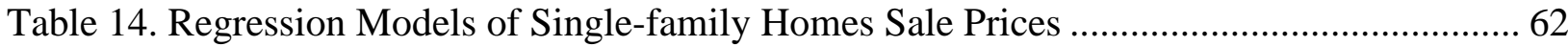

Table 15. Regression Models of Multifamily Homes Sale Prices .................................................... 63

Table 16. Correlation Analysis of Distance-based BAM Score and Block Group Environmental

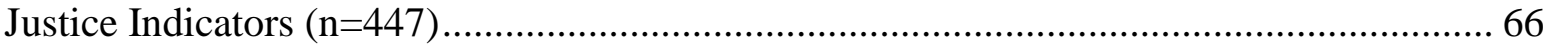

Table 17. Correlation Analysis of Low-stress Network BAM Score and Block Group

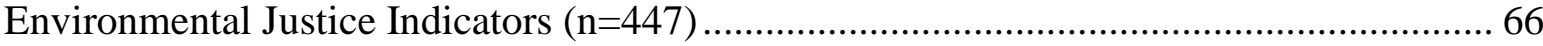

Table 18. BAM Changes by Environmental Justice Indicators .................................................... 72 


\section{LIST OF FIGURES}

Figure 1. Illustration of the Distance-based Bicycle Accessibility Measure (BAM) .................. 22

Figure 2. Important Urban Destinations in Portland, OR .................................................... 25

Figure 3. Illustration of Destination-based Bicycle Accessibility Measure ............................... 26

Figure 4. Distribution of Current and Proposed Urban Greenways in Portland, OR ................. 29

Figure 5. Correlation of Environmental Justice (EJ) Indicators .......................................... 31

Figure 6. Historically Marginalized Communities in Portland, OR ........................................ 32

Figure 7. Distribution of Social Disadvantaged Population in Portland..................................... 33

Figure 8. Histogram of Distance to Nearest Urban Greenways Before and After Urban Greenway

Improvement ........................................................................................... 35

Figure 9. Distance to Nearest Urban Greenways Before and After Proposed 2035 City

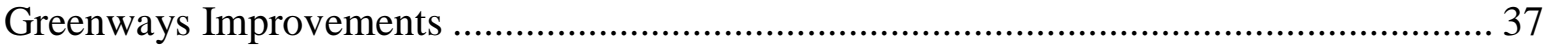

Figure 10. Bikeable Importation Destinations in Portland: (a) Work/Employment; (b) Retail; (c) Service; (d) Park \& Recreations .................................................................................. 40

Figure 11. Portland Bike/Greenways Facilities Before and After Urban Greenway Improvement

Figure 12. Proximity to Closest 5 Important Employment Destinations Weighted by Low-Stress Street Level 48

Figure 13. Level of Route to Destinations Containing Low-Stress Segments Before and After

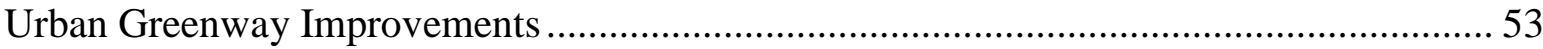

Figure 14. Number of Important Destinations Reached through 2.5-mile Low Stress Network . 55 Figure 15. Distance-Based BAM Score across Environmental Justice Indicator Quintiles (by census block groups) 68

Figure 16. Low-Stress Network Proximity BAM Score across Environmental Justice Indicator Quintiles (by census block groups)

Figure 17. Low-Stress Network Stress Level BAM Score across Environmental Justice Indicator

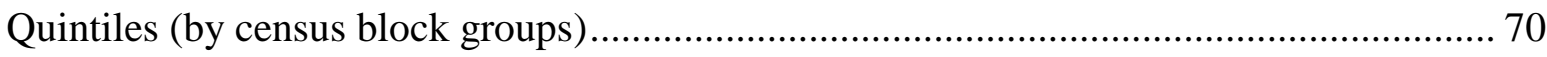




\section{EXECUTIVE SUMMARY}

“City Greenways” is a concept proposed as a part of Portland's 2035 Comprehensive Plan, which calls for a citywide network of park-like pedestrian and bicycle friendly streets crisscrossing the city at roughly three-mile intervals. This research establishes several approaches to measure the transportation network impact of the "City Greenways" and relate bicycle network measures to economic and social equity outcomes. In other words, this report explores and defines several bicycle accessibility measures (BAMs) that characterize urban greenway networks for this purpose.

Past research has shown that changes, improvements and additions to urban greenways can result in multiple types of economic impacts, such as decreases in overall travel costs through lower congestion levels, economic growth, and changes in the distribution of access to opportunities. FHWA (2016) uses a six-principle framework to define a complete urban greenway network, including cohesion, directness, accessibility, alternatives, safety and security, and comfort. Several measures of urban greenway networks are reviewed, including distance-based, destination-based, topology-based and walkability/bikeability measures, based on the FHWA six-principle framework. Expanding upon this field of research, we derived three sets of BAMs. The three sets of BAMs are distance-based BAM, destination-based BAM, and low-stress network-based BAM.

- The distance-based BAM measures accessibility of the active transportation infrastructure via a proximity measurement;

- The destination-based BAM measures the ease of access to the closest five important employment, retail, service and parks/recreation destinations; and

- The low-stress network-based BAM measures the comfort levels and willingness to use active transportation modes as a travel option. It incorporates bicycle level of stress factors (level of service (LOS) of urban greenways), such as link stress, link slope and turn factor to determine the overall accessibility of the urban greenway network.

After we constructed the various BAMs, the relationship between these bicycle accessibility measurements and economic and equity indicators were examined. We measured the economic impact of greenways through correlation analysis between BAMs and employment, and hedonic pricing regression analysis between BAMs and property values. In addition, we examined the equity impact through spatial analysis of BAMs within several definitions of disadvantaged populations in Portland.

Next, the three sets of defined BAMs were applied to Portland's current (2016) and proposed 2035 scenarios. These urban greenway network scenarios, both current and hypothetical future ones, are defined as the advanced bike facility network in Portland, including cycle tracks/separated bike lanes, buffered bike lanes, bike boulevards and regional multiuse paths. We found that after the implementation of Portland's "City Greenway" network, all three sets of BAMs show improvements in accessibility compared to the existing network, although at 
varying degrees. The improvements in the distance-based BAM indicates more proximity to the urban greenway network for the general public. Additionally, the added urban greenway facilities will increase the ease of access to all four types of important destinations, including employment, retail, service and parks/recreation destinations. When high-quality urban greenways are connected to existing bicycle facilities, they contribute to a well-formed and lowstress active transportation network for the city. The improved urban greenway network not only decreases the travel costs of active transportation due to a well-connected network and higher comfort and safety levels of cycling. It will also provide increased accessibility to important destinations at lower stress levels within the same distances.

When we explored the relationship between the bicycle accessibility levels of the urban greenway network and economic indicators, we found positive correlations between two BAMs (distance-based BAM and low-stress network-based BAM) with the number of jobs that are located in each census block. The low-stress network-based proximity BAM appears to be the more preferred measure due to the statistical, significant correlations that we found. In addition, the hedonic price model indicates that higher BAM scores are associated with higher property values, particularly for multifamily homes. In general, better BAMs are associated with higher levels of economic activities.

The spatial equity analysis examines the how bicycle accessibility is distributed across the metropolitan area and amongst identified historically marginalized communities (including communities with higher populations of people of color, low income, limited English proficiency, older adults and younger persons), and how the proposed 2035 City Greenways plan might impact these communities differently. We found that the 2035 City Greenways plan, as measured through BAMs, slightly favors the communities with higher percentages of people of color, low income, and people with limited English proficiency. While the distance-based BAM showed significant improvements in accessibility for many of the transportation-disadvantaged communities, the low-stress network-based BAMs showed tempered improvement in these communities. These results indicate that while residents may be better able to access the urban greenway network as more bicycle infrastructure is built, it does not necessarily translate into better access to important destinations. It also underscores the importance of complementary economic development and land use policies that expand the spatial distribution of important destinations while investing in urban greenway infrastructure or other transportation network improvements.

Future research could expand the understanding of urban greenway networks by incorporating additional active transportation characteristics beyond this research. Given the importance of including access to important destinations, additional geo-cluster analysis can be integrated to further identify the true hot-spot destinations that attract the largest number of trips. It is also plausible to imagine that different types of urban greenway facilities will contribute differently to active transportation behavior (e.g., commuting bicycling versus recreational bicycling) and, thus, economic outcomes.

This research utilizes Portland as an urban laboratory for the transportation, economic and social equity impacts of urban greenway networks. We hope to be able to replicate this methodology in 
other metropolitan areas gearing up to invest in urban greenway networks, to validate and construct a more robust and practice-oriented measurement framework for bicycle accessibility. 


\subsection{INTRODUCTION}

“City Greenways” is a concept proposed as part of Portland’s 2035 Comprehensive Plan, which calls for a citywide network of park-like pedestrian- and bicycle-friendly streets crisscrossing the city at roughly three-mile intervals. Although studies have shown that such urban greenway infrastructure affects property values, tourism, public health and transportation outcomes, there have not been many studies investigating how active transportation improvements may be associated with broader economic and social equity outcomes. While transportation outcomes (e.g., connectivity and modal shifts) of this type of pedestrian- and bicycle-friendly road infrastructure have been documented in recent research, fewer studies have examined the relationship between different levels of active transportation networks within this context. If cities invest in improving existing active transportation infrastructure and filling in gaps within the infrastructure to improve network accessibility, how can policymakers characterize such improvements in the bicycle or pedestrian network accessibility? How can we best characterize the network accessibility measures in order to understand the equity and economic outcomes of these urban greenway improvements? This study utilizes Portland as an urban laboratory to answer these research questions, and explores how these lessons may be applicable and scalable to other metropolitan areas gearing up to invest in urban greenways.

In summary, the goal of this project is to develop "City Greenways” network accessibility measures, and relate the network transport measures to economic and equity outcomes. Our research questions and objectives are:

- What are the ways that we can characterize and measure the accessibility of the urban greenway network?

o Which urban greenway network accessibility measures are more sensitive to various types of active transportation infrastructure investment scenarios, particularly those aimed at improving the network?

o How do urban greenway network accessibility measures relate to economic outcomes?

o How do urban greenway network accessibility measures correspond to equity outcome in the context of providing equitable access to both the urban greenway network itself, as well as providing connections to employment, service and recreational opportunities via the network? 


\subsection{LITERATURE REVIEW}

Past research has shown that changes, improvements and additions to urban greenways, defined as bicycle- and pedestrian-oriented infrastructure located in both on- and off-street settings, can result in multiple types of economic impacts, such as decreases in overall travel costs through lower congestion levels, growth in economic activities (including local business revenues, employment generation, and property values), and changes in the distribution of access to opportunities. Most of the reviewed literature tends to consider these impacts separately. In the following sections, we provide a comprehensive review of the research literature on the transportation, economic and social equity impacts of active transportation infrastructure to provide context for this project. We start with the literature on transportation impacts, which examines the direct impact of urban greenways on the users of these facilities, and then the literature on the potential economic and equity impacts of active transportation network infrastructure that could be derived from better transportation access.

\subsection{TRANSPORTATION IMPACT MEASURES}

The most direct impacts of urban greenways are gleaned from the users of the facilities. It enables the cyclists to reach their destinations faster, safer and via more attractive means (Krizek, 2007). As defined by FHWA (2016), an active transportation network "consists of a series of interconnected facilities that allow non-motorized road users of all ages and abilities to safely and conveniently get where they need to go." Six principles- cohesion, directness, accessibility, alternatives, safety and security, and comfort - are identified to support a complete active transportation network and are defined as follows:

- Cohesion: connected and cohesive active transportation facilities between destinations;

- Directness: minimized distances for pedestrians and bicyclists to reach destinations;

- Accessibility: facilities designed for all users, regardless of age and ability;

- Alternatives: route options for different types of users;

- Safety and security: minimized risk of injury, danger and crime; and

- Comfort: more welcoming amenities and environment.

We follow the FHWA approach outlined above as a framework to categorize different approaches of measuring active transportation networks. Each approach is evaluated on whether it is able to address the six outlined principles in describing a complete urban greenway (or active transportation) network. Four types of transportation network accessibility measures are summarized below: (i) distance-based, (ii) destination-based, (iii) topological and (iv) walkability/bikeability measures. These measures incorporate and evaluate different aspects of the active transportation network. The distance-based and destination-based measures only take into account the directness principle while the topological and walkability/bikeability measures incorporate additional FHWA (2016) active transportation network principles, such as cohesion, alternatives, safety and security, and comfort. Each transportation network accessibility measure for place i will be defined as $A_{i}$ in the following review, and each is specified with a different equation depending on the incorporated principles and concepts. The table below summarizes the 
four types of transportation network measures, along with the data requirements and units of analysis.

Table 1. Integration of Four Types of Transportation Network Measures within FHWA Six Complete Network Principles

\begin{tabular}{|c|c|c|c|}
\hline Method & Principle & Data required & Unit of analysis \\
\hline Distance-based & Directness & $\begin{array}{l}\text { Facility distribution } \\
\text { Blocks }\end{array}$ & $\begin{array}{l}\text { Micro (point) } \\
\text { Meso (area) }\end{array}$ \\
\hline $\begin{array}{l}\text { Destination-based } \\
\text { (weighted) }\end{array}$ & Directness & $\begin{array}{l}\text { Facility distribution } \\
\text { Blocks } \\
\text { Weighted factors: square } \\
\text { footage, job \#, retail sales, } \\
\text { etc. }\end{array}$ & $\begin{array}{l}\text { Micro (point) } \\
\text { Meso (area) }\end{array}$ \\
\hline $\begin{array}{l}\text { Destination-based } \\
\text { (cumulative) }\end{array}$ & Directness & $\begin{array}{l}\text { Facility distribution } \\
\text { Blocks }\end{array}$ & $\begin{array}{l}\text { Micro (point) } \\
\text { Meso (area) }\end{array}$ \\
\hline $\begin{array}{l}\text { Topological } \\
\text { (morphology) }\end{array}$ & $\begin{array}{l}\text { Cohesion } \\
\text { Directness }\end{array}$ & Facility distribution & $\begin{array}{l}\text { Micro (point) } \\
\text { Meso (area) }\end{array}$ \\
\hline $\begin{array}{l}\text { Topological } \\
\text { (level of service) }\end{array}$ & $\begin{array}{l}\text { Cohesion } \\
\text { Directness } \\
\text { Alternatives } \\
\text { Safety \& Security } \\
\text { Comfort }\end{array}$ & $\begin{array}{l}\text { Facility distribution } \\
\text { Quality of facility: width, } \\
\text { vehicle volume, pavements, } \\
\text { slope, etc. } \\
\text { Blocks }\end{array}$ & $\begin{array}{l}\text { Micro (point, } \\
\text { segment) } \\
\text { Meso (area) }\end{array}$ \\
\hline Bikeability & $\begin{array}{l}\text { Cohesion } \\
\text { Directness } \\
\text { Safety \& Security } \\
\text { Comfort }\end{array}$ & $\begin{array}{l}\text { Facility distribution } \\
\text { Quality of facility: width, } \\
\text { vehicle volume, pavements, } \\
\text { slope, etc. } \\
\text { Blocks }\end{array}$ & $\begin{array}{l}\text { Micro (point) } \\
\text { Meso (area) }\end{array}$ \\
\hline
\end{tabular}

\subsubsection{Distance-based Measures}

This method considers the transportation network accessibility as a function of spatial separation between places. The higher the separation, the worse the network is. The separation (or travel impedance) is usually defined as the distance, calculated as the Euclidean distance ${ }^{1}$, Manhattan distance $^{2}$, shortest network distance, or shortest network time. This distance-based approach can be interpreted as the distance to the closest urban greenway facility, specified as follows:

$$
A_{i}=f\left(D_{i}\right)
$$

where $A_{i}$ is the transportation network accessibility of place $i$ and $D_{i}$ is the distance to urban greenway facilities. Typically, $A_{i}$ is represented as an impedance function of $D_{i}$, where it is specified as an inverse power function or negative exponential function.

\footnotetext{
${ }^{1}$ Euclidean distance refers to the straight-line distance between two location points.

${ }^{2}$ Manhattan distance refers to the distance along grid lines (that is, strictly horizontal or/and vertical paths) between two points.
} 
This distance-based measure is useful when transportation facilities are seen as substitutes for each other. It assumes that individuals would like to access the closest facility, and there are no differences between facilities and each facility is weighed equally. This simple approach addresses the directness principle within the FHWA (2016) complete active transportation network framework.

\subsubsection{Destination-based Measures}

The second type of measure involves travel destinations, which represent the transportation network as the conduit to access important destinations. Although each study focuses on different destination types, they are typically categorized by land use types, such as residential, employment opportunities, commercial destinations, basic services, supermarkets, and local services (Vale, Saraiva and Pereira, 2016). Several studies propose the following methods to identify the appropriate destinations for analysis:

a. Destination Basket: Similar to the market basket of consumer goods constructed to calculate the Consumer Price Index (CPI), a destination basket refers to a set of important destination types chosen by the research team. Destination-based measures analyze the proportion of reachable destination types using the transportation network in question (Lowry et al., 2016).

b. Clustering: These studies utilize spatial analysis to identify employment, recreation or shopping centers as analyzable destinations (Iacono, Krizek and El-Geneidy, 2010). This method can be interpreted as an aggregate measure of destination distribution, rather than OD (origin-destination) route distribution for actual trips.

After important destinations are defined using one of the identification methods above, there are two categories of measuring active transportation network characteristics depending on the chosen impedance function. The first category assumes attenuation toward travel distance, that is, access decreases with increasing distance to the destination. Some methods equally weigh different destinations, while others weigh destinations by impedance, such as distance and travel time and/or by attractiveness of destinations. The measure of attractiveness of destinations is further defined using measurements that include land-use types, residential parcels, square footage of buildings, or number of jobs (Vale, Saraiva and Pereira, 2016). This transportation network measure can be expressed as:

$$
\mathrm{A}_{i}=\Sigma \mathrm{O}_{j} \mathrm{f}\left(\mathrm{C}_{i j}\right)
$$

where $A_{i}$ is the transportation network accessibility measure of location $i, O_{j}$ is the importance of destinations $\mathrm{j}$, $C_{i j}$ is the travel cost between $i$ and $j$, and $f\left(C_{i j}\right)$ is the impedance function for travel time, distance or generalized costs, which is determined by the distance between $\mathrm{i}$ and $\mathrm{j}$.

The destination-based measure of transportation networks measures the cumulative opportunities that can be reached via the transportation network, which is estimated by the number of 
destinations within a certain distance of a catchment area. Studies have typically used floating catchment areas ranging from 500 meters to two kilometers (Apparicio et al., 2008).

This destination-based measure is particularly useful when opportunities are seen as complementary, where being closer represents higher accessibility. It addresses the directness principle within the FHWA (2016) complete active transportation network framework.

\subsubsection{Topological Measures}

The topological measures take into account the characteristics of the built environment in the analysis of the network accessibility or connectivity of urban greenway facilities. Within the topological approach, there are two main groups of measures: the first group measures the urban transportation and built environment morphology parameters of the facility network (i.e., link/node ratio), and the second group adds infrastructure evaluation aspects to the measurement.

Lundberg (2012) summarized various urban connectivity parameters in the following table. Besides the effective walking area and route directness parameters, all of the other parameters within this approach are built environment morphology measures, which measure the connectivity based on the distribution of facilities. The unit of analysis can be adjusted to different scales based on the purpose of analysis. Effective walking area, defined as the "ratio of the number of parcels within a 1/4-mile walking distance from an origin,” measures connectivity according to the residential land use characteristics. Route directness, defined as the "ratio of route distance to straight-line distance," depends on the choice of origin and destination, which is more computationally complex and less practical within policymaking contexts (Dill, 2004).

Table 2. Urban Connectivity Parameters Summary 


\begin{tabular}{|c|c|c|c|}
\hline Measure & Definition & Calculation & Comments \\
\hline $\begin{array}{l}\text { Intersection } \\
\text { Density }\end{array}$ & $\begin{array}{l}\text { Number of interactions } \\
\text { per unit of area. }\end{array}$ & $\begin{array}{l}\text { Number of real nodes / } \\
\text { area }\end{array}$ & $\begin{array}{l}\text { Higher density indicates } \\
\text { higher connectivity. }\end{array}$ \\
\hline Network Density & $\begin{array}{l}\text { Number of linear miles of } \\
\text { a network per unit of area. }\end{array}$ & $\begin{array}{l}\text { Total network length / } \\
\text { area }\end{array}$ & $\begin{array}{l}\text { Higher density indicates } \\
\text { higher connectivity }\end{array}$ \\
\hline $\begin{array}{l}\text { Connected Node } \\
\text { Ratio }\end{array}$ & $\begin{array}{l}\text { Number of street } \\
\text { intersections divided by the } \\
\text { total number of all } \\
\text { intersections. }\end{array}$ & $\begin{array}{l}\text { Number of real nodes / } \\
\text { number of total nodes }\end{array}$ & $\begin{array}{l}\text { Values range } \\
\text { between } 0 \text { and } 1 . \\
\text { Higher number indicates } \\
\text { higher connectivity. }\end{array}$ \\
\hline Link-Node Ratio & $\begin{array}{l}\text { Number of links divided by } \\
\text { the number of nodes. }\end{array}$ & $\begin{array}{l}\text { Number of Links / } \\
\text { Number of Nodes }\end{array}$ & $\begin{array}{l}\text { A perfect grid has a } \\
\text { ratio of } 2.5 \text {. }\end{array}$ \\
\hline $\begin{array}{l}\text { Average Block } \\
\text { Length }\end{array}$ & $\begin{array}{l}\text { Measures the street length } \\
\text { from center of intersection } \\
\text { to center of intersection. }\end{array}$ & $\begin{array}{l}\text { Sum of link length per } \\
\text { unit a rea / number of } \\
\text { nodes per unit area }\end{array}$ & $\begin{array}{l}\text { Shorter blocks indicates } \\
\text { more intersection. }\end{array}$ \\
\hline $\begin{array}{c}\text { Effective Walking } \\
\text { Area }\end{array}$ & $\begin{array}{l}\text { Ratio of the number of } \\
\text { parcels within a } 1 / 4-\text { mile } \\
\text { walking distance from } \\
\text { an origin. }\end{array}$ & $\begin{array}{l}\text { Taxlots within } 1 / 4 \text { mile } \\
\text { walking distance of origin } \\
\text { / total taxlots }\end{array}$ & $\begin{array}{l}\text { Higher value indicates } \\
\text { higher connectivity. }\end{array}$ \\
\hline Route Directness & $\begin{array}{l}\text { Ratio of route distance } \\
\text { to straight-line distance }\end{array}$ & $\begin{array}{l}\text { Route distance / } \\
\text { straight-line distance }\end{array}$ & $\begin{array}{l}\text { Numbers closer to } 1 \\
\text { indicate more direct route }\end{array}$ \\
\hline Gamma Index & $\begin{array}{l}\text { Ratio of the number of } \\
\text { links to the maximum } \\
\text { possible number of links } \\
\text { between nodes. }\end{array}$ & $\begin{array}{l}\text { Number of links per unit } \\
\text { of area / } \\
3^{*} \text { (number of nodes }-2 \text { ) }\end{array}$ & $\begin{array}{l}\text { Values range } \\
\text { between } 0 \text { and } 1 . \\
\text { Higher number indicates } \\
\text { higher connectivity. }\end{array}$ \\
\hline Alpha Index & $\begin{array}{l}\text { Ratio of the number } \\
\text { of actual circuits } \\
\text { to the maximum } \\
\text { number of circuits. }\end{array}$ & $\begin{array}{l}\text { Number of links - number } \\
\text { of nodes }-1 / \\
2^{*} \text { (number of nodes) }-5\end{array}$ & $\begin{array}{l}\text { Values range } \\
\text { between } 0 \text { and } 1 . \\
\text { Higher number indicates } \\
\text { higher connectivity. }\end{array}$ \\
\hline
\end{tabular}

Source: Lundberg, 2012

The second group within topological measures emphasizes infrastructure evaluation, using measurements such as level of service (LOS) or low-stress network. The Highway Capacity Manual (HCM) (Huff and Liggett, 2014) defines the bike level-of-service (BLOS) for a given link as:

$$
\mathrm{I}=0.760+\mathrm{F}_{\mathrm{w}}+\mathrm{F}_{\mathrm{v}}+\mathrm{F}_{\mathrm{S}}+\mathrm{F}_{\mathrm{p}}
$$

where $\mathrm{I}$ is the BLOS for each link, $\mathrm{F}_{\mathrm{w}}$ is the width adjustment factor, $\mathrm{F}_{\mathrm{v}}$ is the vehicle volume adjustment factor, $F_{S}$ is the vehicle speed adjustment factor, and $F_{p}$ is the pavement condition adjustment factor. Ten attributes are needed to calculate BLOS for a link: width of outside lane, width of bike lane, width of shoulder, proportion of occupied on-street parking, vehicle traffic volume, vehicle speeds, percent of heavy vehicles, pavement condition, presence of curb, and number of through lanes.

Following a similar idea, Lowry et al. (2016) proposed an alternative to the BLOS as the lowstress network, taking into account both the quality of the facilities and the built environment 
attributes of the route segments. The low-stress status (M. B. Lowry, Furth, and Hadden-Loh, 2016) for a given link can be calculated as:

$$
\begin{gathered}
\mathrm{W}_{\mathrm{e}}=\mathrm{L}_{\mathrm{e}}\left(1+\mathrm{F}_{\text {slope,e }}+\mathrm{F}_{\text {stress, } \mathrm{e}}\right) \\
\text { Subject to } \mathrm{F}_{\text {stress,e }}=\mathrm{F}_{\text {roadway,e }} *\left(1-\mathrm{F}_{\text {bikeaccom,e }}\right)
\end{gathered}
$$

$\mathrm{W}_{\mathrm{e}}$ is the impedance for link $e, \mathrm{~L}_{\mathrm{e}}$ is the length of link $e, \mathrm{~F}_{\text {slope,e }}$ is slope factor for link $\mathrm{e}$, while $\mathrm{F}_{\text {stress,e }}$ is the stress factor for link $e, \mathrm{~F}_{\text {roadway, }}$ is the roadway factor of link $e$ (defined by roadway classification, speed limit, and annual average daily traffic (AADT)), and $\mathrm{F}_{\text {bikeaccom,e }}$ is bicycle accommodation stress reduction factor for link $e$ (categorized as bike route, sharrows, conventional bike lanes, buffered bike lanes, and protected bike lanes). The impedance factors are determined by marginal rate of substitution (MRS) derived from previous route choice behavior studies (Hood, Sall and Charlton, 2011; Broach, Dill and Gliebe, 2012).

Given the BLOS or stress impedance for each link, the accessibility of the transportation network can further be calculated as (Hansen, 1959; M. B. Lowry, Furth and Hadden-Loh, 2016):

$$
A_{i}=E_{j} * e^{-\beta r}{ }_{i j}
$$

where $A_{i}$ is the transportation network accessibility measure of location $i, E_{j}$ is the importance of destinations $j$, and $e^{-\beta r}{ }_{i j}$ is the impedance function (using a negative exponential function) for travel time, distance, or generalized costs, which is determined by distance between $i$ and $j, r_{i j}$, and $\beta$ is a calibrated parameter.

These topological measure approaches analyze the impact of overall transportation network characteristics, which is useful for project prioritization in planning practice. It incorporates the principles of cohesion, directness, safety and security, and comfort from the FHWA (2016) framework to measure the transportation network.

\subsubsection{Walkabilty and Bikeability Measures}

The walkability and bikeability measures are a combination of above measures, which provides an indicator to represent the potential for active transportation. Currently, more research is focused on estimating walkability than bikeability (Vale, Saraiva and Pereira, 2016).

One example is a bikeability index comprised of five factors: bike facility availability, bike facility quality, street connectivity, topography and land use (Winters et al., 2013):

Bikeability $=(\mathrm{B} 1 *$ bike route density $)+(\mathrm{B} 2 *$ bicycle route separation $)+(\mathrm{B} 3 *$ connectivity of bicycle-friendly streets $)+(\mathrm{B} 4 *$ topography $)+(\mathrm{B} 5 *$ destination density $)$ 
where bike route density is measured within a 400-meter radius of all designated routes; bike route separation indicates high-quality bicycle routes with separation from motor vehicles; connectivity of bike-friendly streets measures the intersection density of local roads, off-street path or a designated route; topography captures a slope factor; and destination density measures the density of destination parcels. The weights (Bs) are derived from a focus group survey that examined the importance of each bikeability component.

This bikeability measure is a measure of the overall condition of an active transportation network. Although it takes into account a more comprehensive list of the characteristics of the active transportation network, the weights of each component may vary across different contexts and may be arbitrary. This measure incorporates the principles of cohesion, directness, safety and security, and comfort within the FHWA (2016) framework for measuring active transportation networks.

\subsection{ECONOMIC IMPACT MEASURES}

In addition to the direct impacts of urban greenways on transportation, investments in bicycleand pedestrian-related infrastructure also introduce new spending into the economy, which can induce multiplier effects throughout the entire regional economy. In addition to economic multiplier impacts from investments in urban greenways, researchers have also been examining economic impacts in the three following categories: bicycle- and pedestrian-related infrastructure investment, business vitality and consumer spending, and property values. The following sections review the literature that explore these economic impacts from urban greenways.

\subsubsection{Bicycle- and Pedestrian-related Infrastructure Investment}

There are two categories of bicycle infrastructure project costs: capital costs and operating costs (Krizek, 2006a). Capital costs are expenditures directly for constructing facilities and purchasing equipment. The bicycle facilities may include on-street facilities (such as bike lanes, wide curb lanes, striping, signed route); off-street facilities (such as shared-use trails and paths); and the equipment may include signs, signals, barriers and parking, etc. In practice, it may be challenging to identify or separate out the cost for bicycle- and pedestrian-related infrastructure, since some infrastructure such as roadway shoulders and sidewalks are incorporated as an integral part of overall roadway projects (Resource Systems Group, Inc., Economic and Policy Resources, Inc., and Local Motion, 2012). Operating costs, on the other hand, typically include costs of security and policing the facilities, according to a National Cooperative Highway Research Program (NCHRP) report (Krizek, 2006a) as well as maintenance costs for pavement, drainage, traffic controls and landscaping.

Utilizing economic input/output models, such as REMI ${ }^{3}$ and IMPLAN ${ }^{4}$, direct, indirect and induced economic impacts can be estimated in terms of output, employment and labor earnings across multiple geographic regions and industrial sectors. For example, an economic impact

\footnotetext{
${ }^{3}$ REMI refers to the Regional Economic Models, Inc. (http://www.remi.com).

${ }^{4}$ IMPLAN is produced by IMPLAN, previously known as MIG, Inc. (http://www.implan.com).
} 
analysis of bicycle infrastructure investments in Vermont indicated that the expenditures created a large number of construction jobs and supported the professional/technical services sector (Resource Systems Group, Inc., Economic and Policy Resources, Inc., and Local Motion, 2012). The study estimated that each million dollars of active transport program/planning spending translates into nearly 32 jobs, and the total economic contribution is estimated to be at $\$ 17$ million in output, 233 jobs and \$10 million in labor earnings.

\subsubsection{Business Vitality/Consumer Spending}

Evidence also shows that active transportation infrastructure may have positive impacts on business district prosperity and economic vitality in general (Drennen, 2003; Flusche, 2012). Numerous case studies from many North American and European cities examine and compare revenues and consumer expenditures before and after the construction of bicycle infrastructure, and show that the infrastructure investments bring an influx of cyclists and pedestrians and boost retail activities in surrounding businesses (Flusche, 2012; Jaffe, 2015; Rowe, 2013; New York City Department of Transportation, 2012). One study in Vancouver, B.C., found a small net decrease in sales after the implementation of separated bike lanes using collected survey data (Stantec Consulting, 2011), but this atypical result may be the outcome of survey respondent bias and the short-term timeframe of the analysis. While business owners are concerned that active transportation infrastructure that removes parking spaces would decrease business opportunities, Jaffe's 2015 article summarized 12 case studies from different cities around the world and found that such conversions of street parking into bicycle lanes have had little to no impact on local businesses, and, in some cases, might even increase business activity.

A number of other studies focus on how travel mode choices are related to consumer expenditure behaviors (Bent and Singa, 2009; Clifton et al., 2012; O’Connor et al., 2011; Popovich and Handy, 2014). While these studies do not directly link bicycle infrastructure improvements to changes in mode share, they provide useful insights into how different types of consumers may have different expenditure patterns. An analysis of 78 businesses in the Portland metropolitan area found that people who bike or walk spend similar amounts or more on average (per month) than their counterparts driving automobiles, since non-drivers make more frequent trips to businesses than drivers (Clifton et al., 2012). A resident survey comparing spending behavior among different travel modes in Davis, CA, found similar results as well (Popovich and Handy, 2014). A survey of East Village, NY found that cyclists spend about $\$ 163$ per week on average compared to $\$ 143$ among drivers (Jaffe, 2015). Additionally, consumer spending patterns also vary by type of business. The Clifton et al. (2012) Portland study found that cyclists spend less per trip at grocery stores, but more at restaurants, bars, and convenience stores.

\subsubsection{Property Value}

In general, the majority of studies find bicycle- and pedestrian-related facilities or greenway infrastructure tend to have positive, or at least no negative, impacts on property values (Cortright, 2009; Lindsey et al., 2004; Nicholls et al., 2005). Cortright (2009) analyzed 15 different housing markets around the United States and found that walkability had positive impacts on home values in 13 out of 15 housing markets. Another study found that trails and greenways (trails with greenbelts) are correlated with 2, 4, and 5\% home price premiums in San 
Antonio, TX (Asabere and Huffman, 2009). Even after controlling for spatial autocorrelation between greenspaces and property value, Conway et al.'s (2010) empirical study still found that greenspaces have significant positive impacts on residential property values. Expanded research efforts found positive effects of active transportation infrastructure on commercial and apartment values, but no effect on industrial property values (Pivo and Fisher, 2011).

However, it is important to point out that different types of active transportation facilities may have differential effects on property values. One study distinguished the impacts of different bike facility types, including on-street, off-street roadside and off-street non-roadside, on both cities and suburban residential properties (Krizek, 2006b). The results indicated that bike facilities had significant negative impacts on home values, and roadside bike trails in both city and suburban area both significantly reduced home values, even after controlling for proximity to busy streets.

The most common empirical methodology within this field of research is the hedonic pricing model, with various specifications (from simple ordinary least squares specifications to more complex spatial autocorrelation specifications) to explore the impacts of bicycle facilities and greenways on property values (Brander and Koetse, 2011; Krizek, 2007; Lindsey et al., 2004). In addition, some studies applied stated preference analysis, such as contingent valuation or stated preference surveys, to provide additional insight into the property value impacts of active transportation infrastructure (Brander and Koetse, 2011; Krizek, 2006b).

\subsection{EQUITY IMPACTS MEASURES}

While the positive economic outcomes of active transportation infrastructure have been shown in numerous empirical studies as described above, it is also known that both transportation and environmental amenities are typically unevenly distributed in the urban context. How to broaden the benefits of infrastructure investments across boundaries of race, class, gender, or language becomes an emerging issue during the transportation planning process (Golub et al., 2016). A number of studies (Landry and Chakraborty, 2009; J. Wolch, Wilson and Fehrenbach, 2005; J. R. Wolch, Byrne and Newell, 2014; Dai, 2011) highlight socioeconomic and racial/ethnic disparities in the distribution of desirable urban environmental amenities such as parks and street trees. Transportation equity research more abundantly focuses on access to motorized modes of transportation (Litman, 2017) and public transit (Lubitow, Rainer and Bassett, n.d.). Lindsey et al. (2001) more specifically emphasize the importance of equity and distributional analysis of urban greenways due to spatial segregation and distribution of bicycle and pedestrian infrastructure.

Studies show that those who are the most socioeconomically disadvantaged (i.e., low income, people of color, etc.) are also those who disproportionately experience transportation disadvantages (Lucas, 2012). In addition, these underserved populations also tend to have greater demand for transportation access, especially for non-motorized modes of travel (Sandt, Combs and Cohn, 2016). Immigrants, people with language barriers and low-income households are more likely to travel by walking and bicycling, even when they reside in locations that lack accessible and safe pedestrian and cycling infrastructure (Guo and Gandavarapu, 2010; Gotschi, 2011). Low-income households are less likely to own a car and tend to walk and bike more, even under unsafe conditions (Turrell et al., 2013). Apparicio et al. (2008) further show that children, older adults and those with disabilities are more likely to rely on non-motorized travel modes, 
but face even more challenges to access active transport facilities. Therefore, transportation disadvantaged populations need access to active transportation infrastructure, but they also tend to live in regions with lower levels of access to these facilities, limiting their access to social and economic opportunities.

The literature on environmental justice emphasizes policies that enable different demographic groups to achieve equitable access to benefits and protection from environmental harm (Rowangould, Karner and London, 2016; Schlosberg, 2009; Litman, 2017). Yet, in the context of transportation systems and access to transportation, minority communities often receive fewer benefits and greater harms when compared with the rest of the population. Commonly used environmental justice (EJ) indicators include unemployment, household income, elderly residents, children, and ethnic/racial minorities (Foth, Manaugh and El-Geneidy, 2013), and other indicators may include zero-vehicle households, limited English proficiency, single-parent households, residents with disabilities, etc. Once the indicators are selected, metropolitan planning organizations (MPOs) generally utilize threshold-based methods to identify concentrations of highly disadvantaged or vulnerable populations, including 1) equal shares of target and non-target communities; 2) equal percentage or standard deviation greater than regional mean; 3) top or bottom decile/quintile groups (Williams and Golub, 2017). In addition, combinations of different indicators might be applied to reflect degrees or levels of disadvantage (Rowangould, Karner and London, 2016). Following the literature review, this paper adapts the historically marginalized community criteria as defined by Metro, Portland's regional MPO, to identify transportation disadvantaged communities in the region (Portland Metro, 2017) for our equity impact analysis. 


\subsection{METHODOLOGY \& DATA}

Following the literature reviewed in the previous sections, we proceed to establish appropriate methodologies to characterize and measure urban greenway network mobility and accessibility. These measures will be referred to as bicycle accessibility measures (BAMs). Then, the following sections will explore methods that measure how the developed BAMs correspond to economic and social equity outcomes, and how changes in BAMs from improving and linking the urban greenway network in the Portland metropolitan area in various scenarios may pose differential impacts on disadvantaged communities.

\subsection{METHODS FOR TRANSPORTATION IMPACTS}

Travel cost, typically a direct function of travel distances, is an essential measure of transportation outcomes. In this analysis of the transportation impacts of improvements or additions to bicycle infrastructure, travel distance to urban greenways or important destinations will be used as direct proxies for travel costs (which can include both explicit costs of travel and implicit costs of travel, such as time). While Euclidean (straight line) distance and Manhattan (grid-based vertical and horizontal) distance methods are easier to calculate, the network distance (or time) method tends to more accurately reflect actual travel distances, and is widely applied in recent studies (Apparicio et al., 2008). All of the travel distances mentioned in this study will refer to actual network distance rather than more simplistic measures of straight-line distances (such as Manhattan distance or Euclidean distance). The network distances are calculated using the ArcGIS 10.5.1 Network Analysis toolbox. Depending on the specific bicycle accessibility measure, the travel distances are weighted differently to reflect different aspects of transportation outcomes from urban greenways improvements.

Three sets of bicycle accessibility measures (BAMs) are constructed: (1) distance-based BAM, (2) destination-based BAM, and (3) low-stress network BAM. Detailed methods to estimate each BAM are described below, which may include disaggregate-level (block-level) measures and aggregate-level (block-group or city-level) measures as specified.

\subsubsection{Distance-based BAM}

The distance-based BAM considers the impact on transportation as a function of spatial separation between target places and potential opportunities/destinations. This straightforward measure involves calculating the network distance from the centroid of each city census block to the closest urban greenway to examine the proximity to urban greenway infrastructure at the disaggregated-block level.

Then, the distance-based BAM of each census block group is computed as the average of all census block BAMs in that block group. Figure 1 is a stylized illustration of this measure: the distance from the centroid of blocks within Block Group 1 to the nearest bicycle facility ranges from 0.125 miles to 0.875 miles, averaging 0.542 miles across all blocks within that block group. 


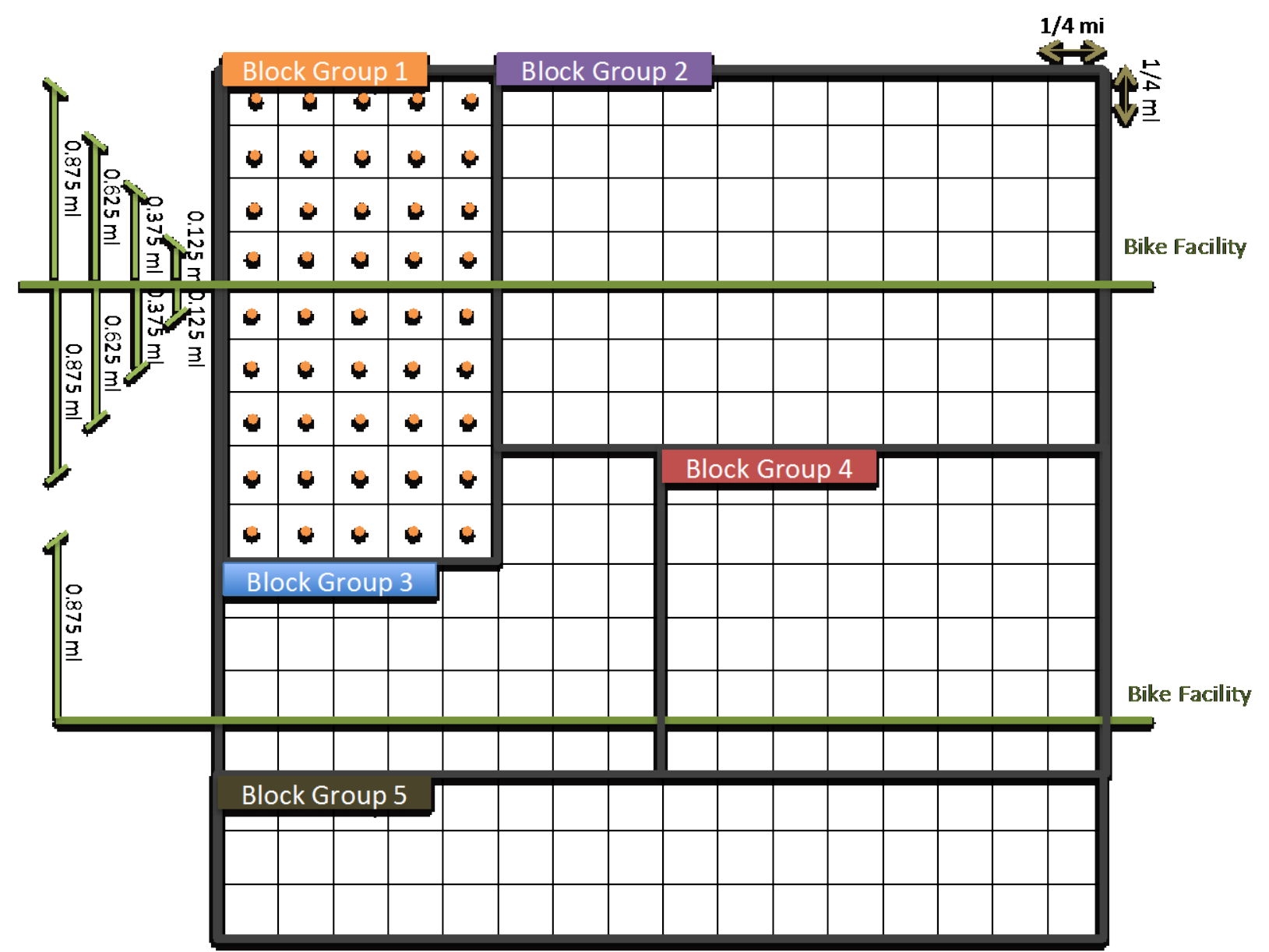

Figure 1. Illustration of the Distance-based Bicycle Accessibility Measure (BAM)

\subsubsection{Destination-based BAM}

The second BAM takes into account important destinations, as the literature points out the importance of characterizing the transportation network as the conduit to access important destinations. It evaluates the capability of transportation networks to carry people to where they need to go. Destination-based BAMs involve calculating cumulative destinations, as the number of important destinations or weighted number of important destinations, within a quarter-mile catchment area because those destinations are more accessible for bicyclists.

In order to calculate a destination-based BAM, we need to first identify important destinations across the city. Previous literature defined different types of travel destinations, and commonly used important destinations included employment/work, school, commercial, service, leisure and recreation. In addition, researchers typically weighed these destinations by the number of jobs, retail sales or building square footage to represent the attractiveness of each destination, and others also included a distance impedance function (Iacono, Krizek and El-Geneidy, 2010; Silva and Pinho, 2010; M. Lowry et al., 2012).

For the purposes of our research, we defined four of the most common types of important destinations from the literature: employment, retail, services and park/recreation. For 
employment, retail and services destinations, we used the number of jobs as weights for the attractiveness of the destination. For parks and recreational destinations, we used the acreage of the park as weights for attractiveness of the destination. While actual usage patterns of the recreational sites or facilities available at the destination may be better proxies for destination attractiveness, this type of data is less readily available and its accuracy varies widely. Therefore, we chose to stick with acreage to weigh the pull of parks and recreational destinations.

Job density at each census block is calculated using the Longitudinal Employment-Household Dynamics (LEHD) dataset. The top 15\% in job density of all census blocks within each category, including overall employment, retail and services, are defined as important destinations of that type. Employment destinations include all retail- and service-related NAICS (North American Industry Classification System) sectors ${ }^{5}$ in the LEHD dataset; retail jobs include retail trade and food and accommodation (NAICS sector 44, 45 and 72), while service jobs include information, professional, administrative, education, healthcare, arts and other public services (NAICS sector 51-56, 61, 62, 71, 92). Parks and recreation data is retrieved from Portland Metro's Regional Land Information System (RLIS) Outdoor Recreation and Conservation Areas (ORCA) Sites dataset, where we categorize parks less than 0.5 acre as small parks, parks between 0.5 and 5 acres as medium parks, and parks greater than 5 acres as large parks. Finally, 2,141 important work/employment destinations, 2,142 retail destinations, 2,143 service destinations, and 1,004 parks are identified (Figure 2).

\footnotetext{
${ }^{5}$ NAICS sectors: 44-45 Retail Trade; 72 Accommodation and Food Services; 51 Information; 52 Finance and Insurance; 53 Real Estate and Rental and Leasing; 54 Professional, Scientific, and Technical Services; 55 Management of Companies and Enterprises; 56 Administrative Support, Waste Management and Remediation Services; 61 Education Services; 62 Health Care and Social Assistant; 71 Arts, Entertainment, and Recreation; 92 Public Administration
} 


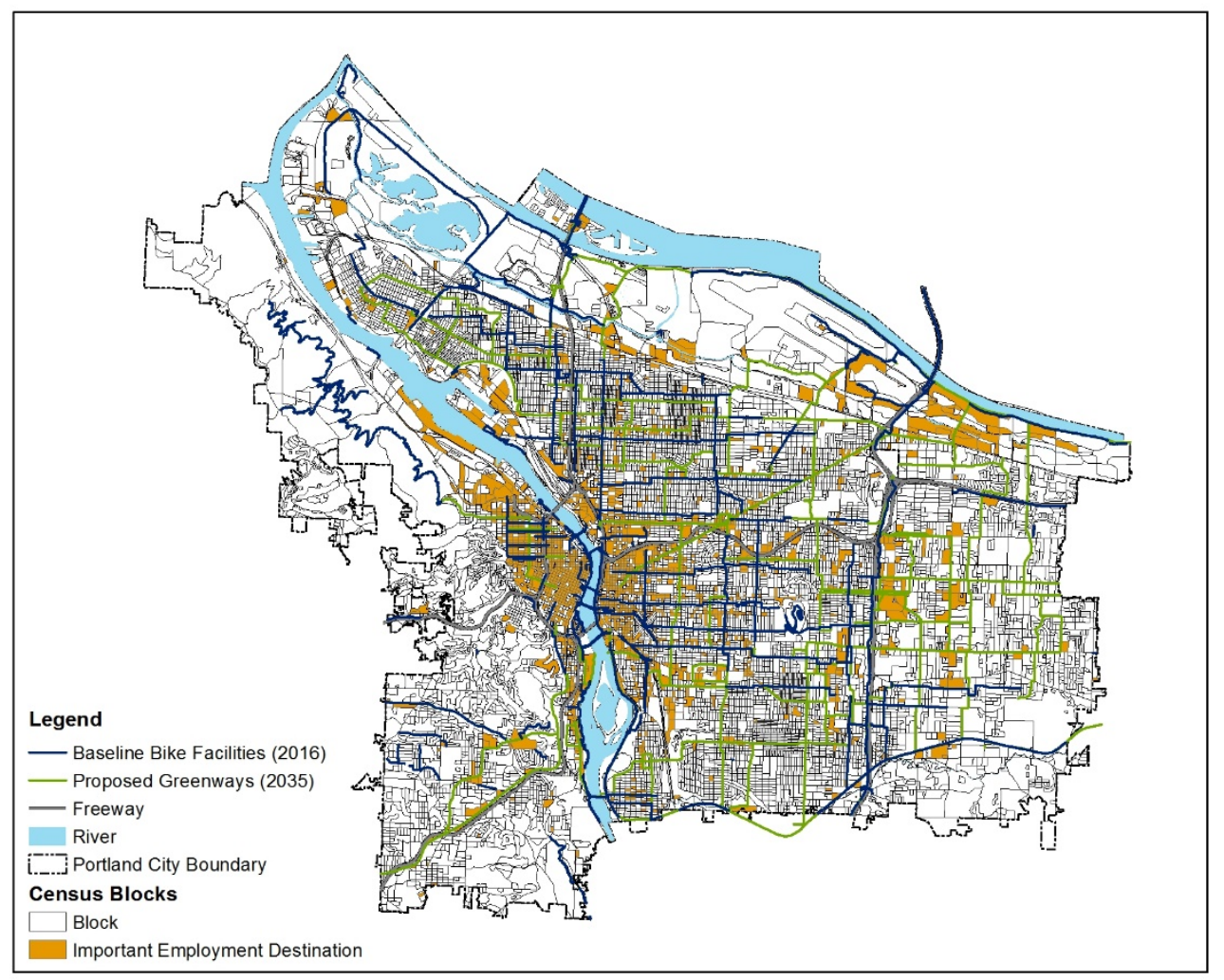

(a) Work/Employment Destinations

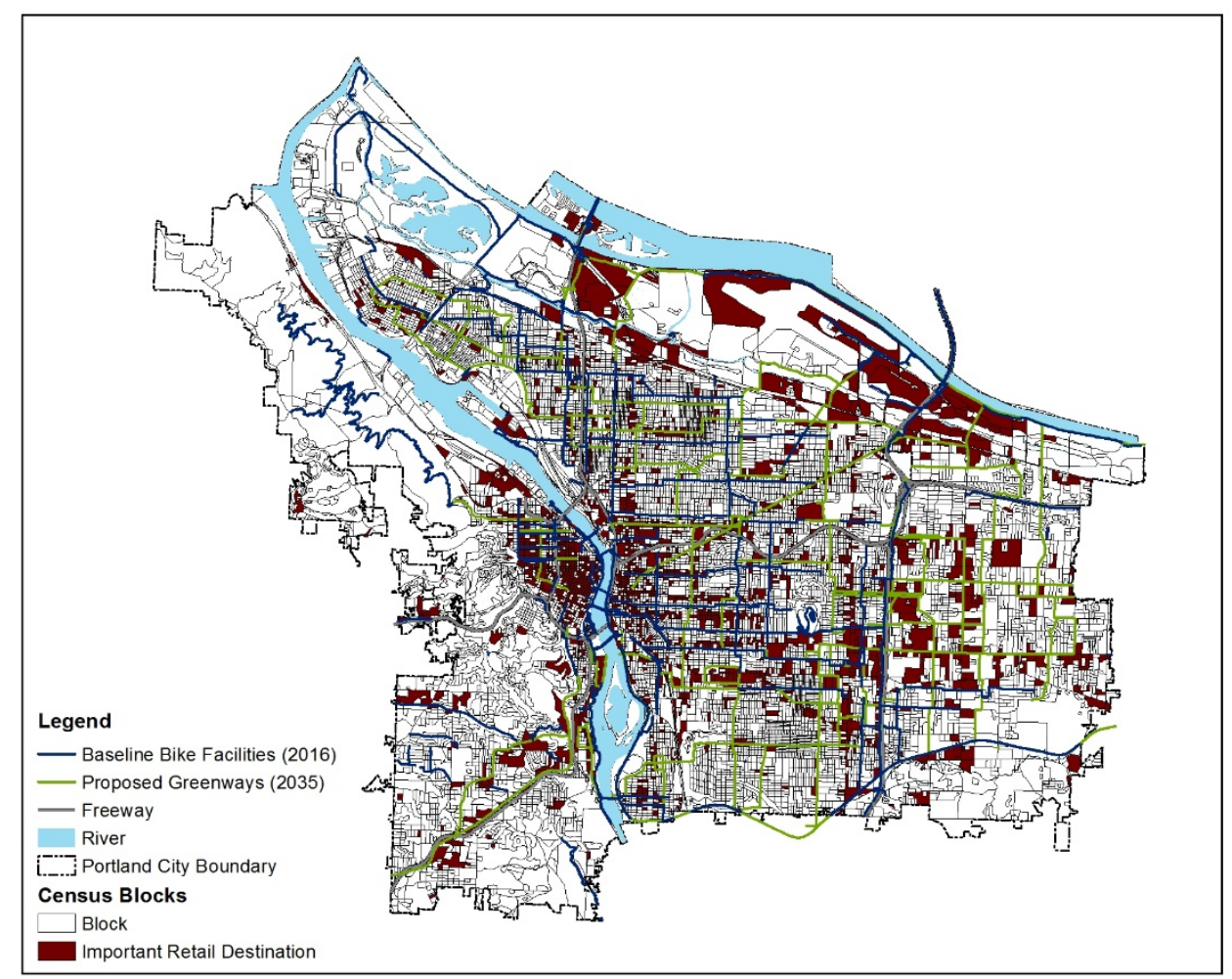

(b) Retail Destinations 


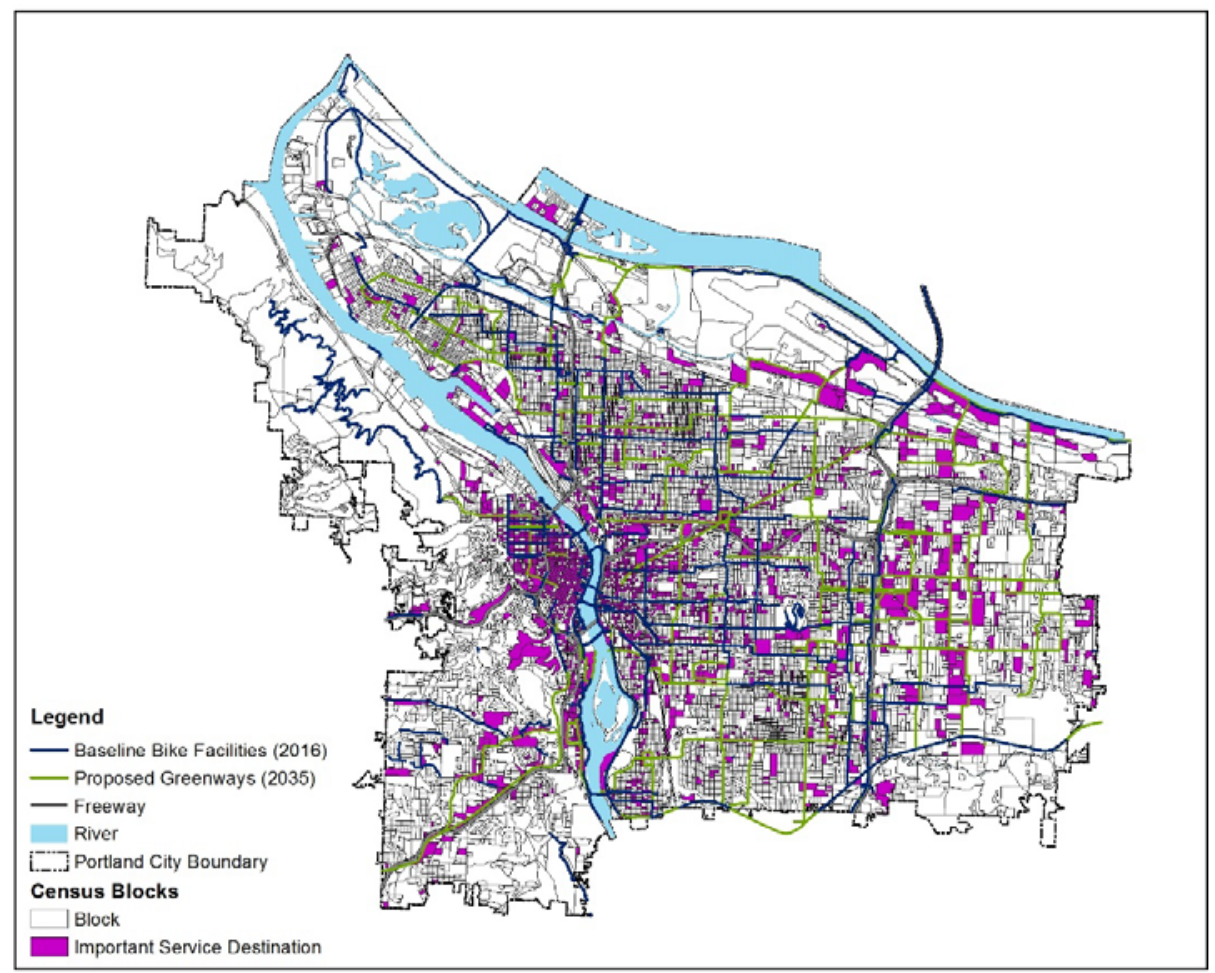

(c) Service Destinations

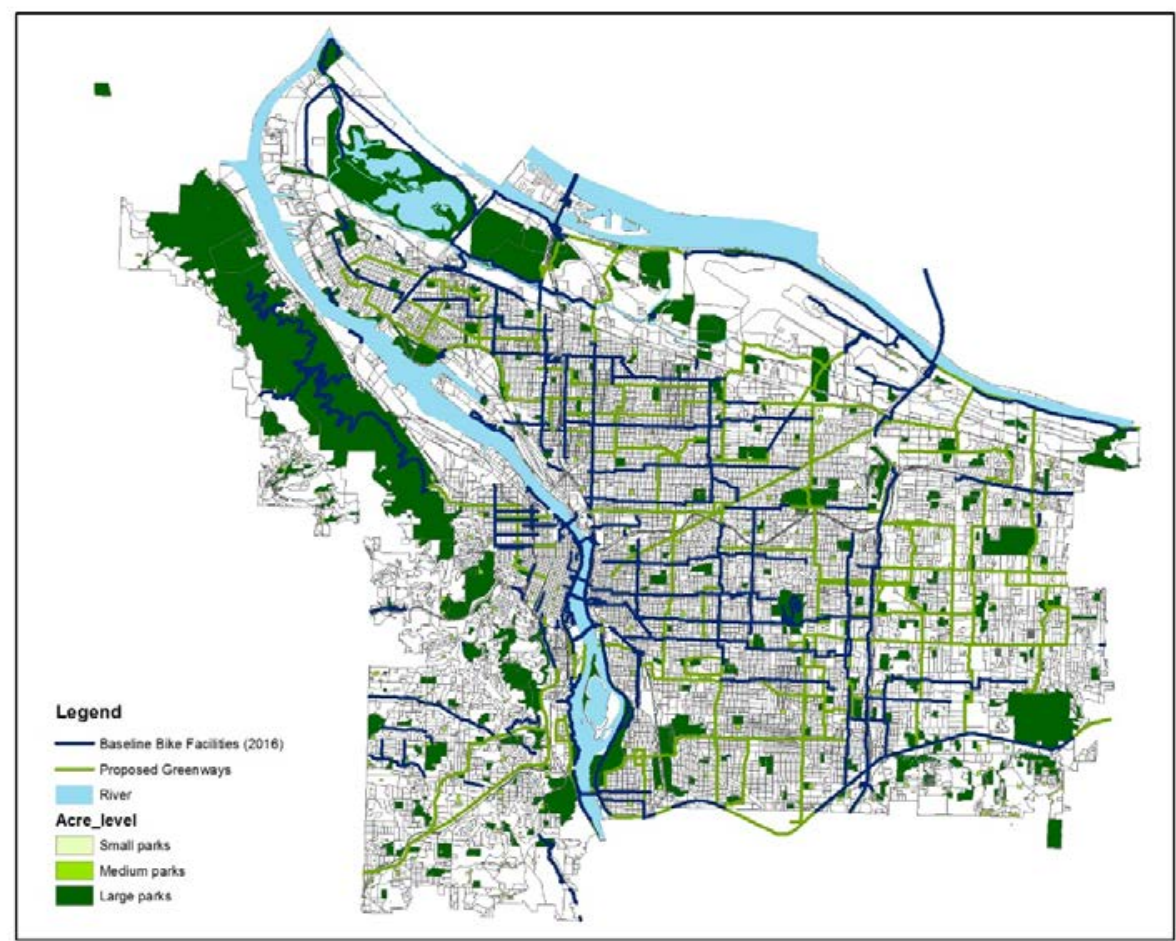

(d) Park/Recreation

Figure 2. Important Urban Destinations in Portland, OR 
The aggregated measure for census block groups is calculated based on the concept that bikeable 20-minute neighborhoods contain destinations within a 2.5-mile radius (McNeil, 2011). First, the number of jobs that are easily accessible via bicycle facilities (defined as within 0.25 miles) are retrieved from each census block. Then, among those jobs, the number of jobs easily accessible via bicycle facilities within a 1-mile cycle zone (based on network distance) of the census block group centroid is weighted as 1 , and the jobs within the 1-2.5-mile cycle zone are given a weight of 0.5 as a simple distance impedance calculation. Figure 3 below is a stylized illustration of this bicycle accessibility measure. For example, Block Group 1 can easily access 7,900 jobs (those within blocks that are shaded with horizontal lines) using bicycle facilities within its 1-mile cycle zone, and 5,000 jobs (those within blocks that are shaded with slanted lines) within its 2.5-mile cycle zone. After weighting, the gravity-based opportunities bicycle accessibility measure is 10,400 jobs $(7,900$ plus half of 5,000).

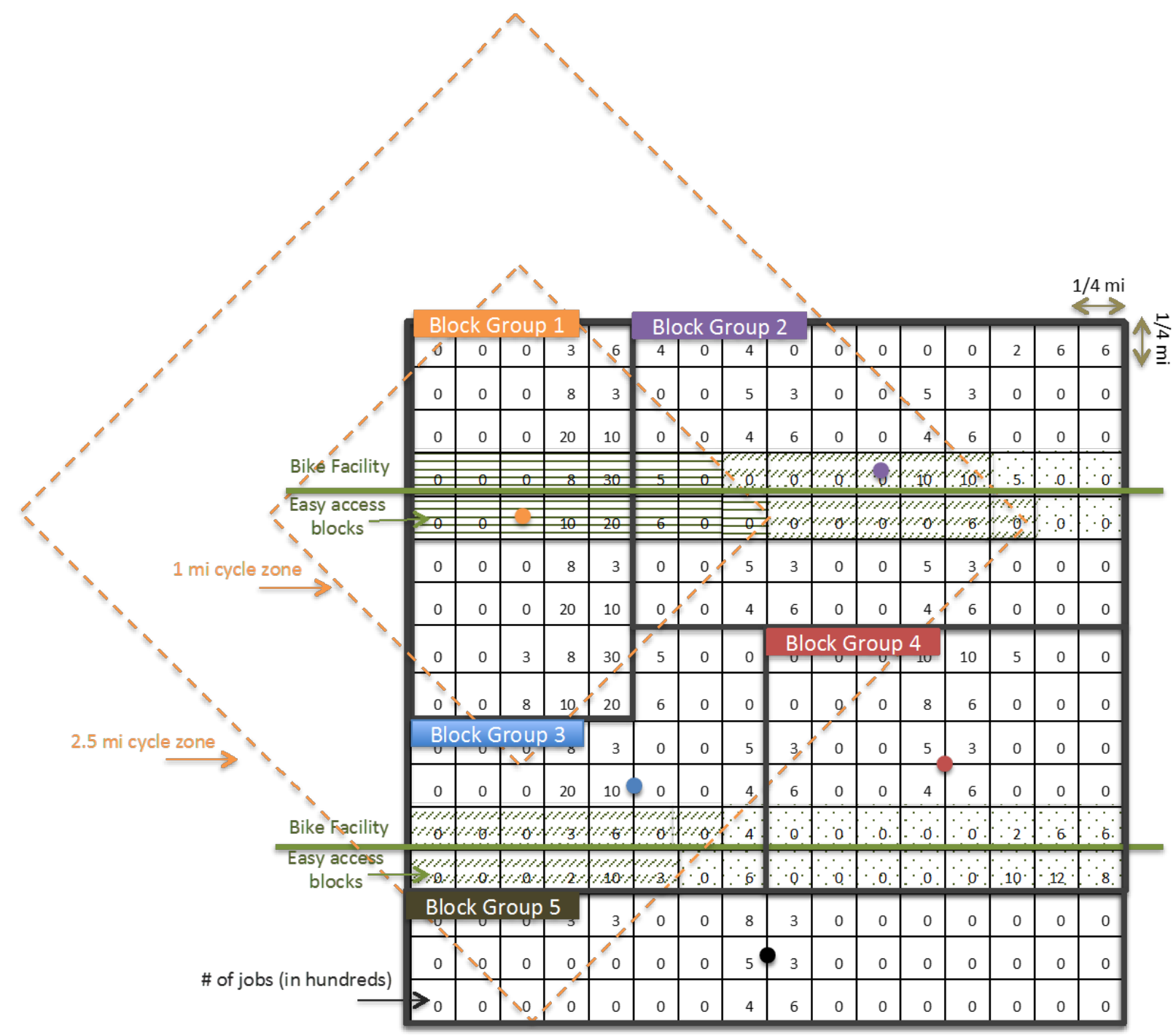

Figure 3. Illustration of Destination-based Bicycle Accessibility Measure 


\subsubsection{Low-stress Network BAM}

In addition to proximity to urban greenways and access to important destinations, we construct a third BAM set that takes into account the level of service (LOS) of urban greenways. It applies an index of bicycle stress level to indicate the actual comfort of the bicycle facility/infrastructure and to indicate willingness of residents to choose a bicycle as a travel mode. Following Lowry et al.'s (2016) method, we calculate bike-stress impedance for the entire urban greenway network, and further apply important destinations identified in the previous methodology to estimate a low-stress network-based BAM.

First, the stress impedance for each urban greenway segment is calculated based on road classification (using AADT - annual average daily traffic) and bike facility/infrastructure, namely link-stress factor (F_stress). We derived a stress factor table (Table 3) according to a bicycle route-choice study using Portland GPS data (Broach, Dill and Gliebe, 2012). This study explores the effects of bike facility/infrastructure and other road network factors on bicycle route choice, and derived Marginal Rates of Substitution (MRS) for each bicycle facility/infrastructure type in the Portland context. For example, biking on bike lanes on streets with less than 10,000 daily travel volume is equivalent to a reduction of $5 \%$ of the distance compared to roadways with no bike facilities. In general, cyclists tend to prefer off-street bike paths over protected bike lanes (buffered bike lanes are also included in this category), followed by bike boulevards and then bike lanes. There is no significant preference for simple striped bike lanes when compared with roadways with no designated bike facilities in the Portland context. The stress factors in the following table are the average commute and non-commute MRS in Broach et al.'s (2012) study.

Table 3. Change in the Stress Factor for Various Types of Bicycle Facility/Infrastructure on Different Roadway Types

\begin{tabular}{|l|l|l|l|l|l|}
\hline Roadway & \multicolumn{2}{|l}{ Bicycle Accommodation } \\
\hline AADT & $\begin{array}{l}\text { w/o bike } \\
\text { facility }\end{array}$ & $\begin{array}{l}\text { Bike } \\
\text { lane }\end{array}$ & $\begin{array}{l}\text { Bike } \\
\text { Boulevard }\end{array}$ & $\begin{array}{l}\text { Protected bike } \\
\text { lane }\end{array}$ & $\begin{array}{l}\text { Bike } \\
\text { path }\end{array}$ \\
\hline $\begin{array}{l}\text { Below } \\
10 \mathrm{k}\end{array}$ & 0 & $-5 \%$ & $-14 \%$ & $-18 \%$ & $-21 \%$ \\
\hline $10-20 \mathrm{k}$ & $29.5 \%$ & 0 & $-10 \%$ & $-15 \%$ & NA \\
\hline $20-30 \mathrm{k}$ & $138.7 \%$ & 0 & NA & $-10 \%$ & NA \\
\hline $30 \mathrm{k}+$ & $667.5 \%$ & 0 & NA & $-5 \%$ & NA \\
\hline
\end{tabular}

Note: NA indicates that there are no segments of that facility type with that level of AADT.

Table 4. Change in the Slope Factor for Different Slope Categories

\begin{tabular}{|l|l|l|l|}
\hline Slope & F_slope & Commuter & Non-commuter \\
\hline $2-4 \%$ & $55 \%$ & $37 \%$ & $72 \%$ \\
\hline $4-6 \%$ & $205 \%$ & $120 \%$ & $290 \%$ \\
\hline
\end{tabular}




\begin{tabular}{|l|l|l|l|}
\hline $6 \%+$ & $715 \%$ & $324 \%$ & $1107 \%$ \\
\hline
\end{tabular}

In addition, active transportation route choices are sensitive to the slope of the route, as one may imagine that hilly terrain tends to be more difficult for cyclists to navigate than flat terrain. A slope factor (F_slope) is derived from Broach et al.'s (2012) model results, where ascending on a street with a slope between $2-4 \%$ is equivalent to increasing the travel distance by $55 \%$ compared with riding on slopes of less than $2 \%$.

Given the link factor and slope factor specified for each segment of the urban greenway network in Portland, the impedance for each link (W_link) of the roadway is calculated to represent the actual travel cost for each segment of the urban greenway.

$$
\text { W_link = Segment Length * }(1+\text { F_stress }+ \text { F_slope })
$$

In addition, required turns can have a significant impact on bicycle route choice behavior (Broach, Dill and Gliebe, 2012; Hood, Sall and Charlton, 2011). Following Lowry et al.'s (2016) assumption, a right turn is equivalent to adding an additional 30 feet to a trip, whereas a left turn is equivalent to adding 60 feet. This turn penalty is a loosely defined factor based on previous route choice models, and is simplistic in that it ignores the impact of turn direction (either from major arterials to local streets or from local streets to major arterials) and intersection treatment effects (such as bike signals and green bike boxes). However, we will stick to this turn penalty to simplify the computational procedure.

With the defined link impedance, slope factor and turn penalty for each roadway link in the city, we can then compute the low-stress network-based shortest distance path between each origindestination (O-D) pair using the ArcGIS Network Analysis toolbox. To be consistent with the previously defined destination-based BAM, the low-stress weighted distance between each block centroid and four types of important destinations are calculated as well. This low-stress networkbased BAM allows for the evaluation of multiple aspects of the urban greenway network: (1) the general travel cost (weighted shortest distance between census blocks and important destinations); (2) quality/comfort of the route for bicyclists (percent of the route containing lowstress segments); and (3) actual bicycle service area (the important destinations accessible within a certain buffer area).

\subsubsection{Data for Transportation Impacts Methods}

Geographic data and maps for the above methods were obtained from Portland Metro's RLIS database. The baseline BAMs are calculated based on the existing advanced bike facilities as of 2016, which includes separated bike lanes/cycle tracks, buffered bike lanes, bike boulevards and regional off-street paths. The hypothetical bicycle facility improvement scenario incorporates both the existing baseline bicycle network and the proposed 2035 City Greenways system. "City Greenways" is conceptualized by the Portland Bureau of Planning and Sustainability (BPS), calling for a citywide network of park-like pedestrian- and bicycle-friendly streets crisscrossing the city at roughly three-mile intervals, which served as a hypothetical scenario. We use both the baseline scenario and hypothetical scenarios to test whether BAMs can capture changes in infrastructure improvement and transportation network outcomes. The geographic distribution of 
bicycle facilities/infrastructure within the two scenarios is shown in Figure 4. Employment data was obtained from the Census Longitudinal Employer-Household Dynamics (LEHD) dataset.

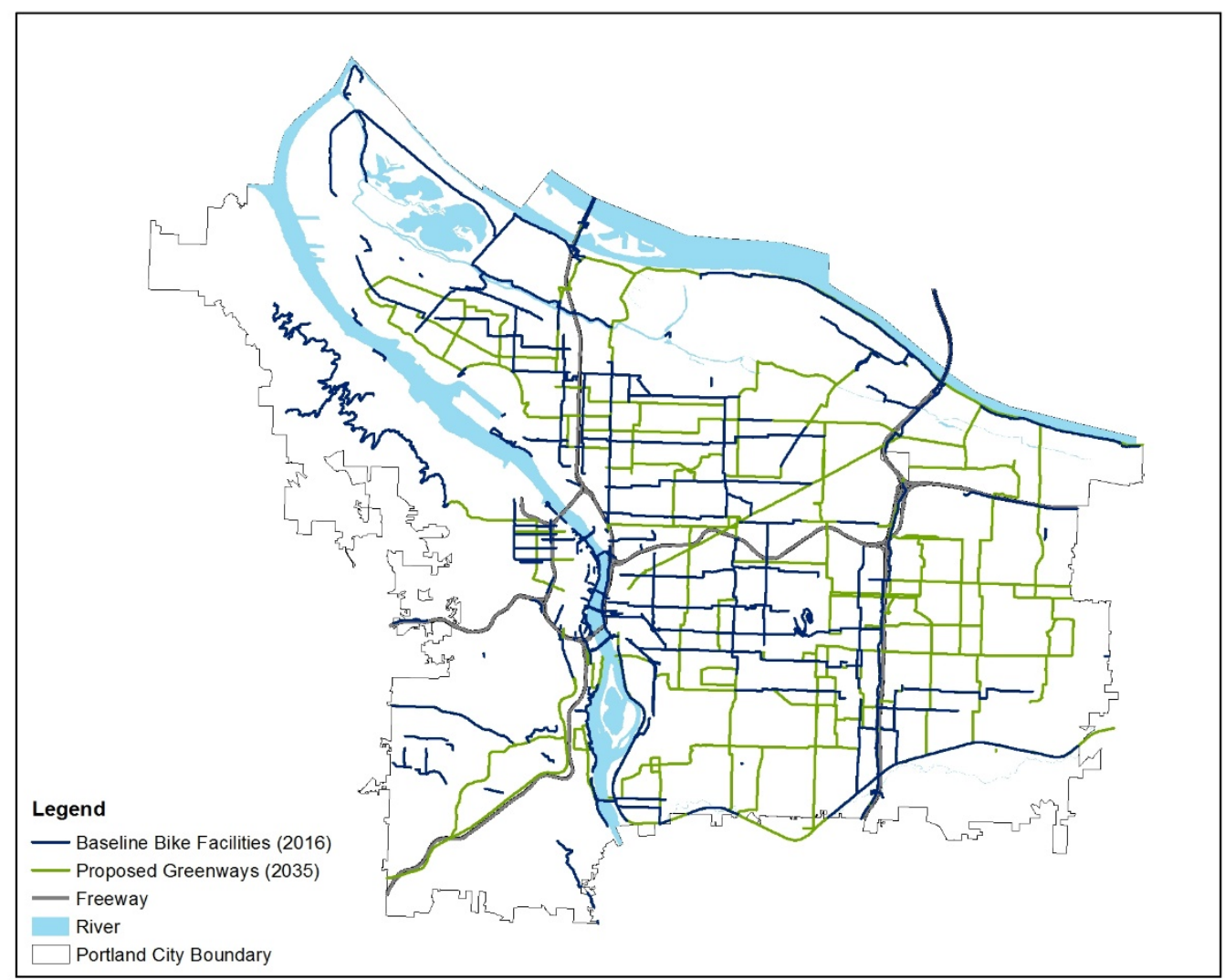

Figure 4. Distribution of Current and Proposed Urban Greenways in Portland, OR

\subsection{METHODS FOR ECONOMIC IMPACTS}

After formulating the three categories of bicycle accessibility measures (distance-based BAM, destination-based BAM and low-stress network BAM), this section will introduce the methodology that links these measures to economic indicators. One of the objectives of this study is to understand how to best characterize urban greenway networks, and to identify the BAMs that are most helpful in examining the economic impacts of such bicycle and pedestrian networks. Correlation analysis and regression analysis are utilized for this purpose.

Correlation analysis examines the linear relationship between two variables, which we apply to the various BAMs and economic indicators in our case. The correlation coefficients will reflect the statistical dependence of these BAMs and different types of economic impact. The main economic indicators that we utilize are the number of jobs (employment) in each census block, and residential property values. These are commonly used economic indicators that can reflect economic vitality and consumer preferences for amenities near their homes, such as bicycle accessibility (Jaffe, 2015; Liu and Shi, 2017). Employment data were retrieved from the 2015 
Quarterly Census of Employment and Wages (QCEW) dataset. Total employment of each census block is used as a proxy to indicate the economic activity of the block.

The regression analysis follows the conventional hedonic pricing model (Rosen, 1974), using an ordinary least squares (OLS) specification to identify consumer preferences toward bicycle accessibility, measured as BAMs, through residential property values. The general specification includes a vector of urban greenways characteristics $\left(\mathrm{UG}_{\mathrm{i}}\right)$; a vector of property transaction characteristics $\left(\mathrm{T}_{\mathrm{i}}\right)$ such as year and season of the sale that reflect general economic conditions; a vector of internal property characteristics $\left(\mathrm{H}_{\mathrm{i}}\right)$ such as age, size and property tax liability of the property; and a vector of external neighborhood or regional characteristics $\left(\mathrm{R}_{\mathrm{i}}\right)$ such as school quality or crime rate, and $\mathrm{P}_{\mathrm{i}}$ is the dependent variable representing property sale price:

$$
\mathrm{P}_{\mathrm{i}}=\beta_{0}+\beta_{1} \mathrm{~T}_{\mathrm{i}}+\beta_{2} \mathrm{H}_{\mathrm{i}}+\beta_{3} \mathrm{R}_{\mathrm{i}}+\beta_{4} \mathrm{UG}_{\mathrm{i}}+\varepsilon_{\mathrm{i}}
$$

Property sales and other property characteristics data was obtained from the Multnomah County residential property tax roll and sales data for transactions conducted in 2016. Basic property characteristics are included in this dataset, including sale price, property square footage, year built, as well as property taxes assessed. A property tax variable, AV/RMV (property assessed value divided by real market value), is also included (Liu and Renfro, 2014). After geo-coding each property, neighborhood amenities and regional characteristics are further incorporated, including school quality, distance to central business district (CBD), and crime rate.

\subsection{METHODS FOR EQUITY IMPACTS}

We utilize Metro’s two-tiered definition of historically marginalized communities (or transportation disadvantaged communities) in order to characterize environment justice (EJ) communities in the Portland region (Portland Metro, 2017). These communities are highlighted in this analysis to elucidate the impacts on distributional justice from infrastructure investments that improve bicycle accessibility, through both distance-based and gravity-based opportunities measures (Rowangould, Karner and London, 2016; Schlosberg, 2009).

Metro, guided by the Transportation Equity Work Group, selected people of color, low-income people, those with limited English proficiency (LEP), older adults and young persons as EJ indicators. Two tiers of transportation disadvantaged communities are defined: Tier I (Historically Marginalized Communities) includes communities with any indicator above a regional level, while Tier II (Focused Historically Marginalized Communities) specifically adds a population density threshold to indicators of people of color, low-income people, and those with LEP (see Table 5). Although Metro defines these communities at the census tract geography, we are able to incorporate additional spatial detail (at the census block group geography level) using data from American Community Survey (ACS) 2011-2015 (five-year estimates). These five indicators may appear separate and discrete, but the correlation analysis shown in Figure 5 below points to high levels of statistically significant correlation between many of the indicators. Communities with large proportions of people of color are positively correlated with being both low-income and having lower English proficiency. On the other hand, communities with higher percentages of senior residents tend to be whiter and less poor. In addition, there are also greater numbers of children in communities with higher non-white populations and LEP residents. 
Table 5. Portland Metro Historically Marginalized Communities Criteria

\begin{tabular}{|c|c|c|c|}
\hline Indicators & Definition & $\begin{array}{l}\text { Tier I - } \\
\text { Historically } \\
\text { Marginalized } \\
\text { Communities }\end{array}$ & $\begin{array}{l}\text { Tier II - } \\
\text { Focused Historically } \\
\text { Marginalized Communities }\end{array}$ \\
\hline $\begin{array}{l}\text { People of } \\
\text { color }\end{array}$ & $\begin{array}{l}\text { Persons who } \\
\text { identify as non- } \\
\text { white }\end{array}$ & $\begin{array}{l}\text { Census Tracts } \\
\text { (CTs) above } \\
\text { regional rate } \\
22.4 \%\end{array}$ & $\begin{array}{l}\text { CTs above regional rate } 22.4 \% \\
\text { AND has twice }(2 \mathrm{X}) \text { the } \\
\text { population density of the } \\
\text { regional average }(4,147 \\
\text { persons per sq. mi.) }\end{array}$ \\
\hline Low income & $\begin{array}{l}\text { HH with incomes } \\
\text { equal to or less } \\
\text { than } 200 \% \text { of } \\
\text { federal poverty } \\
\text { level }\end{array}$ & $\begin{array}{l}\text { CTs above } \\
\text { regional rate } \\
35.6 \%\end{array}$ & $\begin{array}{l}\text { CTs above regional rate } 35.6 \% \\
\text { AND has twice }(2 X) \text { the } \\
\text { population density of the } \\
\text { regional average }(4,147 \\
\text { persons per sq. mi.) }\end{array}$ \\
\hline $\begin{array}{l}\text { Limited } \\
\text { English } \\
\text { proficiency }\end{array}$ & $\begin{array}{l}\text { Persons who } \\
\text { identify as unable } \\
\text { to speak English } \\
\text { very well }\end{array}$ & $\begin{array}{l}\text { CTs above } \\
\text { regional rate } \\
9.0 \%\end{array}$ & $\begin{array}{l}\text { CTs above regional rate } 6.6 \% \\
\text { AND has twice }(2 \mathrm{X}) \text { the } \\
\text { population density of the } \\
\text { regional average }(4,147 \\
\text { persons per sq. mi.) }\end{array}$ \\
\hline Older adults & $\begin{array}{l}\text { Persons } 65 \text { years } \\
\text { of age and older }\end{array}$ & $\begin{array}{l}\text { CTs above } \\
\text { regional rate } \\
11.5 \%\end{array}$ & N/A \\
\hline $\begin{array}{l}\text { Young } \\
\text { persons }\end{array}$ & $\begin{array}{l}\text { Persons } 17 \text { years } \\
\text { of age and } \\
\text { younger }\end{array}$ & $\begin{array}{l}\text { CTs above } \\
\text { regional rate } \\
18.7 \%\end{array}$ & N/A \\
\hline
\end{tabular}

Source: (Portland Metro, 2017)

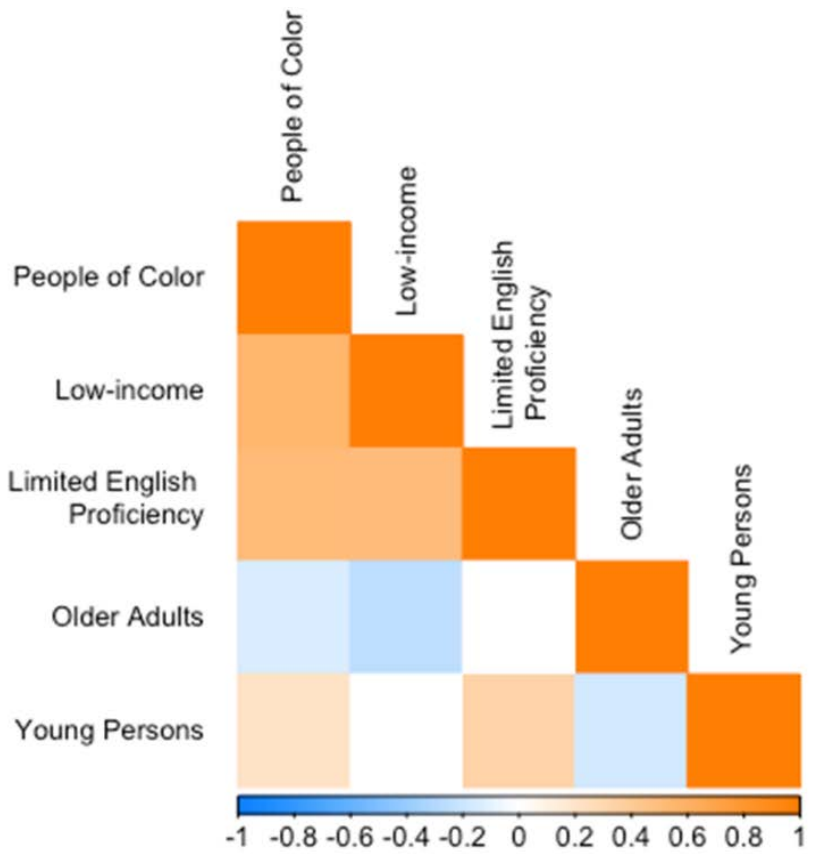

Figure 5. Correlation of Environmental Justice (EJ) Indicators 
Figure 6 shows the spatial distribution of historically marginalized communities in Portland. While the Tier I communities is a broader measure that highlights 388 out of 447 block groups in the city, Tier II focuses on 114 block groups that may warrant the greatest amount of attention in terms of transportation investment decisions. We additionally examine each of the five environmental justice indicators separately to underscore the patterns of how these different groups are geographically spread across the region. Figure 6 shows the spatial distribution of indicator quintiles, with dark colors representing a higher level of potential transportation disadvantage, such as higher percentages of people of color, low-income people, those with limited English proficiency, older adults and young persons. In general, North and outer East Portland tend to house more disadvantaged populations, and the same areas plus a few downtown block groups are also where low-income households are concentrated. Similar patterns persist when looking at concentrations of immigrants with limited English proficiency.

After identifying all of the transportation disadvantaged EJ communities, we analyzed the spatial relationships between our bicycle accessibility measures and EJ groups in all five categories of historically marginalized communities.

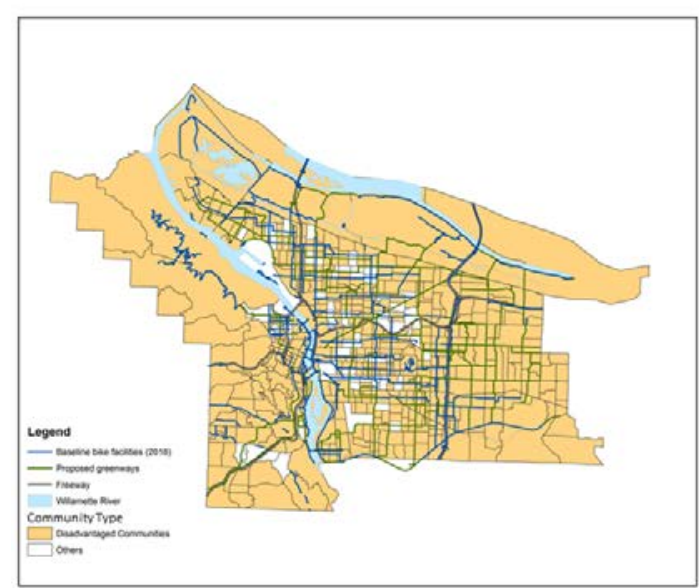

(a) Historically Marginalized Communities (Tier I)

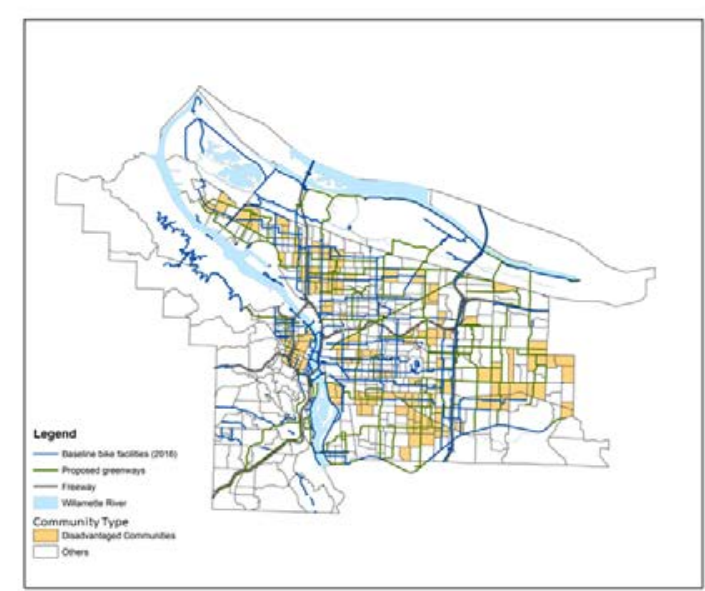

(b) Focused Historically Marginalized Communities (Tier II)

Figure 6. Historically Marginalized Communities in Portland, OR 

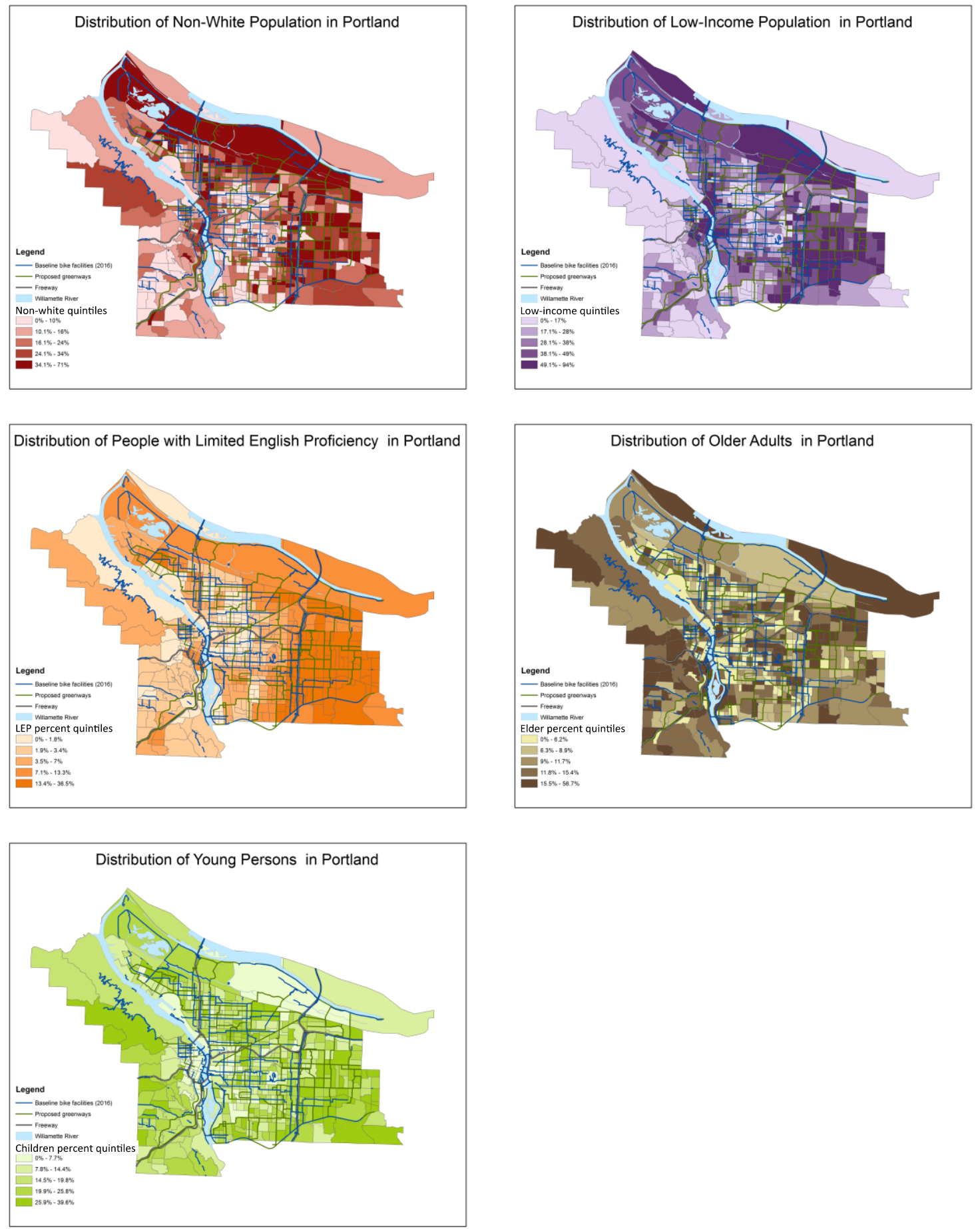

Figure 7. Distribution of Social Disadvantaged Population in Portland 



\subsection{RESULTS - TRANSPORTATION IMPACTS}

Improvements or additions to urban bicycle and pedestrian infrastructure that improve transportation accessibility may affect urban active transportation in many ways. Intuitively, these types of investments mean that more people will be within closer proximity to greenway facilities. In addition, improvements to the overall urban greenway network can provide better access to many important urban destinations. High-quality urban greenways that connect existing bicycle facilities can also contribute to a more complete active transportation network for the city, providing a comfortable and safe environment for cyclists. The following sections show the estimated transportation impacts of the current and future Portland urban greenway network scenarios through the three BAMs introduced in Section 3.0: a (1) distance-based BAM, (2) destination-based BAM, and (3) low-stress network BAM.

\subsection{DISTANCE-BASED BAM}

Distance-based BAM considers the spatial separation between the urban greenway network facilities and its users. The network distance from the centroid of each census block to the nearest bike/greenway facilities is measured to represent the BAM of each block. On average, the distance-based BAM, measured as distance to nearest bike/greenways facilities in each census block, improved from 0.40 mile (2,134 feet) to 0.23 mile $\left(1,213\right.$ feet ${ }^{6}$ when the City Greenways concept is implemented. In addition, when we examine the distribution of accessibility improvements using the following histogram, we observe that more census blocks will enjoy better access (shorter distance) to bike/greenways facilities after the City Greenways improvements (Figure 8).

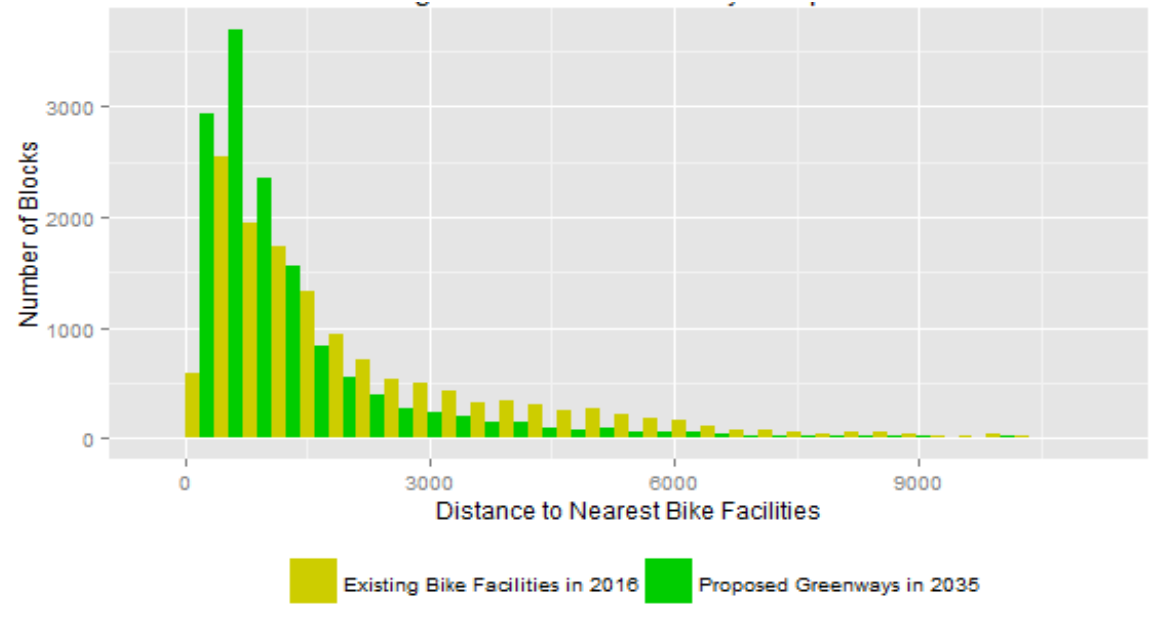

Figure 8. Histogram of Distance to Nearest Urban Greenways Before and After Urban Greenway Improvement

\footnotetext{
${ }^{6}$ Extreme outliers are excluded from these summary statistics. Approximately $2 \%$ of over 14,000 census blocks were excluded.
} 
The change in the distance-based BAM for the two scenarios is shown in Figure 9. While the existing urban greenways are mostly concentrated in the urban center and inner East Portland, the proposed City Greenways expands investments into bicycle facilities toward the city edge, mostly within outer east, south, and northeast areas of Portland. These expansion areas tend to have fewer transportation amenities and are home to many of the identified historically marginalized communities.

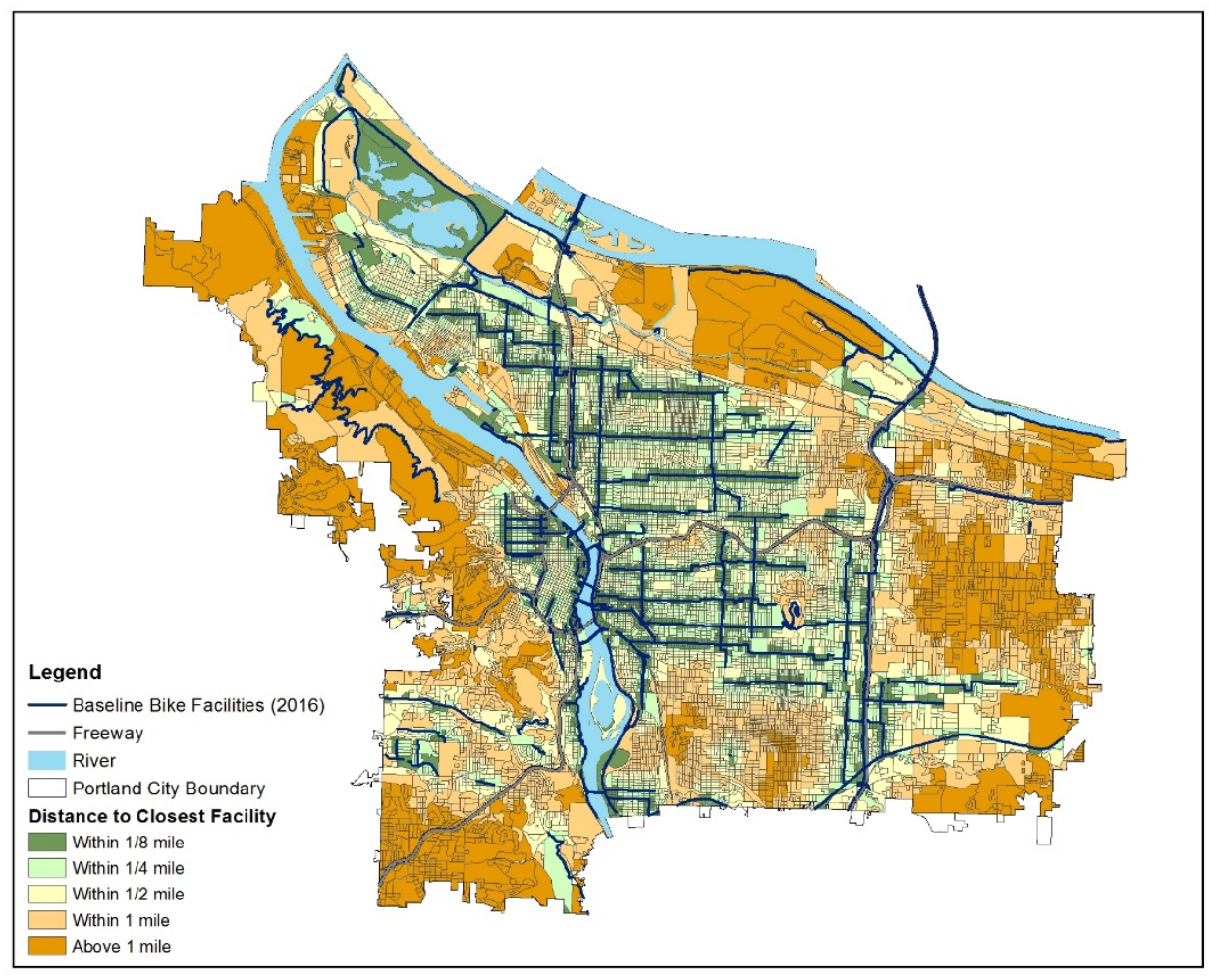




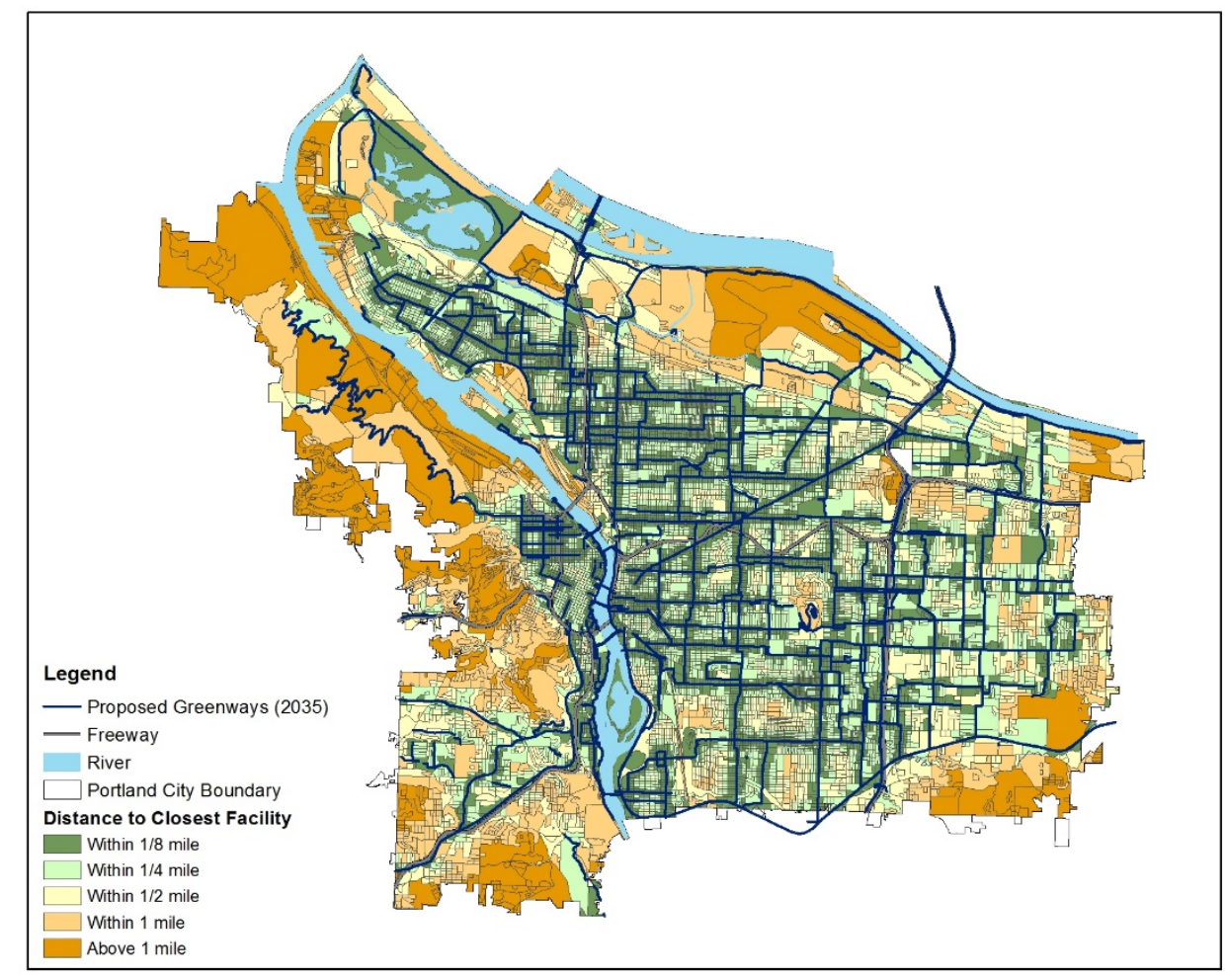

Figure 9. Distance to Nearest Urban Greenways Before and After Proposed 2035 City Greenways Improvements

\subsection{DESTINATION-BASED BAM}

While proximity to transportation facilities as estimated in our distance-based BAM is one of the most straightforward measures to calculate, the literature has pointed out the importance of viewing transportation infrastructure and networks as the means to access essential destinations such as jobs and other services. Therefore, the destination-based BAMs presented here will measure cumulative destinations that can be accessed via the urban greenway network.

Using the important destinations as defined in Section 3.1.2, we measure the destination-based BAM as whether these important destinations can be easily reached by urban greenway facilities within a quarter-mile catchment zone. The cumulative reachable destinations of two urban greenway scenarios are calculated through the spatial package in ArcGIS. In general, a larger proportion of important destinations can be reached in the 2035 urban greenway scenario compared to the 2016 current scenario. With the existing bicycle greenway infrastructure, 1,334 important employment destinations, 1,211 important retail destinations, 1,274 important service destinations, and 440 parks/recreational areas can be easily reached using the urban greenway infrastructure. After improvements to the urban greenway network in the proposed 2035 City Greenways plan, the easily accessible important destinations increases to 1,864 employment destinations, 1,847 retail destinations, 1,865 service destinations, and 627 parks/recreation 
destinations. In addition, the percentages of important destinations easily accessible via the urban greenways for two scenarios are summarized below.

Table 6. Percent of Important Destinations Easily Reachable Using Urban Greenways

\begin{tabular}{|c|c|c|c|c|}
\hline & $\begin{array}{c}\text { Employment } \\
\text { Centers }\end{array}$ & Retail Centers & Service Centers & $\begin{array}{c}\text { Parks/ } \\
\text { Recreation }\end{array}$ \\
\hline 2016 Scenario & $62.3 \%$ & $56.5 \%$ & $59.4 \%$ & $43.8 \%$ \\
\hline 2035 Scenario & $87.1 \%$ & $86.2 \%$ & $87.0 \%$ & $62.4 \%$ \\
\hline
\end{tabular}

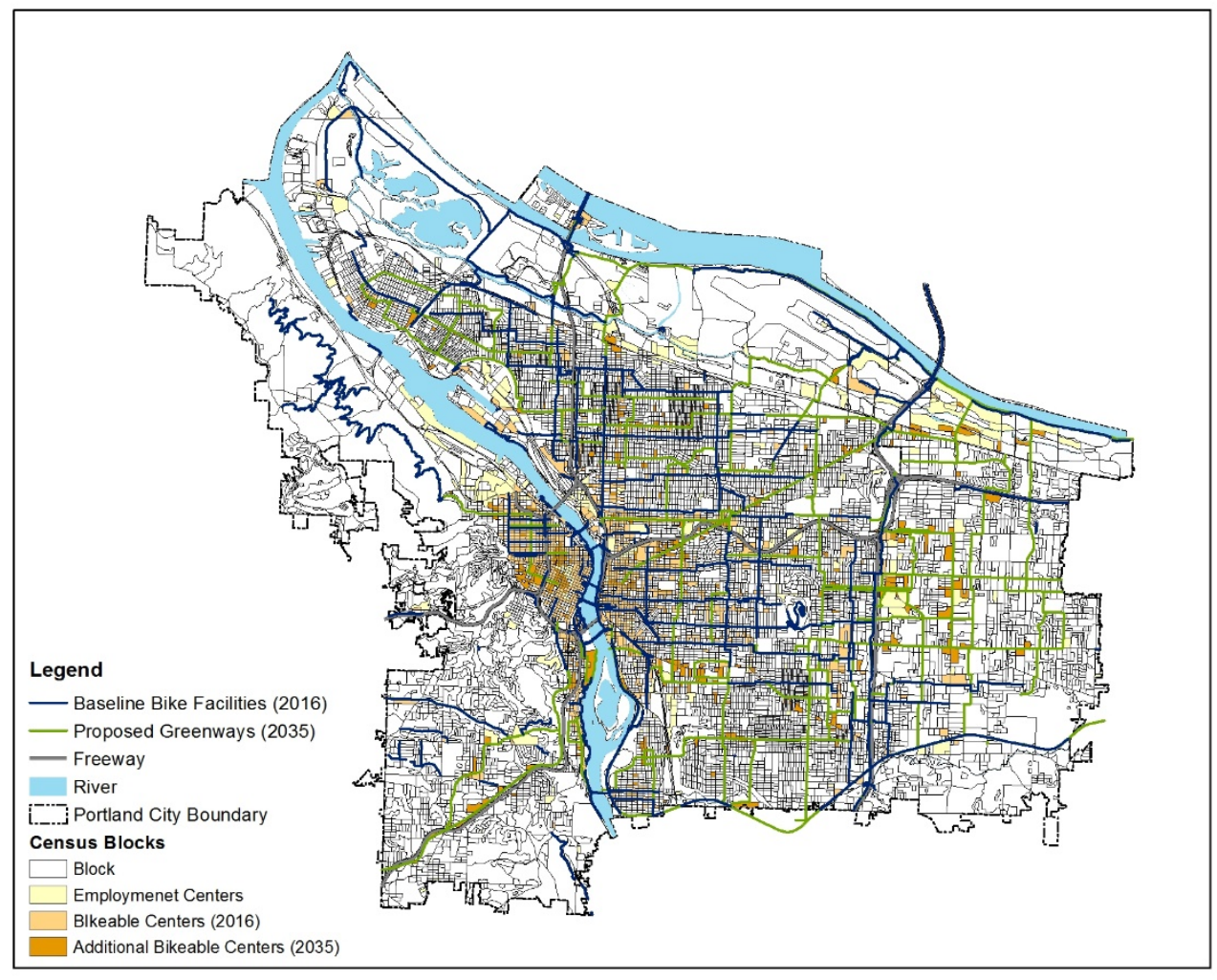

(a) Work/Employment Destinations 

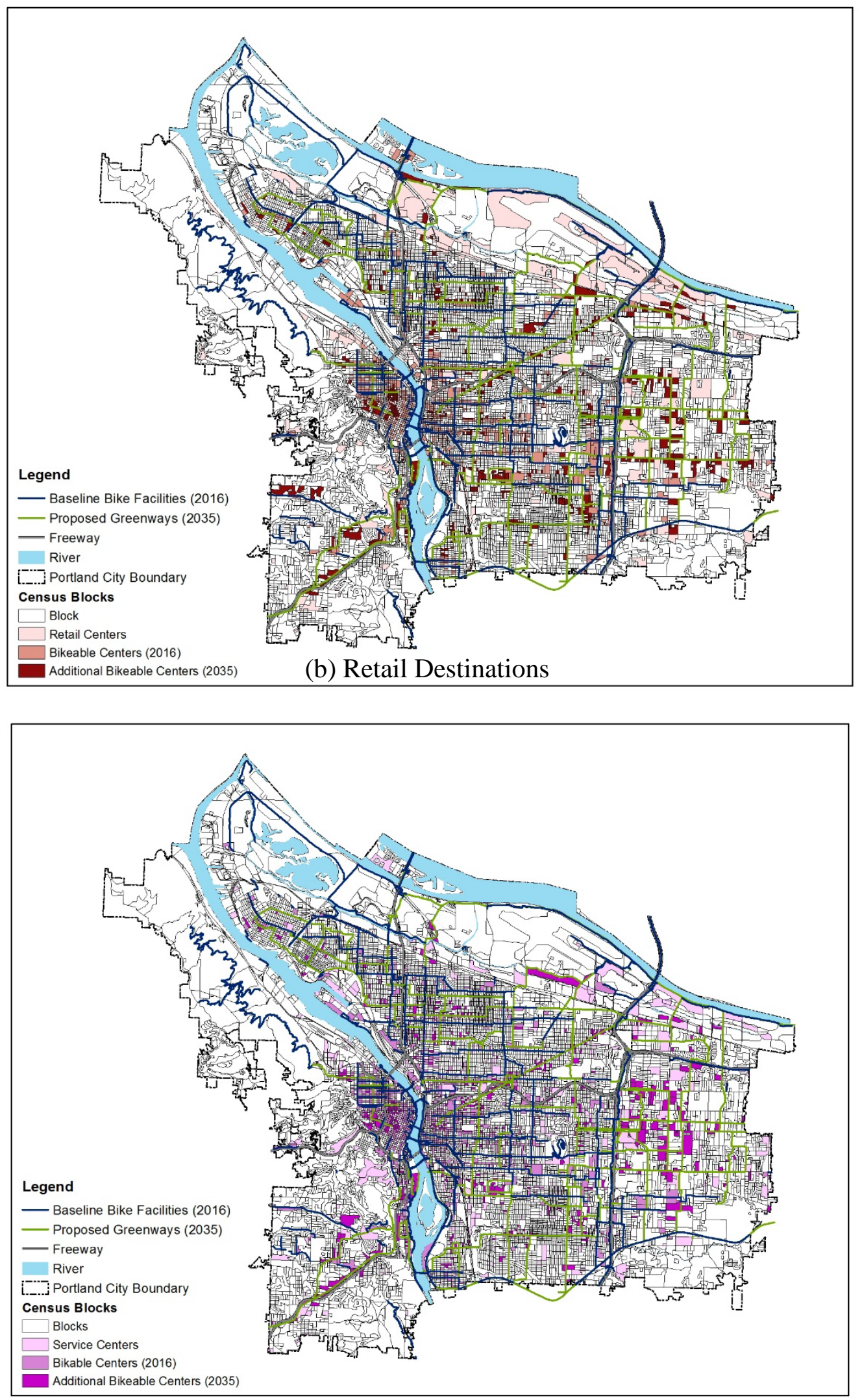

(c) Service Destinations 


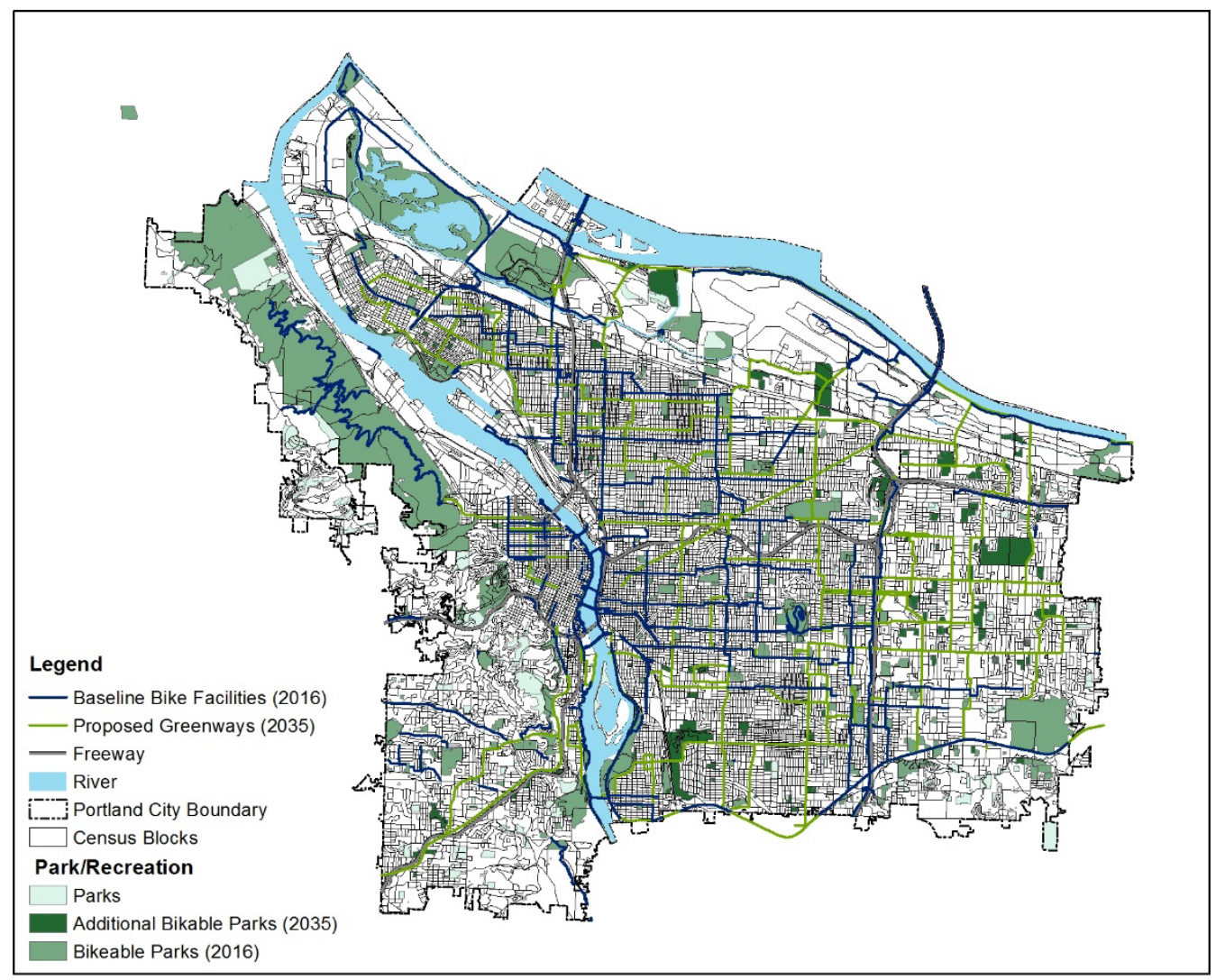

(d) Park/Recreation

Figure 10. Bikeable Importation Destinations in Portland: (a) Work/Employment; (b) Retail; (c) Service; (d) Park \& Recreations

In addition, we further incorporated a destination attractiveness factor by weighting destinations by employment (for employment, retail and service destinations) or by acreage (for parks/recreation destinations) for an extended destination-based BAM. This extension allows policymakers to identify more important destinations that attract a larger number of travelers instead of simply equally weighting all top destinations. Using this extended weighting methodology, we found that a higher weighted destination-based BAM in the 2035 City Greenways scenario compared to the existing 2016 scenario (Table 7). Additionally, we found increased access to more of the smaller important destinations. Given that our identified destinations are already in the top 15\% census blocks in terms of job density, these results indicate that the proposed City Greenways spreads out the investment in bicycle infrastructure to reach more diverse destinations in regions not currently well-serviced by the urban greenway network. 
Table 7. Percent of Centers Covered by Quarter Bike Network Catchment Zone (weighted destination access BAM)

\begin{tabular}{|c|c|c|c|c|}
\hline & $\begin{array}{l}\text { Employment } \\
\text { Centers }\end{array}$ & $\begin{array}{l}\text { Retail } \\
\text { Centers }\end{array}$ & $\begin{array}{l}\text { Service } \\
\text { Centers }\end{array}$ & Parks/Recreation \\
\hline $\begin{array}{l}\text { Weighting } \\
\text { method }\end{array}$ & \multicolumn{3}{|c|}{$\begin{array}{l}\text { Number of jobs in centers / jobs in all centers in } \\
\text { that category }\end{array}$} & $\begin{array}{l}\text { Park size (small, medium } \\
\text { and large) }\end{array}$ \\
\hline 2016 Scenario & $56.7 \%$ & $46.2 \%$ & $47.9 \%$ & $46.8 \%$ \\
\hline 2035 Scenario & $79.6 \%$ & $74.1 \%$ & $66.7 \%$ & $66.6 \%$ \\
\hline
\end{tabular}

\subsection{LOW-STRESS NETWORK-BASED BAMS}

Because a majority of the cycling population (60\%) fits the "interested but concerned" type of cyclists (Dill and McNeil, 2013), it is plausible to assume that improvements to the quality of the urban greenway network, as well as the overall accessibility of the network, may induce more users to utilize the infrastructure. The low-stress network-based BAMs aim to incorporate an index of bicycle stress level on each link of the urban greenway network to indicate the comfort levels and willingness to use a bicycle as a travel mode.

The stress level is estimated with two components: link stress and turn stress. The link-stress factor is derived from discrete choice model results based on a Portland study (Broach et al., 2012), and more details can be found in Section 3.1.3.

- Link stress is based on road classification (based on AADT) and bike accommodation type, and results in a link-stress factor (F_stress), which is then combined with the slope factor (F_slope) to calculate the stress impedance for each link (W_link); and

- Turn factor is based on network route impedance factor for left turns vs. right turns (60 feet vs. 30 feet). This distance is then added to the link-stress route distance.

The figure below illustrates the stress level of all roadway links in the Portland urban greenway network before and after the proposed 2035 City Greenways improvements. One thing to keep in mind is that the stress-level map only represents the bikeability of each network segment, not the actual route quality. It is evident from this figure that many parts of the network in the west side of Portland and some other locations scattered around the city are high-stress links within the network, indicated by red links, and most of this is due to the extremely hilly terrain that makes it difficult for most cyclists to feel comfortable on these segments. However, with the proposed improvements in the 2035 City Greenways plan towards the east and south edges of the city, there are more and denser segments with low-stress facility features. In addition, these additional low-stress links within the network will contribute positively towards a complete urban greenway network that can provide better active transportation accessibility for a larger portion of the population. The low-stress network BAMs in the following sections will illustrate this concept further.

The low-stress network-based BAM measures the comfort levels and willingness to use an active transportation mode as a travel option. It incorporates bicycle level-of-stress factors (level of 
service [LOS] of urban greenways), such as link stress, link slope and turn factor to determine the overall accessibility of the urban greenway network. There are three detailed measures calculated that fall within this BAM category:

- Low-stress network BAM - proximity to important destinations: It is calculated by distance weighted by stress level to the closest five important destinations for each destination type.

- The low-stress network BAM - stress level to important destinations: It is based on the ratio of routes to important destinations containing low-stress segments,

- The last low-stress network BAM we constructed is a combination of the low-stress network proximity BAM and the low-stress network stress level of route BAM. It is calculated as the percentage of important destinations that can be reached through the low-stress urban greenway network within a 2.5-mile buffer radius.

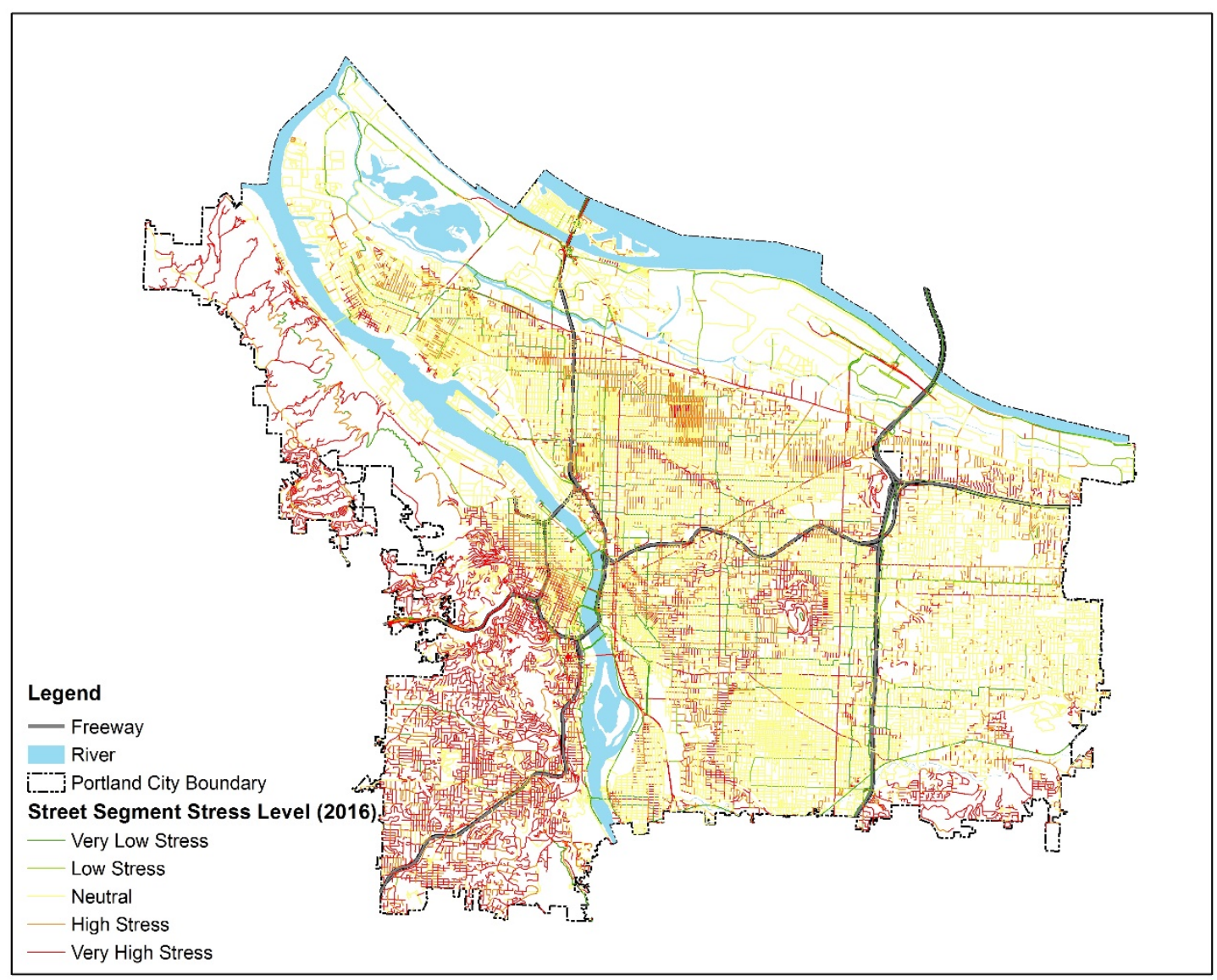

(a) Stress Level of Current Urban Greenways 


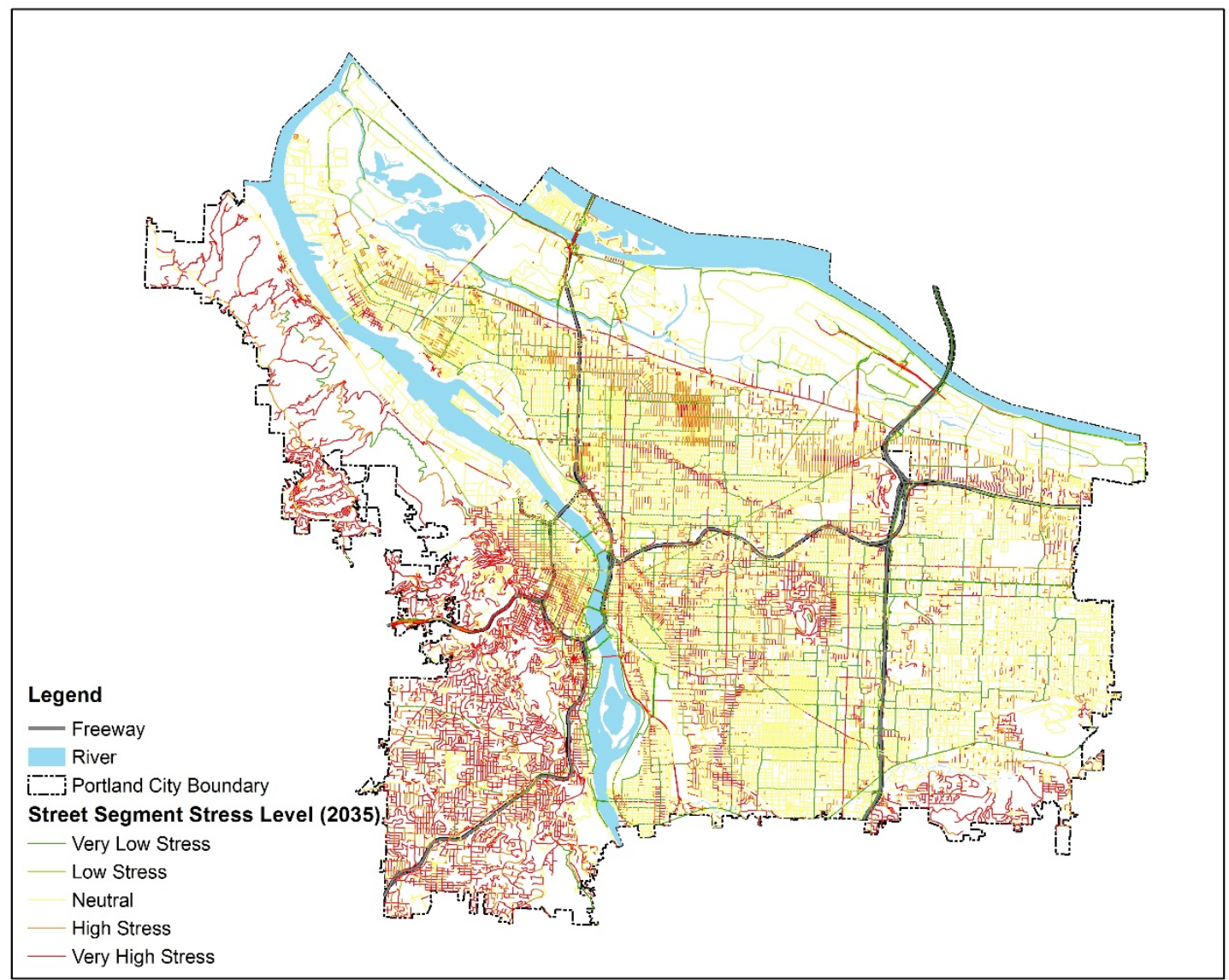

(b) Stress Level of 2035 Urban Greenways

Figure 11. Portland Bike/Greenways Facilities Before and After Urban Greenway Improvement

\subsubsection{Low-Stress Network BAM - Proximity to Closest Five Important Destinations}

Low-stress network BAM - proximity to important destinations is calculated by distance weighted by stress level to the closest five important destinations for each destination type. We chose to use the closest five destinations instead of focusing on only one destination, which serves to prevent any skewing when calculating the bicycle accessibility measure for isolated origins that are close to only one destination and far from others. The following table shows the weighted median distance to the closest five important destinations in the two urban greenways scenarios. We found that after the proposed 2035 City Greenways improvements, the low-stress network BAM proximity to all four types of importation destinations have improved. The median distance to the closest five employment destinations decreases from 0.54 mile (2,865 feet) to 0.44 mile (2,323 feet), while the median distances to the nearest five important retail and service destinations decrease from $0.43 / 0.42$ mile to 0.37 mile. The degree of improvement is 
especially significant for parks and recreation destinations, decreasing from 0.66 mile (3,511 feet) to 0.47 mile (2,470 feet).

Table 8. Median Proximity (feet) to Closest Five Important Destinations Weighted by Stress Level

\begin{tabular}{|l|c|c|c|c|}
\hline & $\begin{array}{c}\text { Employment } \\
\text { Centers }\end{array}$ & $\begin{array}{c}\text { Retail } \\
\text { Centers }\end{array}$ & $\begin{array}{c}\text { Service } \\
\text { Centers }\end{array}$ & $\begin{array}{c}\text { Parks/ } \\
\text { Recreation }\end{array}$ \\
\hline 2016 Scenario & 2,865 & 2,286 & 2,226 & 3,511 \\
\hline 2035 Scenario & 2,323 & 1,928 & 1,963 & 2,470 \\
\hline
\end{tabular}

This low-stress network proximity BAM measures the general access to important destinations by proximity (weighted by stress level of the network), which is reflective of the actual travel cost from each block. From the maps below, we can observe overall the proximity to employment destinations is the best within the city center (green color), and West Portland (orange color) tends to be the worst. In terms of employment destinations, there are slight improvements in Northwest and East Portland as well as in the Southwest Corridor.

Although the 2035 City Greenways plan designates many bicycle facility improvements in the far east and northeast regions of Portland, the low-stress network proximity BAM increases only slightly in this region (different than the results from the distance-based BAM). These results indicate that while residents may be better able to access the urban greenway network as more bicycle infrastructure is built, it does not necessarily translate into better access to important destinations. It also underscores the importance of complementary economic development policies that expand the spatial distribution of important destinations while investing in urban greenway infrastructure or other transportation network improvements. 


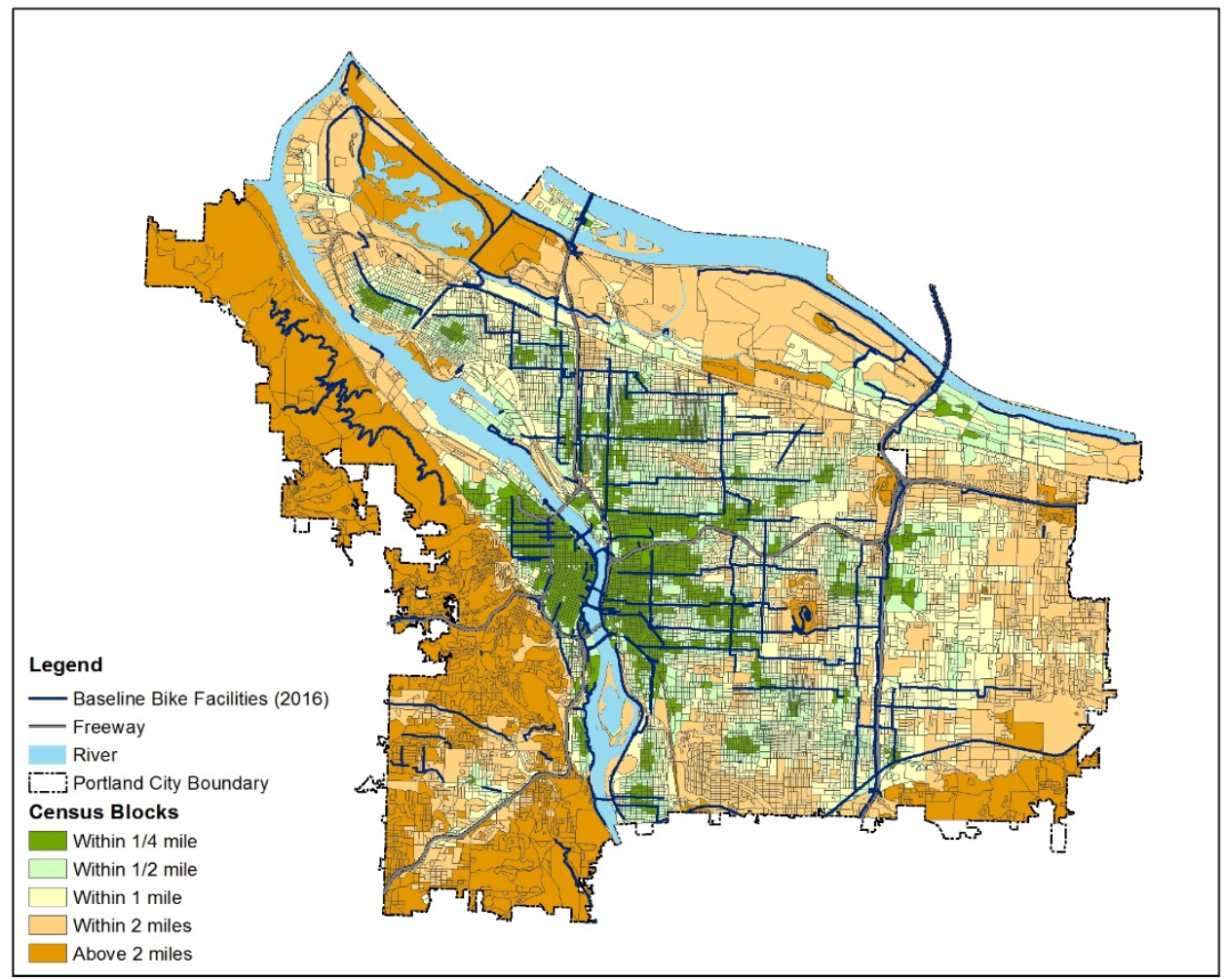

(a_1) Proximity to Employment Destinations (2016)

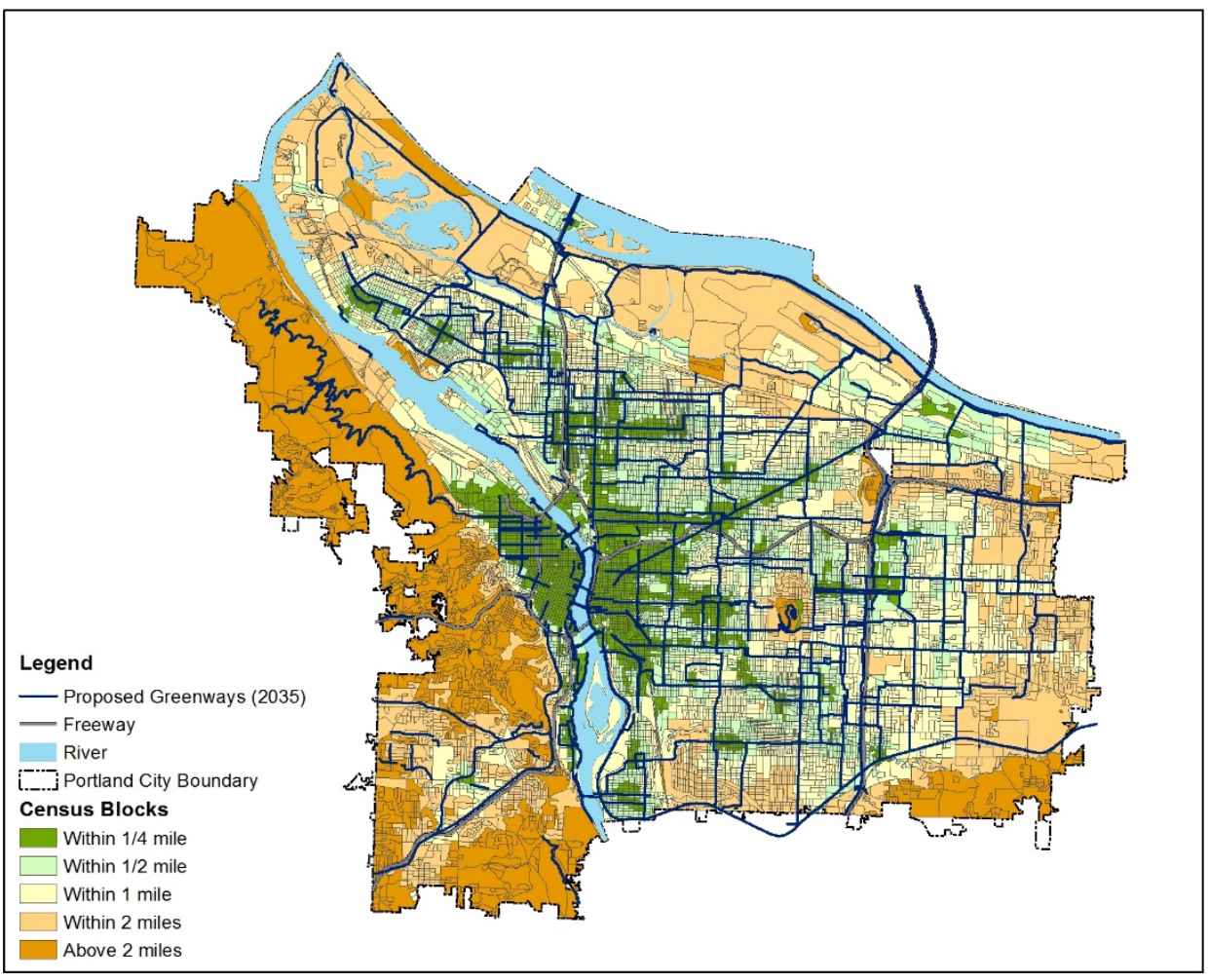

(a_2) Proximity to Employment Destinations (2035) 


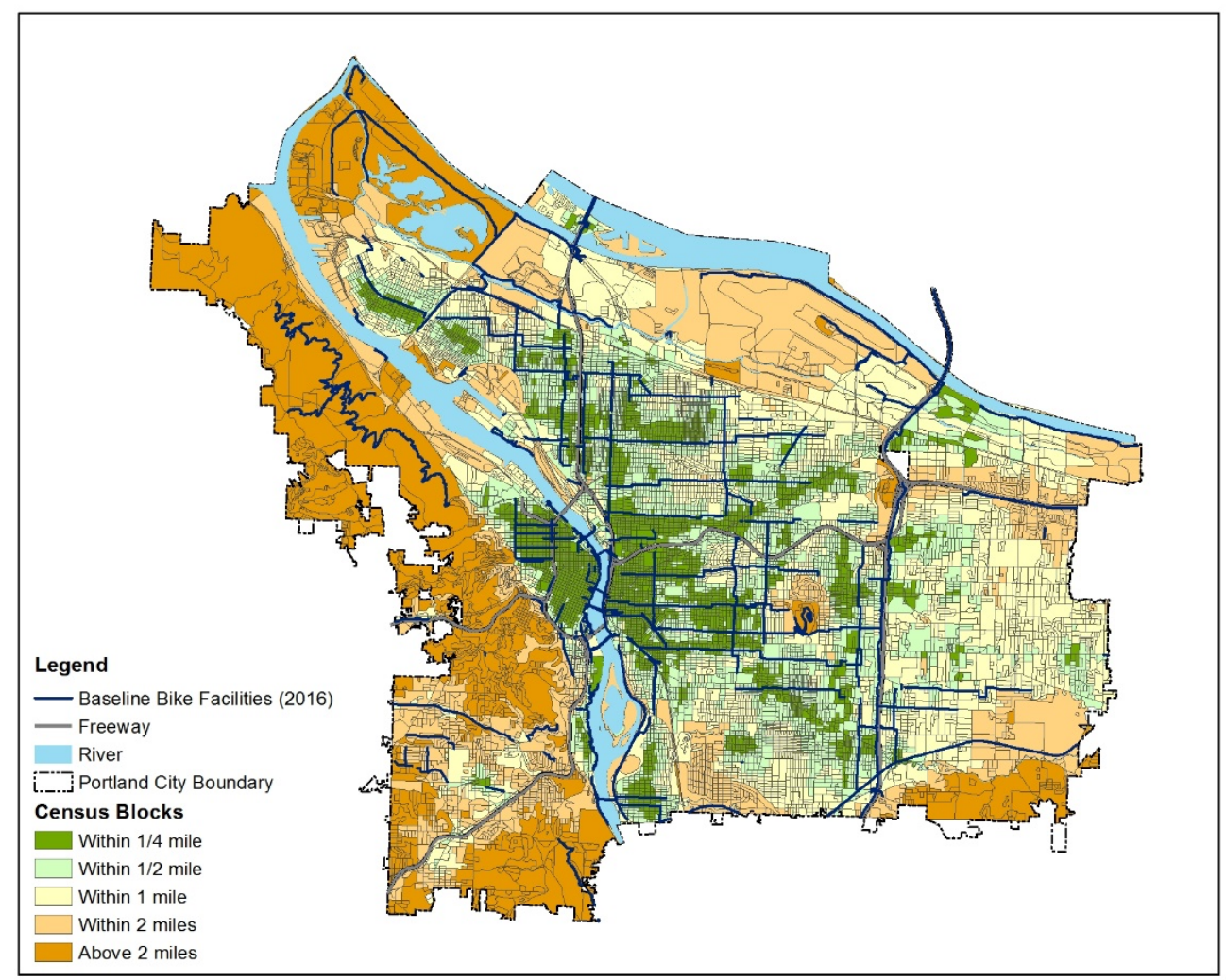

(b_1) Proximity to Retail Destinations (2016)

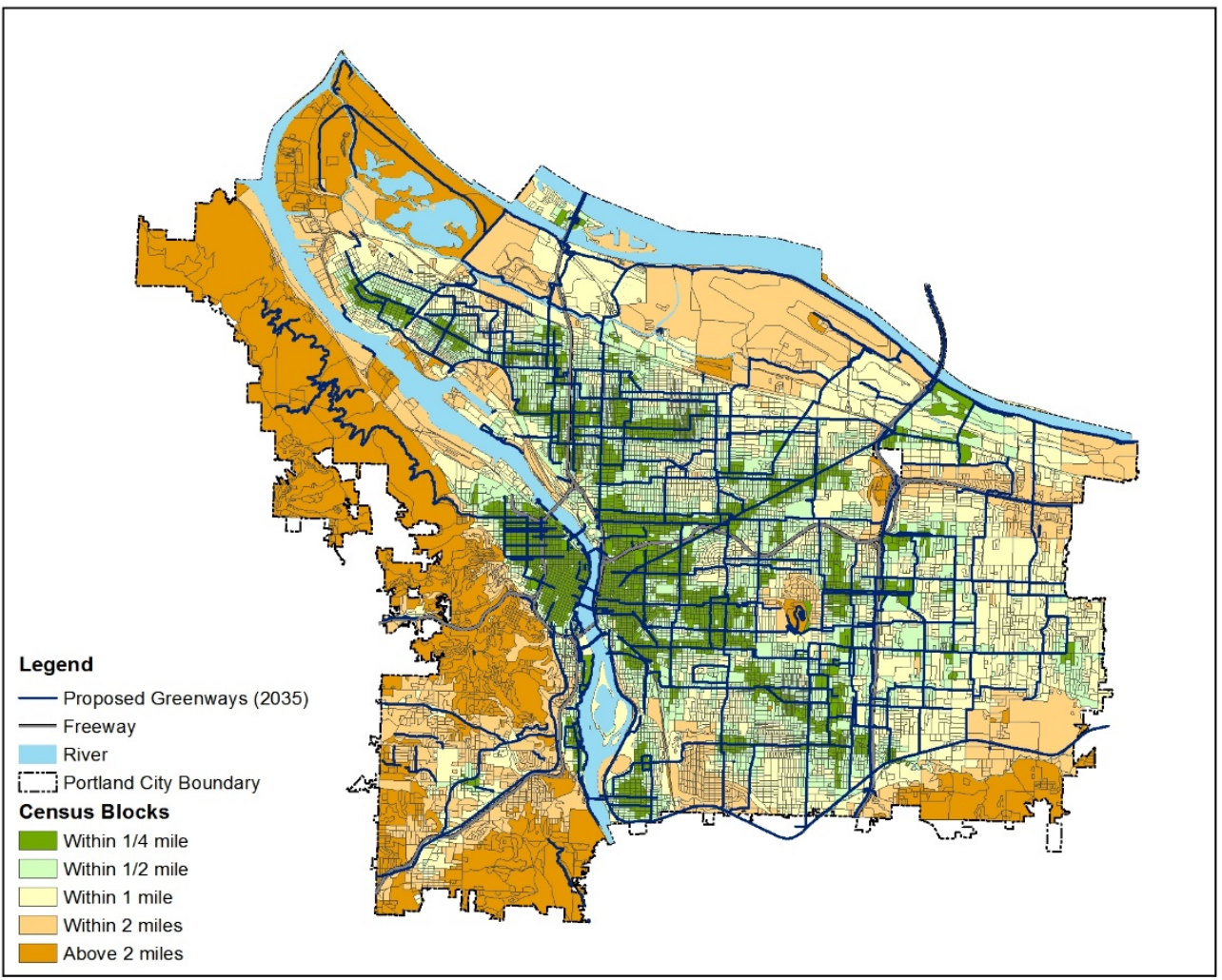

(b_2) Proximity to Retail Destinations (2035) 


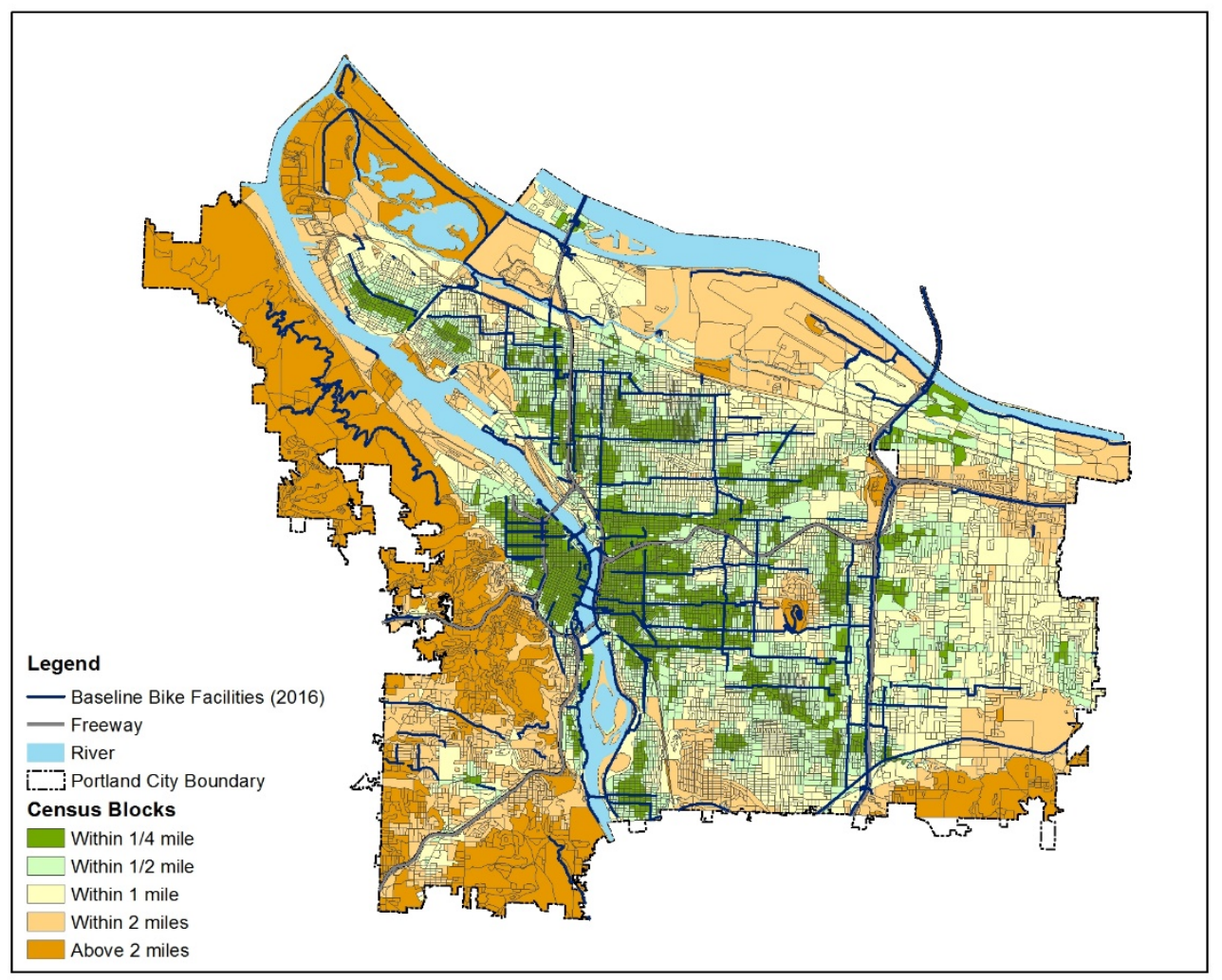

(c_1) Proximity to Service Destinations (2016)

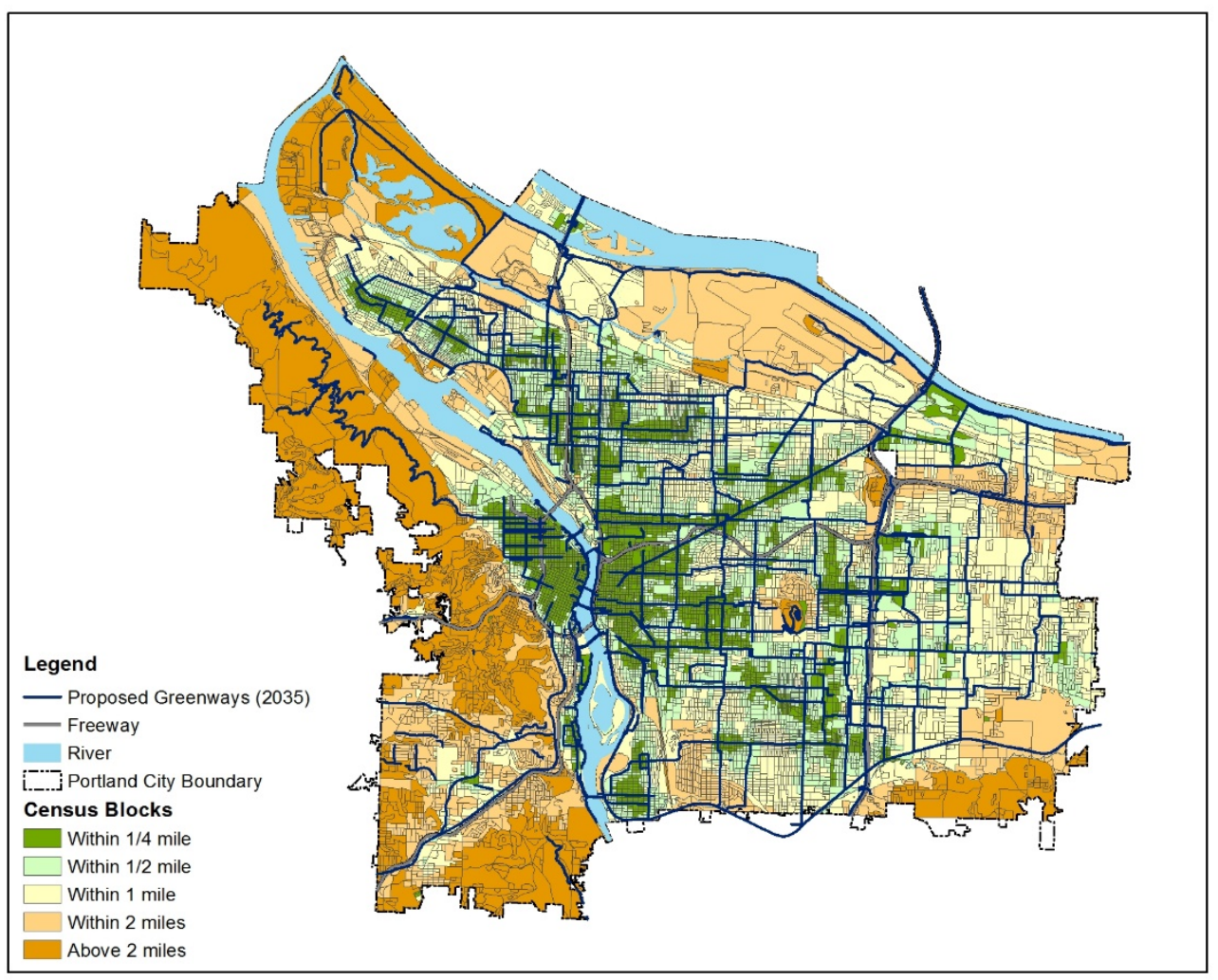

(c_2) Proximity to Service Destinations (2035) 


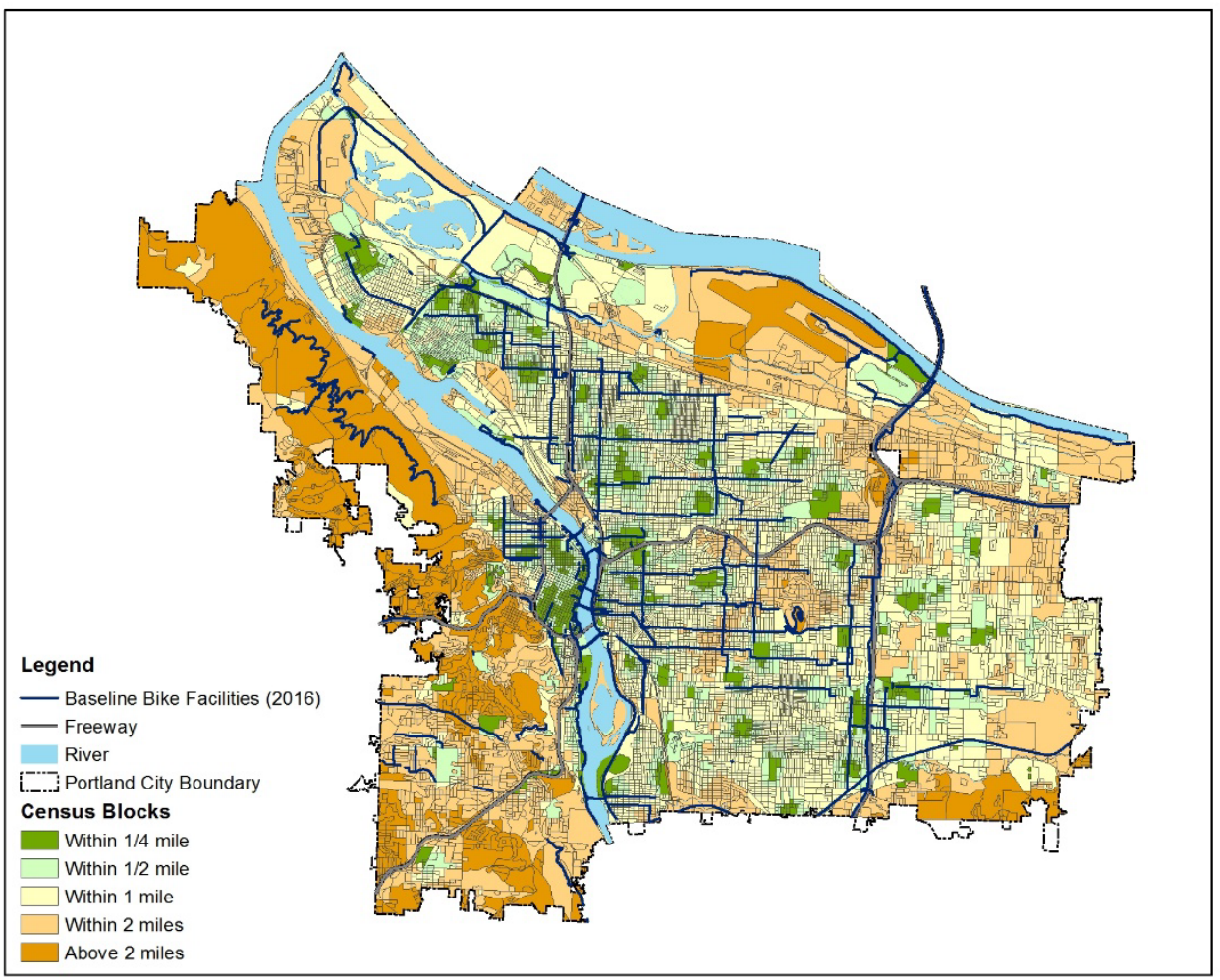

(d_1) Proximity to Park/Recreation (2016)

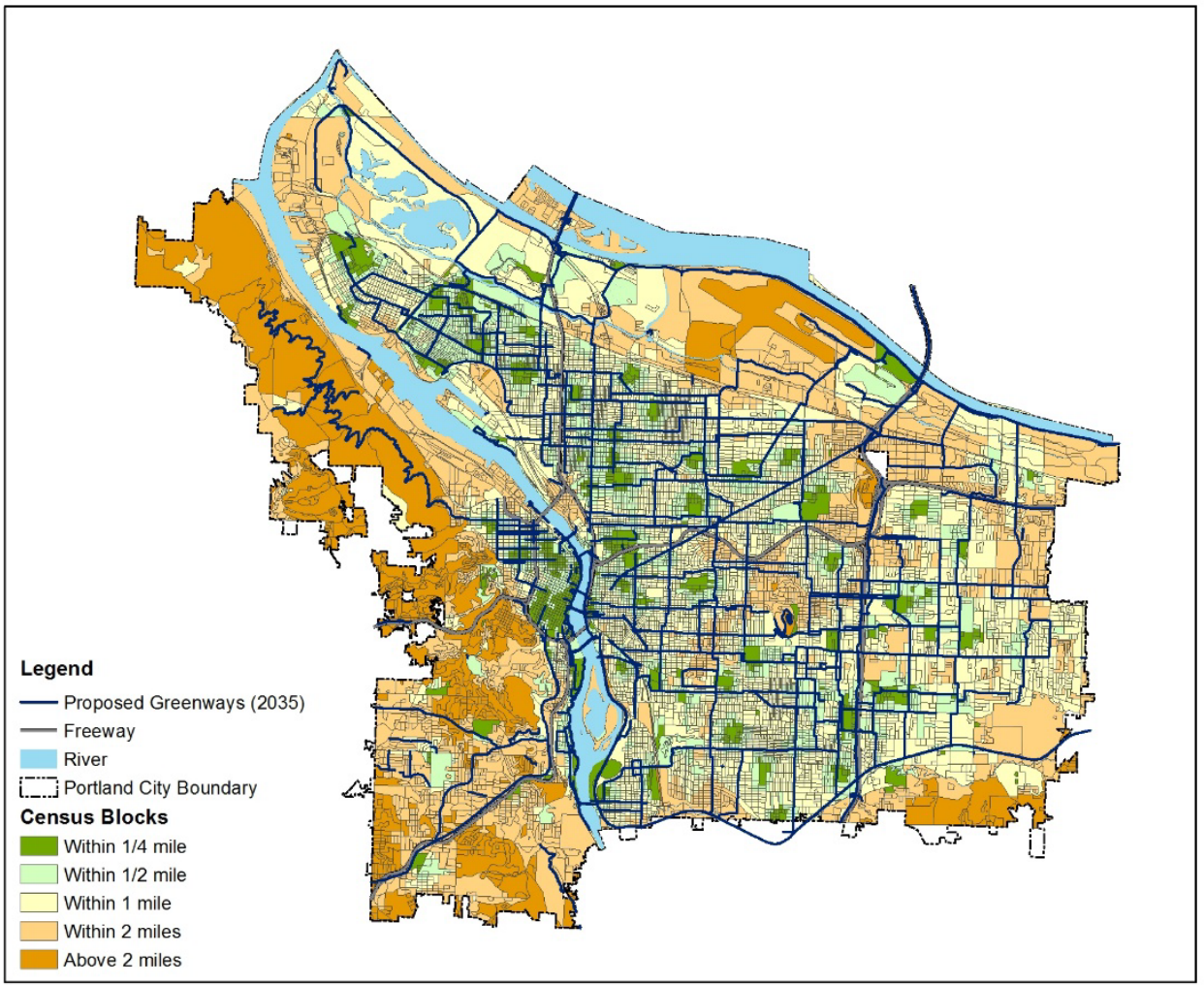

(d_2) Proximity to Park/Recreation (2035)

Figure 12. Proximity to Closest 5 Important Employment Destinations Weighted by LowStress Street Level 


\subsubsection{Low-Stress Network BAM - Stress Level of Route to Closest Five Importation Destinations Containing Low-Stress Segments}

The low-stress network BAM is based on the ratio of routes to important destinations containing low-stress segments. It is an alternative index measure that ranges from 0.79 to 6.67 , with smaller numbers indicating lower stress levels along routes that take people to the nearest five important destinations of each type. To be specific, this measure is calculated by the stress factor weighted length divided by actual network length of distance to the nearest five important destinations. It is the proportion of level of route containing low-stress links. For example, if the route to an important destination is all on multiuse regional paths, this index would be 0.79 ; while if the route to an important destination is on high travel-volume streets with no bike facilities, this index would be 6.67; and if the route is mostly on streets with no bike facilities or relatively busier streets with bike lanes, this index would be close to 1 (refer to Table 3 for detailed stress factor).

Table 9 compares the stress level of route BAM before and after the 2035 City Greenways planned improvements to the urban greenway network. This BAM decreases for all four types of destinations, with particularly large improvements for some extremely high-stress routes. For example, the stress level of the highest stressful route to important retail destinations has improved by $50 \%$.

Table 9. Stress Level of Route BAM

\begin{tabular}{|c|c|c|c|c|c|}
\hline & & $\begin{array}{c}\text { Employment } \\
\text { Centers }\end{array}$ & $\begin{array}{c}\text { Retail } \\
\text { Centers }\end{array}$ & $\begin{array}{c}\text { Service } \\
\text { Centers }\end{array}$ & $\begin{array}{c}\text { Parks/ } \\
\text { Recreation }\end{array}$ \\
\hline \multirow{2}{*}{2016 Scenario } & Mean & 1.091 & 1.015 & 1.010 & 0.998 \\
\cline { 2 - 6 } & Range & $0.83-6.15$ & $0.82-4.06$ & $0.82-3.23$ & $0.79-4.45$ \\
\hline \multirow{2}{*}{2035 Scenario } & Mean & 1.048 & 0.986 & 0.986 & 0.980 \\
\cline { 2 - 6 } & Range & $0.79-5.06$ & $0.80-2.72$ & $0.81-2.83$ & $0.80-3.51$ \\
\hline
\end{tabular}

The stress level of route BAM incorporates the route condition in its measurement, in terms of how stressful the route would be to important destinations for cyclists. The lower the route stress is, the more willingness or preference of consumers to utilize a bike as a travel mode to reach their destinations. Figure 13 illustrates some of the significant changes in the stress level of route BAM before and after the 2035 City Greenways proposed improvements. While many routes in East Portland are relatively low-stress segments due to low travel volumes, the urban greenway network is not necessarily an accessible travel mode to reach important destinations around the city. 


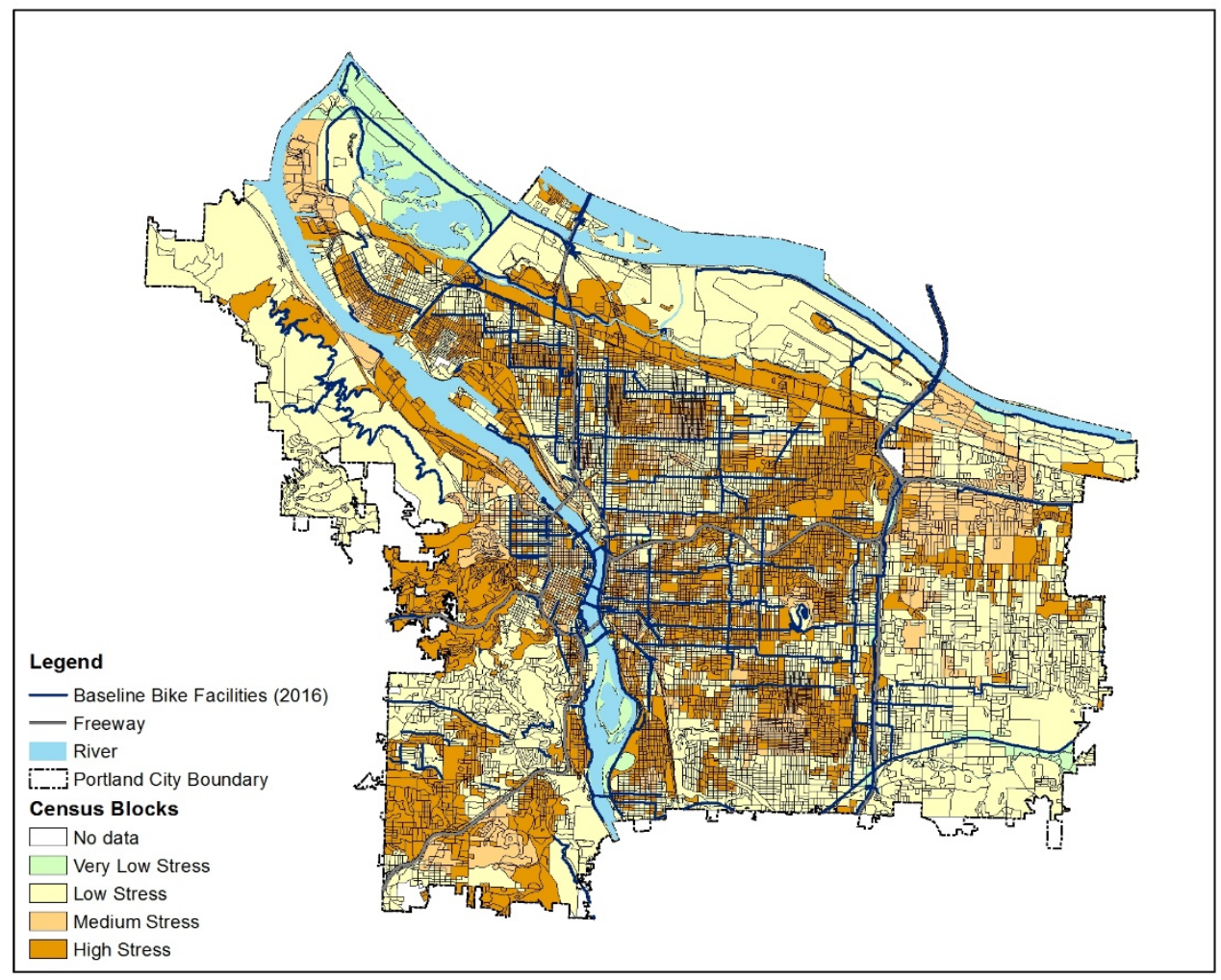

(a_1) Stress Level to Employment Destinations (2016)

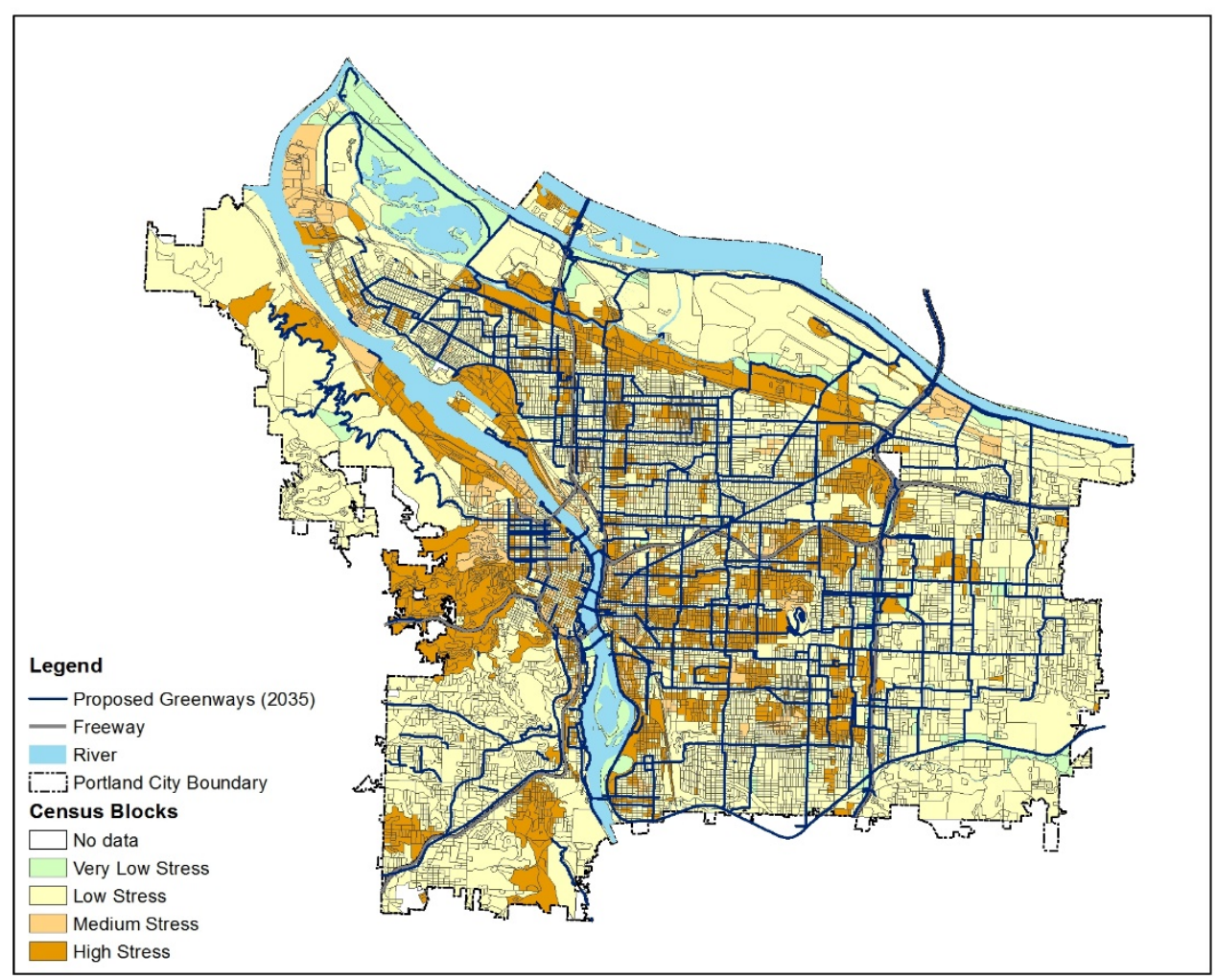

(a_2) Stress Level to Employment Destinations (2035) 


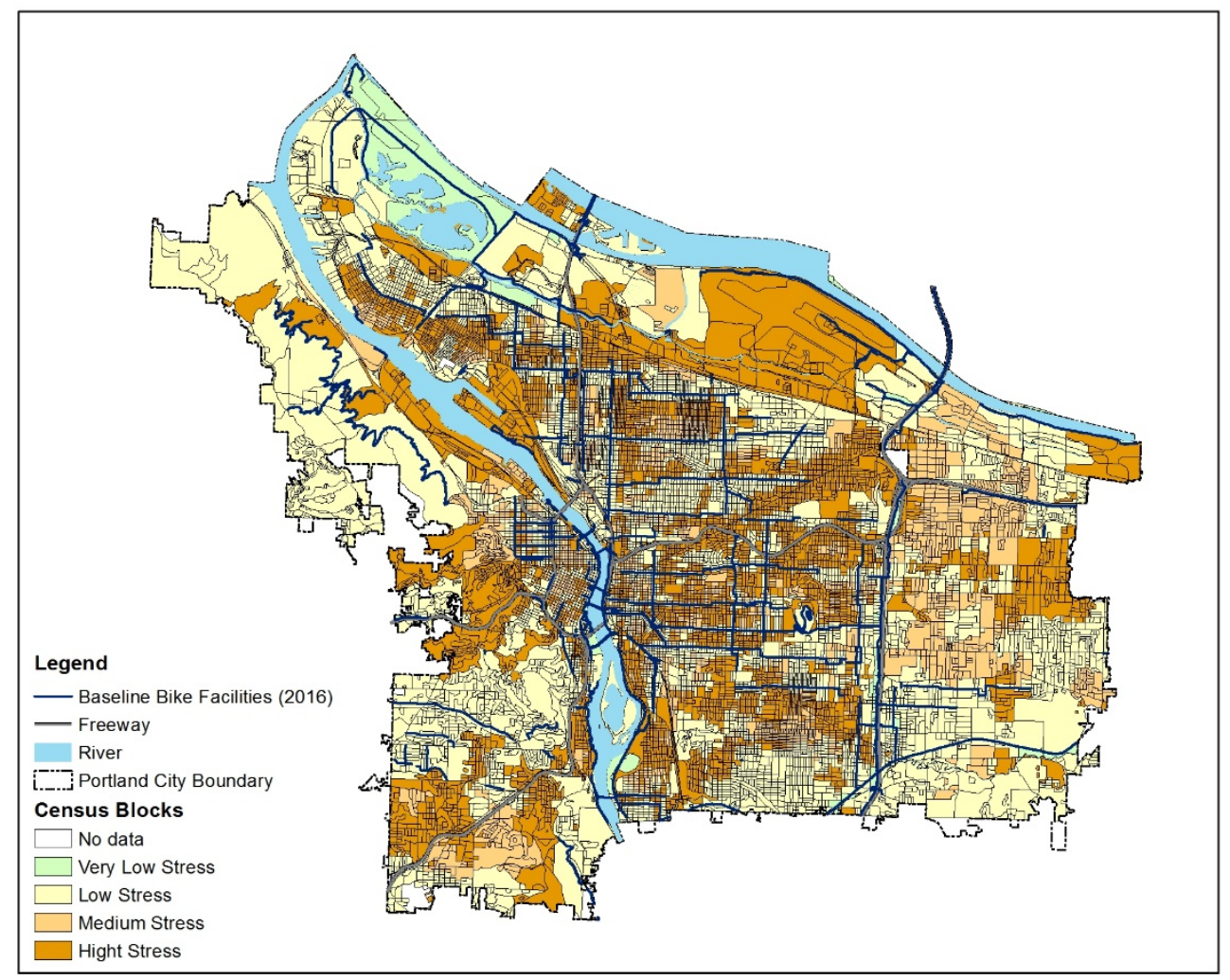

(b_1) Stress Level to Retail Destinations (2016)

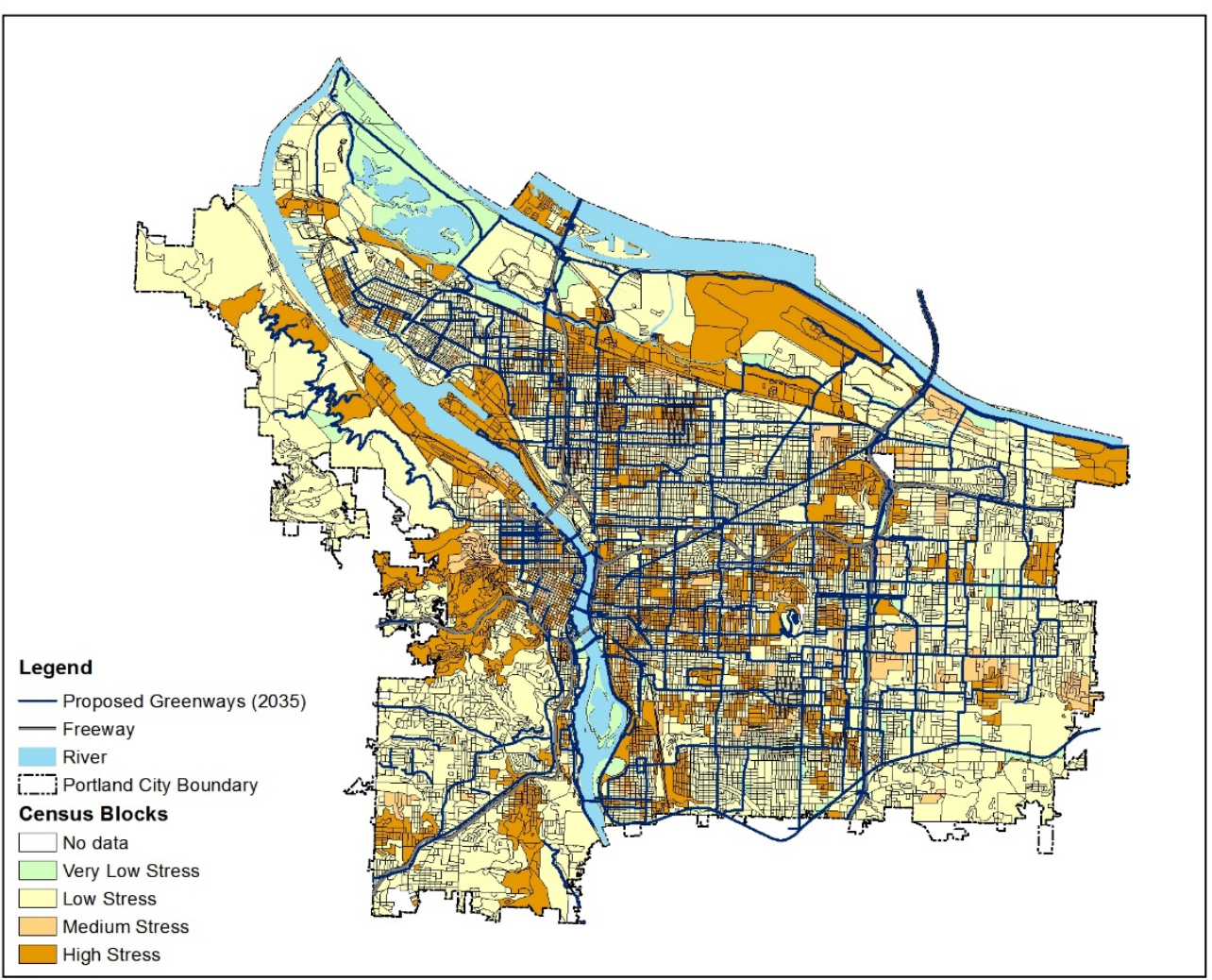

(b_2) Stress Level to Retail Destinations (2035) 


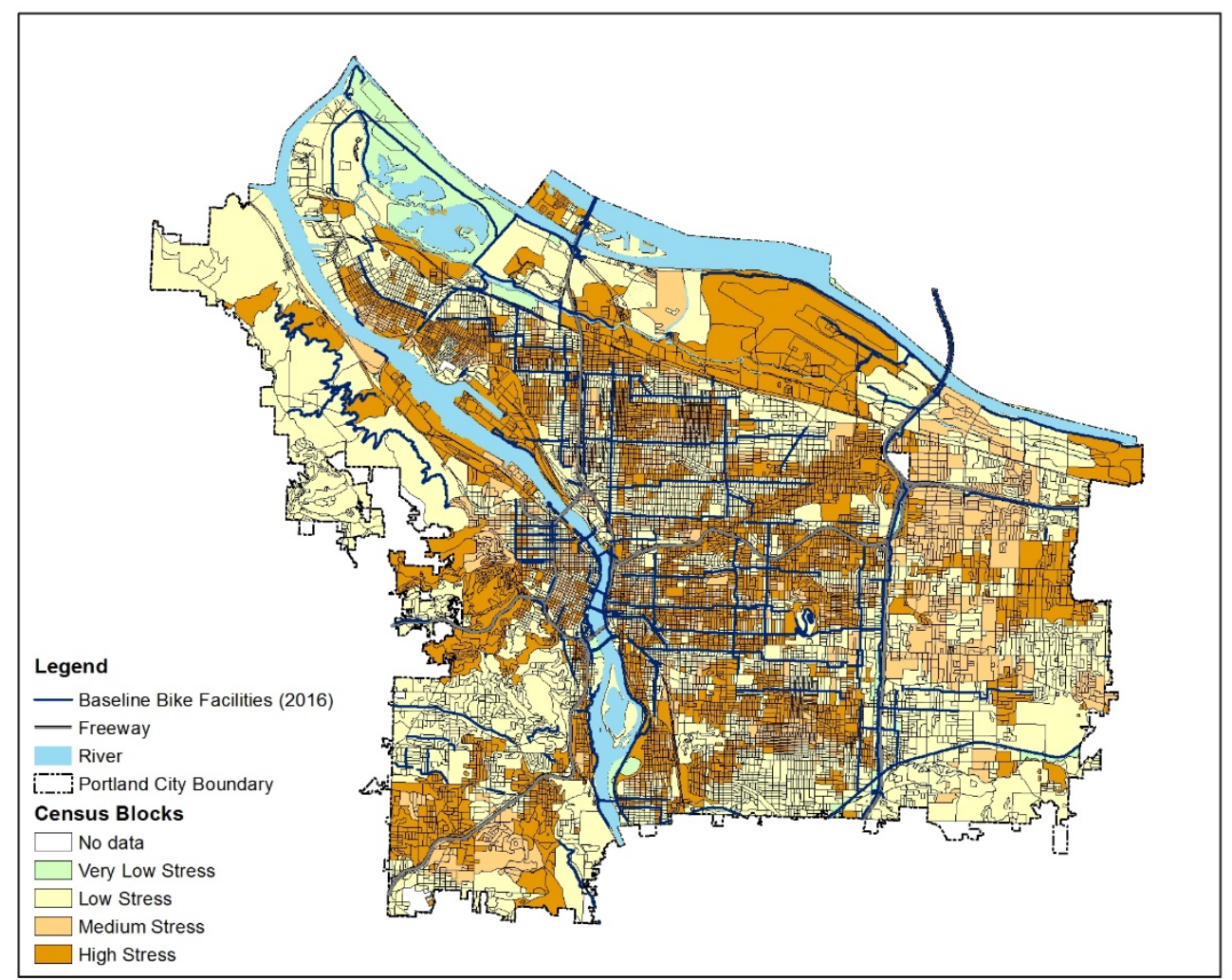

(c_1) Stress Level to Service Destinations (2016)

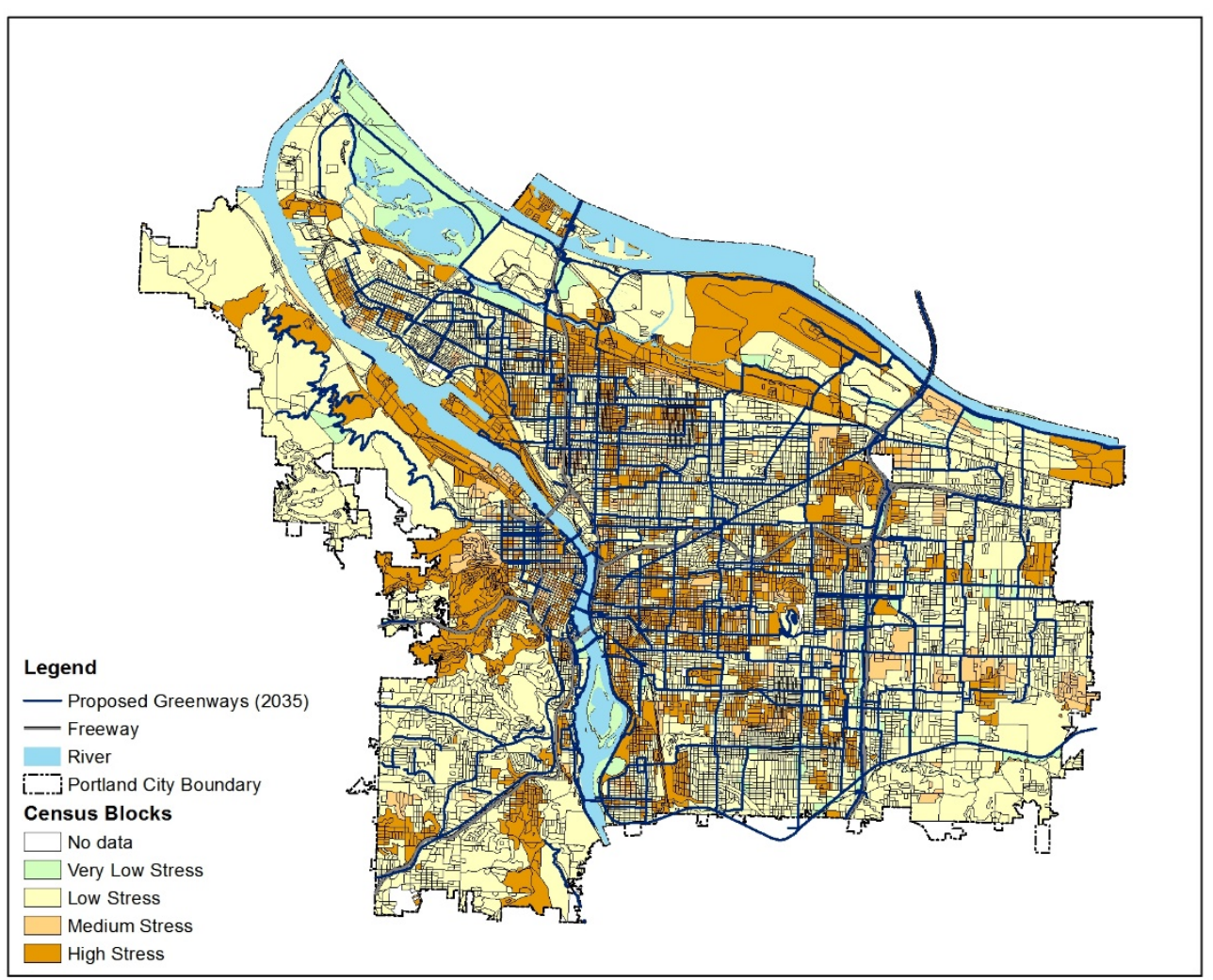

(c_2) Stress Level to Service Destinations (2035) 


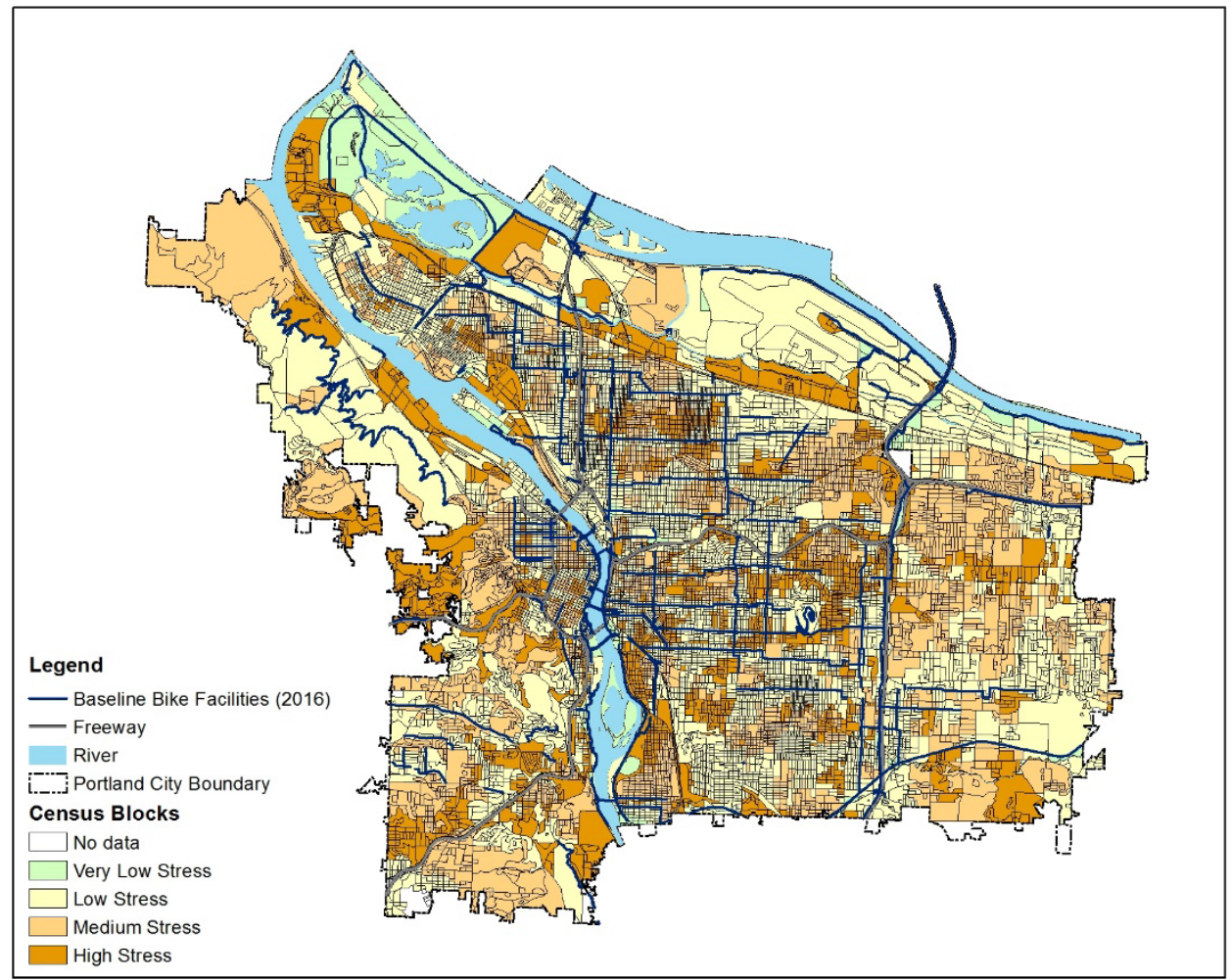

(d_1) Stress Level to Park/Recreation (2016)

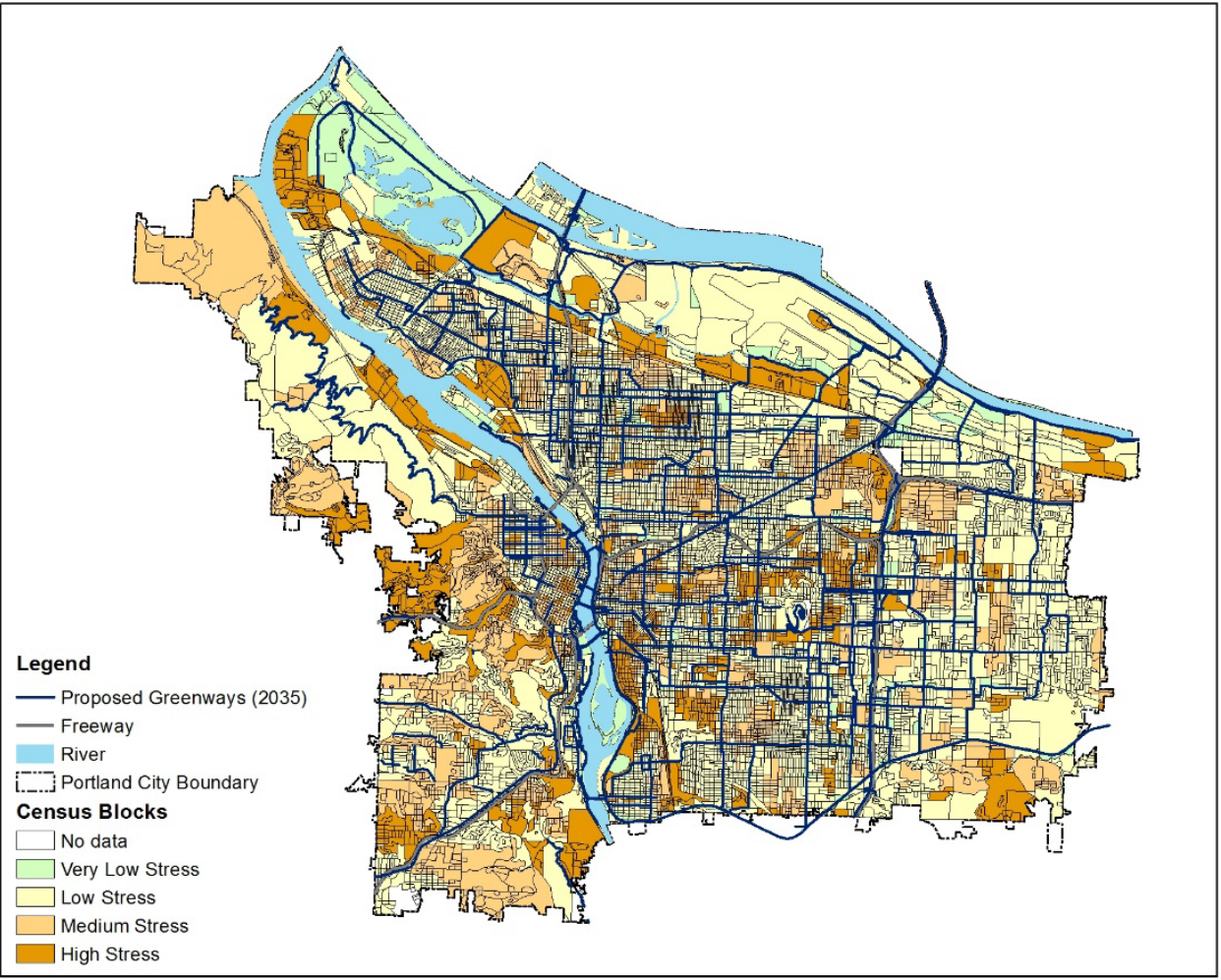

(d_2) Stress Level to Park/Recreation (2035)

Figure 13. Level of Route to Destinations Containing Low-Stress Segments Before and After Urban Greenway Improvements 


\subsubsection{Low-Stress Network BAM - Percentage of Important Destinations Reached through Low-Stress Network}

The last low-stress network BAM we constructed is a combination of the low-stress network proximity BAM and the low-stress network stress level of route BAM. This combination allows us to incorporate both the actual stress weighted distance of important destinations as well as whether cyclists are able to access important destinations of all types using the urban greenway network. It is calculated as the percentage of important destinations that can be reached through the low-stress urban greenway network within a 2.5-mile buffer radius.

Due to computational limitations, we selected four neighborhoods in different areas of Portland to illustrate the combined low-stress network BAM. This measure is calculated for the neighborhoods of South Burlington in Southwest Portland, Arbor Lodge in Northeast Portland, Cully and Montavilla in East Portland, to examine the percentage of important destinations that are accessible for residents within 2.5 miles of the low-stress urban greenway network. We found that there are large variations in bicycle accessibility between neighborhoods in different locations. Southwest neighborhoods, due to the hilly terrain, have smaller low-stress accessible zones and, therefore, they are able to access fewer destinations via bicycle than other areas in the city. This measure illustrates large improvements in bicycle accessibility for the Cully and Montavilla neighborhoods after the implementation of the 2035 City Greenways plan, indicating increases of over $15 \%$ in low-stress bicycle accessible destinations.

Table 10. Percentage of Important Destination Reached by 2.5-mile Low-Stress Network

\begin{tabular}{|l|c|c|c|c|c|c|c|c|}
\hline Neighborhood & \multicolumn{2}{|c|}{$\begin{array}{c}\text { Employment } \\
\text { Center }\end{array}$} & \multicolumn{2}{c|}{$\begin{array}{c}\text { Retail } \\
\text { Center }\end{array}$} & \multicolumn{2}{c|}{$\begin{array}{c}\text { Service } \\
\text { Center }\end{array}$} & \multicolumn{2}{c|}{$\begin{array}{c}\text { Parks \& } \\
\text { Recreation }\end{array}$} \\
\hline & $\mathbf{2 0 1 6}$ & $\mathbf{2 0 3 5}$ & $\mathbf{2 0 1 6}$ & $\mathbf{2 0 3 5}$ & $\mathbf{2 0 1 6}$ & $\mathbf{2 0 3 5}$ & $\mathbf{2 0 1 6}$ & $\mathbf{2 0 3 5}$ \\
\hline $\begin{array}{l}\text { South } \\
\text { Burlingame }\end{array}$ & 0.50 & 0.53 & 0.49 & 0.51 & 0.81 & 0.84 & 1.54 & 1.55 \\
\hline Arbor Lodge & 6.67 & 7.29 & 8.08 & 8.72 & 7.31 & 7.97 & 19.90 & 21.61 \\
\hline Cully & 4.30 & 4.93 & 5.54 & 6.19 & 5.15 & 5.85 & 5.10 & 5.45 \\
\hline Montavilla & 5.85 & 6.82 & 8.47 & 9.71 & 7.54 & 8.77 & 8.83 & 10.15 \\
\hline
\end{tabular}




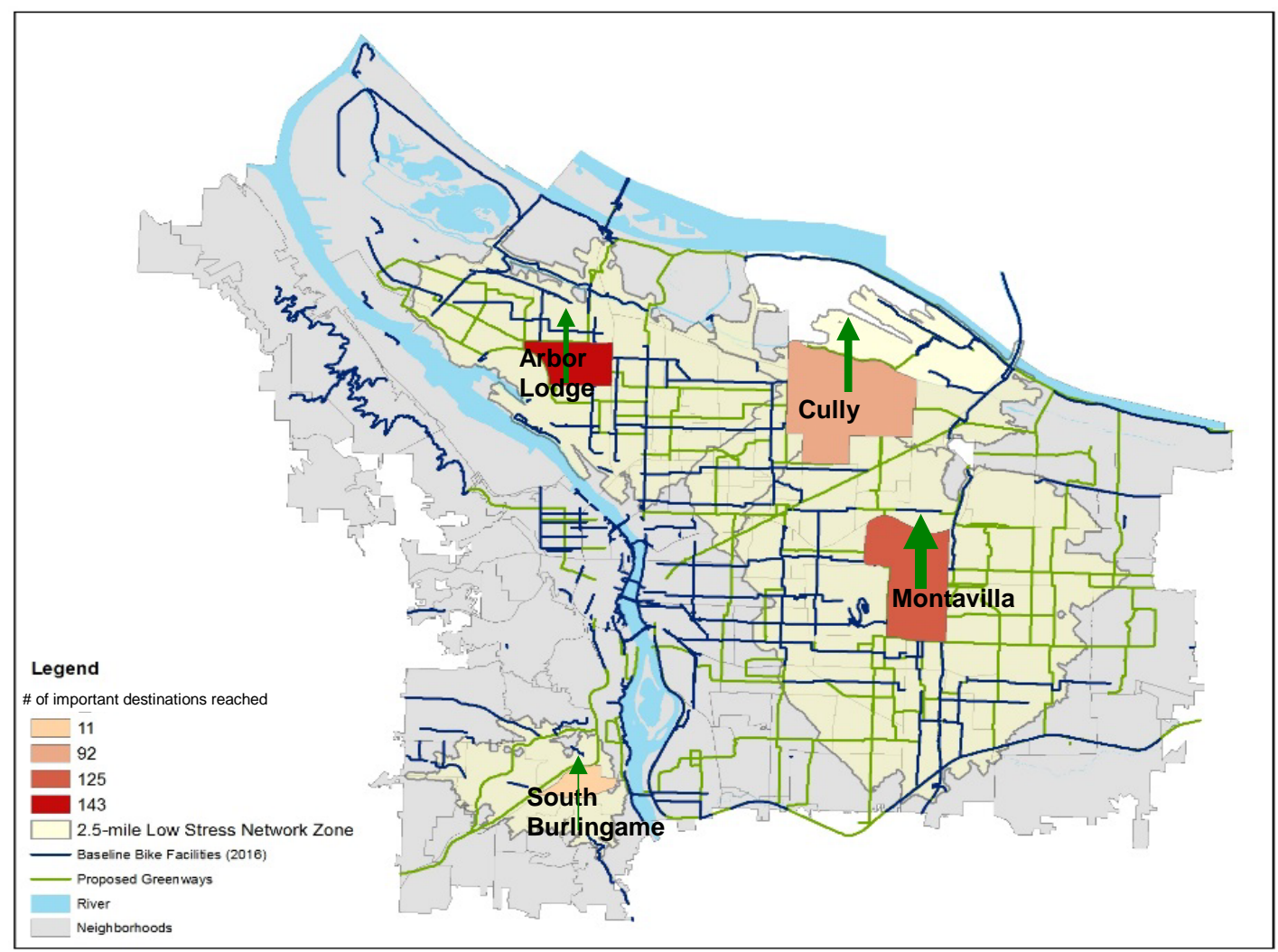

Figure 14. Number of Important Destinations Reached through 2.5-mile Low Stress Network 



\subsection{RESULT - ECONOMIC IMPACTS}

The research literature indicates reason to believe that transportation infrastructure and network improvements would bring about economic prosperity (Deng, 2013). In addition, we will identify which BAMs (bicycle accessibility measures) are more sensitive to scenario changes in the context of economic outcomes. This section presents the results from analyses aimed at identifying the linkages between the accessibility of the urban greenway network (BAM scores) and economic indicators (i.e., number of jobs and property values).

To compare the three different types of BAMs, and consistently estimate the impact of the urban greenway network on the economy, we convert the BAMs into directional indices (or scores). Higher index BAM scores indicate better urban greenway network accessibility. The distancebased BAM and low-stress network-based proximity BAM are converted using a negative exponential impedance function, a common transformation approach for distance-related factors.

$$
\text { BAM Score }=\exp (-B A M<\text { unit in mile }>) * 100
$$

The low-stress network-based stress level BAM is transformed to an index using the inverse of the BAM for each block.

$$
\text { BAM Score }=(1 / \text { BAM })^{*} 100
$$

Table 11. Standardized BAM Score Summary

\begin{tabular}{|c|c|c|c|c|c|}
\hline \multirow{2}{*}{ Indices } & \multicolumn{2}{c|}{$\mathbf{2 0 1 6}$ Scenario } & \multicolumn{2}{c|}{2035 Scenario } \\
\cline { 3 - 6 } & Mean & Median & Mean & Median \\
\hline Distance-based BAM (range 0-100) & 69.3 & 75.7 & 80.8 & 86.5 \\
\hline \multirow{3}{*}{$\begin{array}{c}\text { Low-stress network- } \\
\text { based BAM } \\
\text { proximity } \\
\text { (range 0-100) }\end{array}$} & Employment & 53.6 & 58.1 & 57.7 & 62.5 \\
\cline { 2 - 6 } & Retail & 58.8 & 64.9 & 59.3 & 65.5 \\
\cline { 2 - 6 } & Service & 59.3 & 65.6 & 59.3 & 66.2 \\
\hline \multirow{3}{*}{$\begin{array}{c}\text { Low-stress network- } \\
\text { based BAM } \\
\text { stress level }\end{array}$} & Park & 49.3 & 51.4 & 59.8 & 52.2 \\
\cline { 2 - 6 } & Employment & 99.2 & 100.0 & 101.6 & 101.5 \\
\cline { 2 - 6 } & Setail & 99.2 & 100.0 & 101.3 & 101.3 \\
\cline { 2 - 6 } & Park & 100.9 & 100.2 & 102.8 & 101.9 \\
\hline
\end{tabular}




\subsection{ECONOMIC IMPACTS - EMPLOYMENT}

The three sets of BAM scores are tested respectively against employment indicators at both the census block level and the census block group level. BAMs calculated in previous sections that are at the census block level are aggregated into census block group BAMs using the average BAMs, and then converted into census block group BAM indices for the correlation analysis below.

We find that there is no correlation between the distance-based BAM score with employment indicators at either the census block or the census block group levels. On the other hand, statistically significant positive correlations are found between all stress-based proximity BAMs and employment at the block level, indicating that a better active transport (or urban greenway) network is positively associated with better economic outcomes. Similarly, at the census block group level, the stress-based proximity BAM is positively associated with the number of jobs in each block group as well. Meanwhile, low-stress level-of-route BAM scores are slightly negatively correlated with employment at the block group level, although this result is not statistically significant. We posit that this negative correlation is possibly due to the way that high-stress routes are defined - the travel volume of each street segment is an important component of stress-level calculations, and thus the area with lower travel volume, or low-stress routes, also have lower levels of economic activities.

In general, better BAM scores are correlated with higher economic activities in terms of employment. The low-stress network-based proximity BAMs appear to be better indicators of economic outcomes than the distance-based BAM scores.

Table 12. Correlation Between BAM Score and Employment at Block Level

\begin{tabular}{|c|c|c|c|}
\hline \multicolumn{2}{|c|}{} & $\begin{array}{c}\text { Block Level } \\
\mathbf{( N = 7 7 6 7 )}\end{array}$ & $\begin{array}{c}\text { Block Group Level } \\
\mathbf{( N = 9 7 )}\end{array}$ \\
\hline \multicolumn{2}{|c|}{ Distance-based BAM Scores } & 0.005 & 0.062 \\
\hline \multirow{3}{*}{$\begin{array}{c}\text { Low-stress network } \\
\text { proximity BAM } \\
\text { scores }\end{array}$} & Employment & $0.057^{* * *}$ & $0.186^{* * *}$ \\
\cline { 2 - 4 } & Retail & $0.033^{* * *}$ & $0.111^{* *}$ \\
\cline { 2 - 4 } & Service & $0.063^{* * *}$ & $0.120^{* *}$ \\
\hline \multirow{3}{*}{$\begin{array}{c}\text { Low-stress network } \\
\text { stress level of route } \\
\text { BAM scores }\end{array}$} & Park & $0.033^{* * *}$ & $0.098^{*}$ \\
\cline { 2 - 4 } & Retail & 0.001 & 0.015 \\
\cline { 2 - 4 } & Service & -0.001 & 0.022 \\
\hline
\end{tabular}

Note: Significance sign *** at 0.01 level, $* *$ at 0.05 level, * at 0.1 level. 


\subsection{ECONOMIC IMPACTS - PROPERTY VALUE}

In addition to examining the relationship between our BAM indices and employment indicators, we also explored the relationship between the urban greenway network accessibility and property values, as an additional proxy for economic outcomes. We followed the conventional hedonic price analysis to investigate the effect of BAM scores on property values, controlling for other factors that might impact property value such as property attributes, neighborhood characteristics, etc.

Descriptive statistics of the variables are shown in Table 13, including transaction characteristics, property characteristics and regional characteristics as well as standardized BAM scores.

Property sale outliers, where the sale price is more than two standard deviations away from the average of SFH and MFH, respectively, are excluded from the study because these outliers mostly represent luxury properties at the extremely high end of the market or non "arm's length" transactions. In 2016, a total of 12,861 residential properties were transacted in Portland, at an average price of $\$ 369,555$. Single-family homes (SFH) tend to be larger, older and are sold at higher prices and have lower property tax liabilities (AV/RMV ratios) when compared to multifamily homes (MFH). Multifamily homes sold tend to be located in the central part of the city, with better access to city-center amenities, but with higher crime rates. In large part due to the concentration of multifamily homes in central locations with higher density, multifamily homes tend to also have higher BAM scores, both in distance-based and low-stress networkbased estimations.

The regression models use property sale price as the dependent variable. BAM scores, along with other property, neighborhood and sale characteristics, are specified as determinants of property sale prices to control for conventional factors that influence property values. A pooled OLS hedonic price regression was first conducted on all residential property sales. However, the Chow test $(\mathrm{F}=83.2, \mathrm{p}<0.01)$ indicated the existence of structural change between the determinants of single- and multifamily home values and supported separate SFH and MFH property-type restricted models. R-squared values range from 0.47 to 0.63 for these estimated models, indicating that the specifications describe approximately between $47 \%$ and $63 \%$ of the property sale price variation.

Table 14 and Table 15 show the regression results. As expected, residential property values are positively and statistically significantly impacted by size, proximity to CBD and better school districts. Age contributes positively to property values in single-family homes, but shows negative impacts on multifamily homes, potentially due to the inherent value of historical building structures and also because older homes may be associated with larger lot sizes. The estimated coefficient for the AV/RMV ratio is statistically significant and negative, indicating that consumers are willing to pay higher prices for properties that have relatively lower property tax liabilities (as a percentage of the real market value). Higher crime rates are negatively associated with property values, indicating a clear preference for neighborhood safety. Homes sold between June and September (considered to be the non-rainy season in Portland) tend to garner a price premium compared to those sold during the rainy season. 
Single-family homebuyers prefer better distance-based but worse stress-based proximity BAM, although most of the coefficients are not significant. They show a preference for better stressbased BAM to employment, retail and service centers, but not for parks. Each distance-based and stress-based proximity (to employment) BAM score point increase would lead to a \$53 increase and $\$ 32$ decrease in property value, respectively, and each stress level (to employment) standardized BAM scores point increase is associated with a \$378 premium in property value. Although three different BAMs are transformed to standardized 0-100 score, due to the difference in measure calculation inherently between distance/proximity and stress level BAM, the changes in property value might not be comparable in terms of relating the change of urban greenway network characteristics. They only indicate the direction of impact of urban greenway network accessibility on property values. For multifamily homebuyers, the impact of BAM scores on property values appears to be greater than for single-family homebuyers. The multifamily homebuyers prefer better distance-based and stress-based BAMs. Each additional point of distance-based, stress-based proximity (to employment), and stress-level standardized BAM index increase would lead to \$1,039, \$2,076 and \$777 increases, respectively, in property values. In general, this analysis indicates that better bicycle accessibility does not contribute positively to home values for single-family homebuyers, but appears to contribute positive and significant value for multifamily homebuyers. Low-stress proximity measures tend to have greater impact than purely network distance-based measure, indicating the sensitivity of lowstress BAMs.

Table 13. Descriptive Statistics of Property Sale Variables

\begin{tabular}{l|c|c|c}
\hline \multicolumn{1}{c|}{ Variables } & $\begin{array}{c}\text { Overall } \\
\text { Average } \\
(\mathbf{n = 1 2 , 8 6 1 )}\end{array}$ & $\begin{array}{c}\text { Single-Family } \\
\text { Home (SFH) } \\
\text { (n=11,257) }\end{array}$ & $\begin{array}{c}\text { Multifamily } \\
\text { Home (MFH) } \\
\text { (n=1,604) }\end{array}$ \\
\hline Transaction characteristics & $\$ 369,555$ & $\$ 398,364$ & $\$ 359,984$ \\
\hline Sale price & $37.0 \%$ & $36.8 \%$ & $39.8 \%$ \\
\hline $\begin{array}{l}\text { Seasonality (percentage of } \\
\text { transactions between June to } \\
\text { September) }\end{array}$ & & \\
\hline Property characteristics & 60.69 & 64.73 & 33.47 \\
\hline Age of property (years) & 1,538 & 1,656 & 1,095 \\
\hline $\begin{array}{l}\text { Size of property (sq ft) } \\
\text { AV/RMV ratio }\end{array}$ & 48.48 & 47.57 & 56.03 \\
\hline Regional characteristics & 68.10 & 67.27 & 77.66 \\
\hline School quality (out of 100) & 4.67 & 4.80 & 3.37 \\
\hline Distance to CBD (mi) & 86.51 & 77.75 & 147.1 \\
\hline Crime rate per 1000 residents & 64.78 & 63.66 & 71.96 \\
\hline 2016 BAM Scores (standardized, range 0-100) & \\
\hline Distance-based &
\end{tabular}




\begin{tabular}{l|c|c|c}
\hline $\begin{array}{l}\text { Low-stress based proximity- } \\
\text { employment }\end{array}$ & 47.39 & 45.55 & 60.26 \\
\hline $\begin{array}{l}\text { Low-stress based proximity- } \\
\text { retail }\end{array}$ & 55.39 & 54.06 & 64.75 \\
\hline $\begin{array}{l}\text { Low-stress based proximity- } \\
\text { service }\end{array}$ & 55.28 & 54.13 & 63.36 \\
\hline $\begin{array}{l}\text { Low-stress based proximity- } \\
\text { park }\end{array}$ & 48.24 & 47.22 & 55.44 \\
\hline $\begin{array}{l}\text { Low-stress based stress level- } \\
\text { employment }\end{array}$ & 79.07 & 79.03 & 79.34 \\
\hline $\begin{array}{l}\text { Low-stress based stress level- } \\
\text { retail }\end{array}$ & 75.92 & 75.88 & 76.18 \\
\hline $\begin{array}{l}\text { Low-stress based stress level- } \\
\text { service }\end{array}$ & 76.21 & 76.13 & 73.77 \\
\hline $\begin{array}{l}\text { Low-stress based stress level- } \\
\text { park }\end{array}$ & 73.12 & 73.02 & \\
\hline
\end{tabular}

Note: Values in parentheses represent the minimum and maximum values of each variable. 
Table 14. Regression Models of Single-family Homes Sale Prices

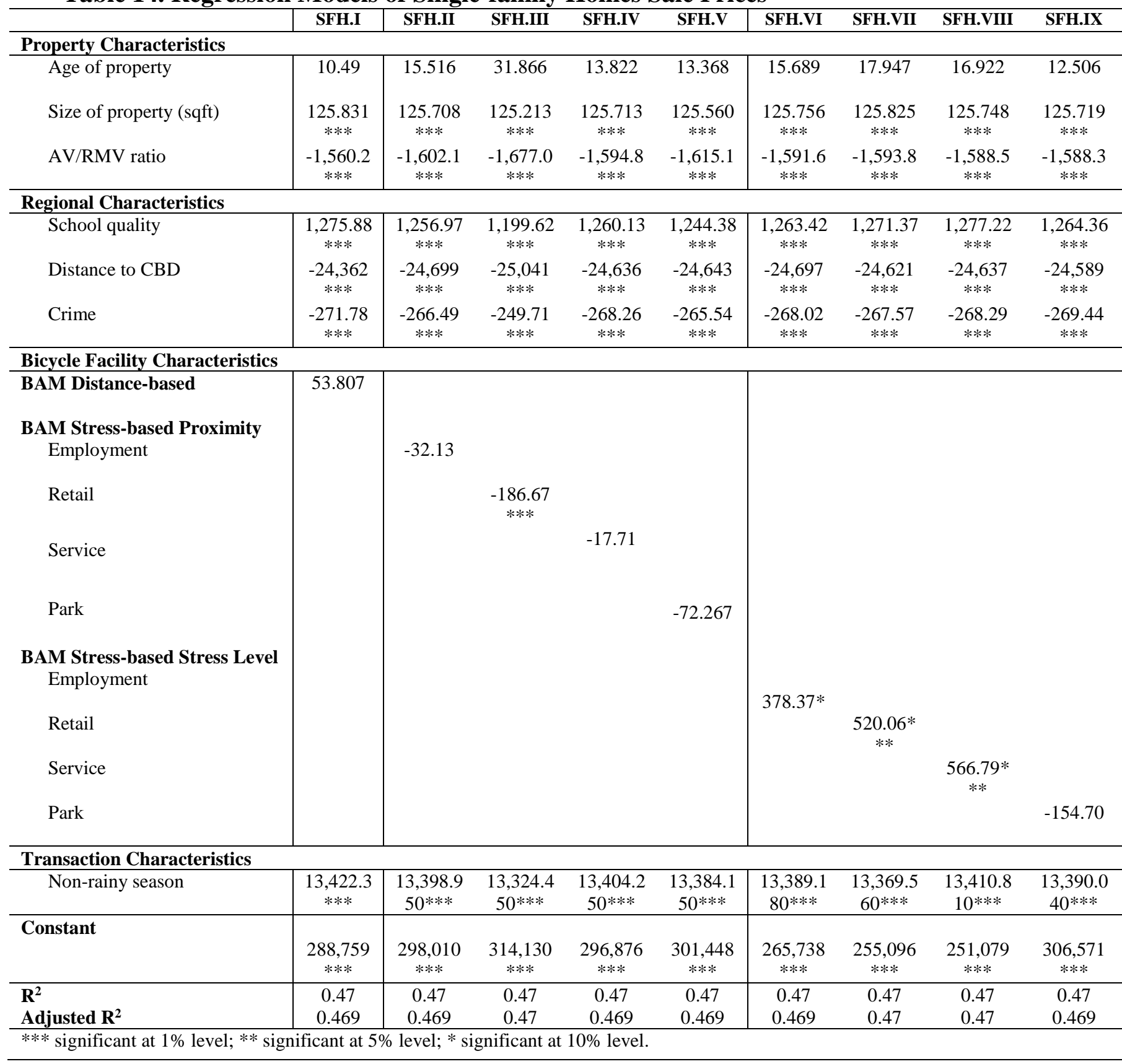


Table 15. Regression Models of Multifamily Homes Sale Prices

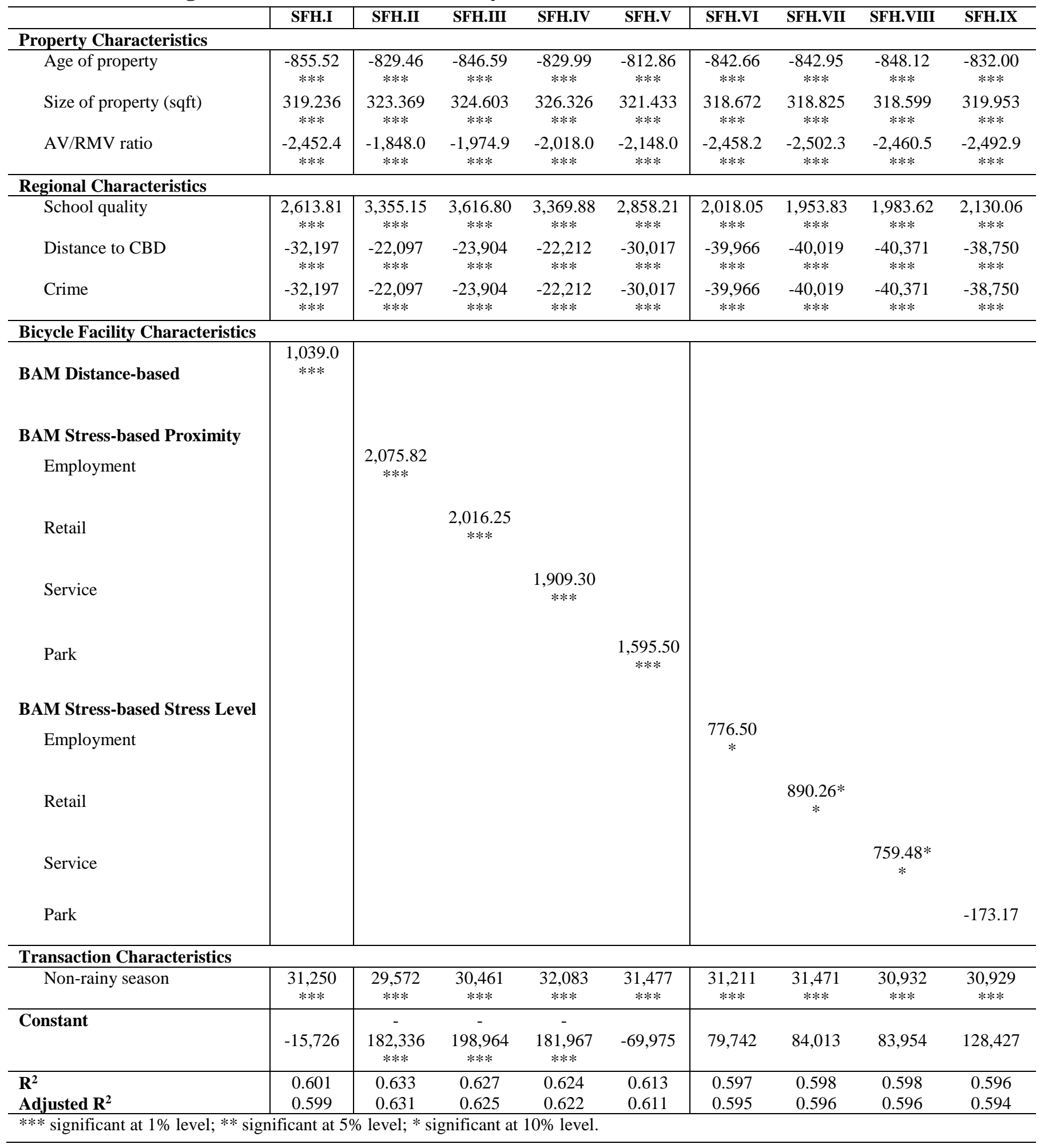





\subsection{RESULTS - EQUITY IMPACTS}

\subsection{CORRELATION ANALYSIS}

To better understand which communities or what populations experience urban greenways benefits as the city invests in additional bicycle infrastructure, correlation analyses between three types of BAM scores and five EJ indicators were conducted (Table 16 and Table 17). The correlation between 2016 and 2035 urban greenways scenarios and indicators are presented in the first two columns. Note that a negative correlation indicates that higher EJ indicator numbers (higher numbers of marginalized populations) is correlated with lower BAM scores (or lower bicycle network accessibility), whereas a positive correlation indicates that a higher number of marginalized populations is correlated with better bicycle accessibility. The third column summarizes positive or negative changes for each EJ group after the proposed 2035 City Greenways improvements, where positive green arrows indicate improvements in the equitable distribution of bicycle accessibility ${ }^{7}$. It is calculated by correlation between BAM score growth rate [(BAM in 2035-BAM in 2016)/BAM in 2016] and each EJ indicators. The positive green arrows indicate a higher percentage of disadvantage population association with more BAM score increase, and vice versa.

When we consider the distance-based BAM, it appears that the distribution of the existing bicycle network in Portland does not particularly vary across different income groups, but favors fewer proficient English speakers, older adults and young persons, and slightly favor less people of color. However, when taking into account the low-stress network and ability to reach important destinations using the low-stress network BAM scores, we can observe a different pattern: The existing bicycle network does provide accessibility for the low-income population, but does not vary much across different racial groups. We observe a different change pattern between 2016 and 2035 greenway scenarios: The distance-based BAM increases significantly for four out of the five EJ indicators. On the other hand, the low-stress network BAM scores do not change significantly across the five EJ indicators, indicating attenuated equity improvements of bicycle accessibility.

\footnotetext{
${ }^{7}$ This is calculated by examining the correlation between the BAM score growth rate [(BAM $\mathrm{B}_{2035}-$ $\mathrm{BAM}_{2016} / \mathrm{BAM}_{2016}$ and each of the EJ indicators
} 
Table 16. Correlation Analysis of Distance-based BAM Score and Block Group Environmental Justice Indicators ( $\mathrm{n}=447)$

\begin{tabular}{|l|c|c|c|}
\hline & $\begin{array}{c}2016 \text { Baseline } \\
\text { Scenario }\end{array}$ & $\begin{array}{c}\text { 2035 City } \\
\text { Greenways } \\
\text { Scenario }\end{array}$ & $\begin{array}{c}\text { Equity } \\
\text { Impacts }\end{array}$ \\
\hline People of color & $-0.084(*)$ & 0.050 & 个 \\
\hline Low-income & 0.010 & $0.200(* * *)$ & 个 \\
\hline LEP & $-0.287(* * *)$ & -0.024 & 个 \\
\hline Older adults & $-0.169(* * *)$ & $-0.235(* * *)$ & \\
\hline Young persons & $-0.240(* * *)$ & $-0.168(* *)$ & 个 \\
\hline
\end{tabular}

Notes: Statistically significant at 0.01 level $(* * *)$, at 0.05 level $(* *)$, and at 0.1 level $(*) ; \uparrow$ and (1) means change between two scenarios statistically significant increase or decrease at 0.1 level

Table 17. Correlation Analysis of Low-stress Network BAM Score and Block Group Environmental Justice Indicators $(n=447)$

\begin{tabular}{|c|c|c|c|c|c|c|}
\hline & \multicolumn{3}{|c|}{ Proximity } & \multicolumn{3}{|c|}{ Stress Level } \\
\hline & $\begin{array}{c}2016 \\
\text { Baseline } \\
\text { Scenario }\end{array}$ & $\begin{array}{l}2035 \text { City } \\
\text { Greenways } \\
\text { Scenario }\end{array}$ & $\begin{array}{l}\text { Equity } \\
\text { Impacts }\end{array}$ & $\begin{array}{c}2016 \\
\text { Baseline } \\
\text { Scenario }\end{array}$ & $\begin{array}{c}2035 \text { City } \\
\text { Greenways } \\
\text { Scenario }\end{array}$ & $\begin{array}{l}\text { Equity } \\
\text { Impacts }\end{array}$ \\
\hline People of color & -0.004 & -0.001 & & $0.089(*)$ & $0.111(* *)$ & \\
\hline Low-income & $0.189(* * *)$ & $0.195(* * *)$ & (1) & 0.001 & -0.006 & \\
\hline LEP & $-0.201(* * *)$ & $-0.197(* * *)$ & & $0.146(* * *)$ & $0.237(* * *)$ & 个 \\
\hline Older adults & $-0.274(* * *)$ & $-0.272(* * *)$ & & 0.083 & 0.042 & \\
\hline Young persons & $-0.371(* * *)$ & $-0.375(* * *)$ & $\uparrow$ & $0.165(* * *)$ & $0.199(* * *)$ & \\
\hline
\end{tabular}

Notes: Statistically significant at 0.01 level $(* * *)$, at 0.05 level $(* *)$, and at 0.1 level $(*) ; \uparrow$ and $(1)$ means change between two scenarios statistically significant increase or decrease at 0.1 level 


\subsection{QUINTILE ANALYSIS}

Figures 15-17 show results from quintile analyses of census block groups, providing a closer examination of how improvements in bicycle infrastructure, as measured by the distance- and low-stress-based BAMs, benefit different demographic groups. Block groups across all EJ indicator quintiles experience large improvements in distance-based BAM score (more proximity to bicycle facilities) in Figure 14, while Figure 15 shows slightly tempered improvements in lowstress network-based proximity BAM as measured by access opportunities by low-stress network. The red line on each figure indicates the percentage change in accessibility across block groups. When the red line skews higher in the higher quintiles, it indicates that the 2035 City Greenways scenario accessibility improvements disproportionately favors the communities with the highest percentages of historically marginalized populations; when the line appears flat, it indicates an even level of accessibility improvements across communities.

While building the city greenways improves the distance-based BAM for the higher quintiles of low-income block groups, these improvements appear more evenly distributed for low-stressbased proximity BAM across all low-income communities except for the top quintile. Communities with more older adults have poor access to the bicycle network in both the baseline and future bicycle scenarios, as measured by both types of BAMs. This may be because older households in Portland tend to be concentrated in neighborhoods with larger homes, where transportation accessibility is lower. Because communities with more children are highly correlated with communities with people of color and limited English, these regions share similar bicycle accessibility characteristics. Immigrant neighborhoods that have high levels of language isolation currently have the worst bicycle accessibility across both accessibility measures even when compared with other disadvantaged communities, particularly those in the top quintile neighborhoods. Fortunately, both BAMs improve significantly for these top quintile LEP neighborhoods with investments into city greenways infrastructure and contribute to equity across quintiles as well. 

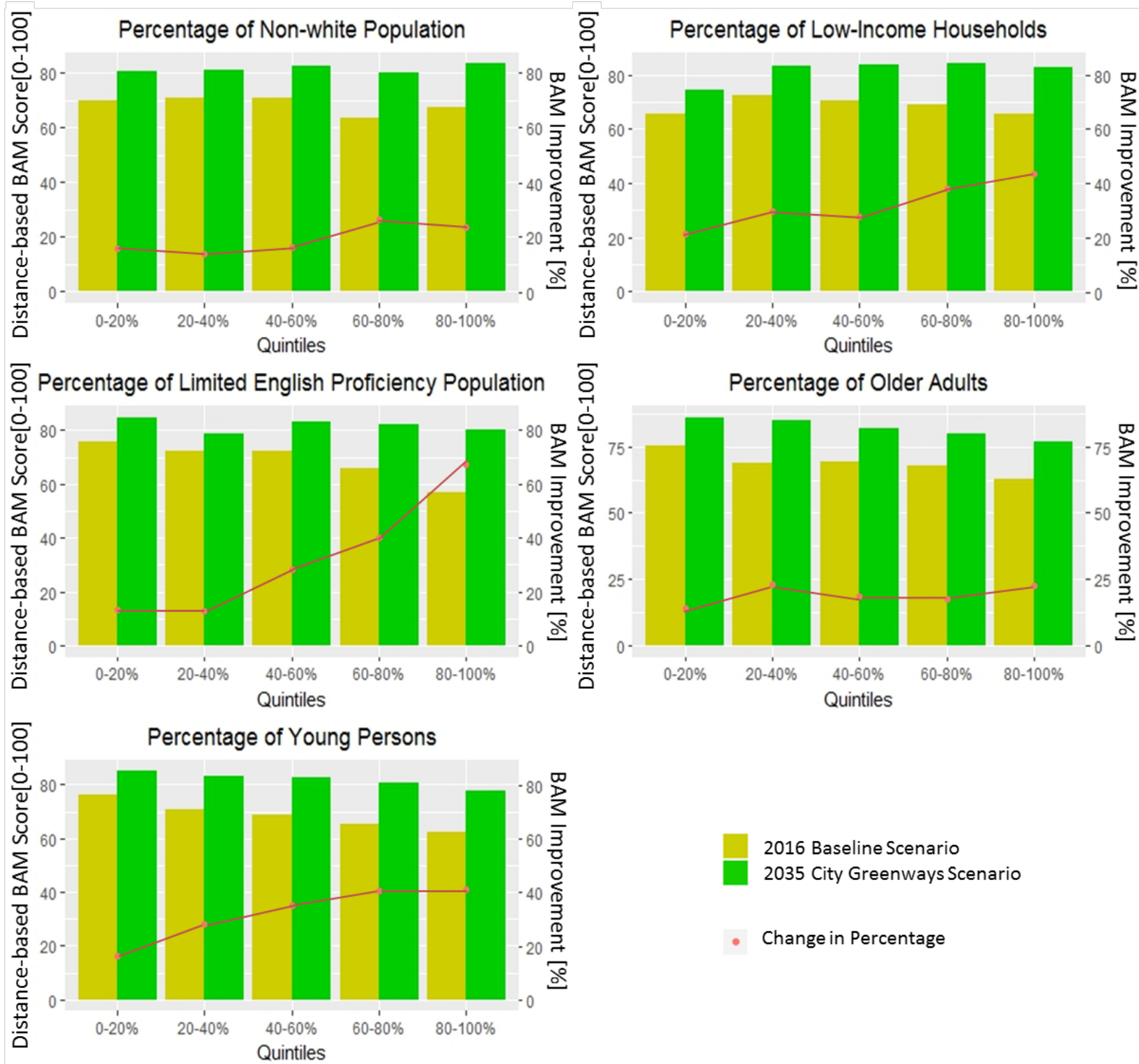

2016 Baseline Scenario

2035 City Greenways Scenario

- Change in Percentage

Figure 15. Distance-Based BAM Score across Environmental Justice Indicator Quintiles (by census block groups) 


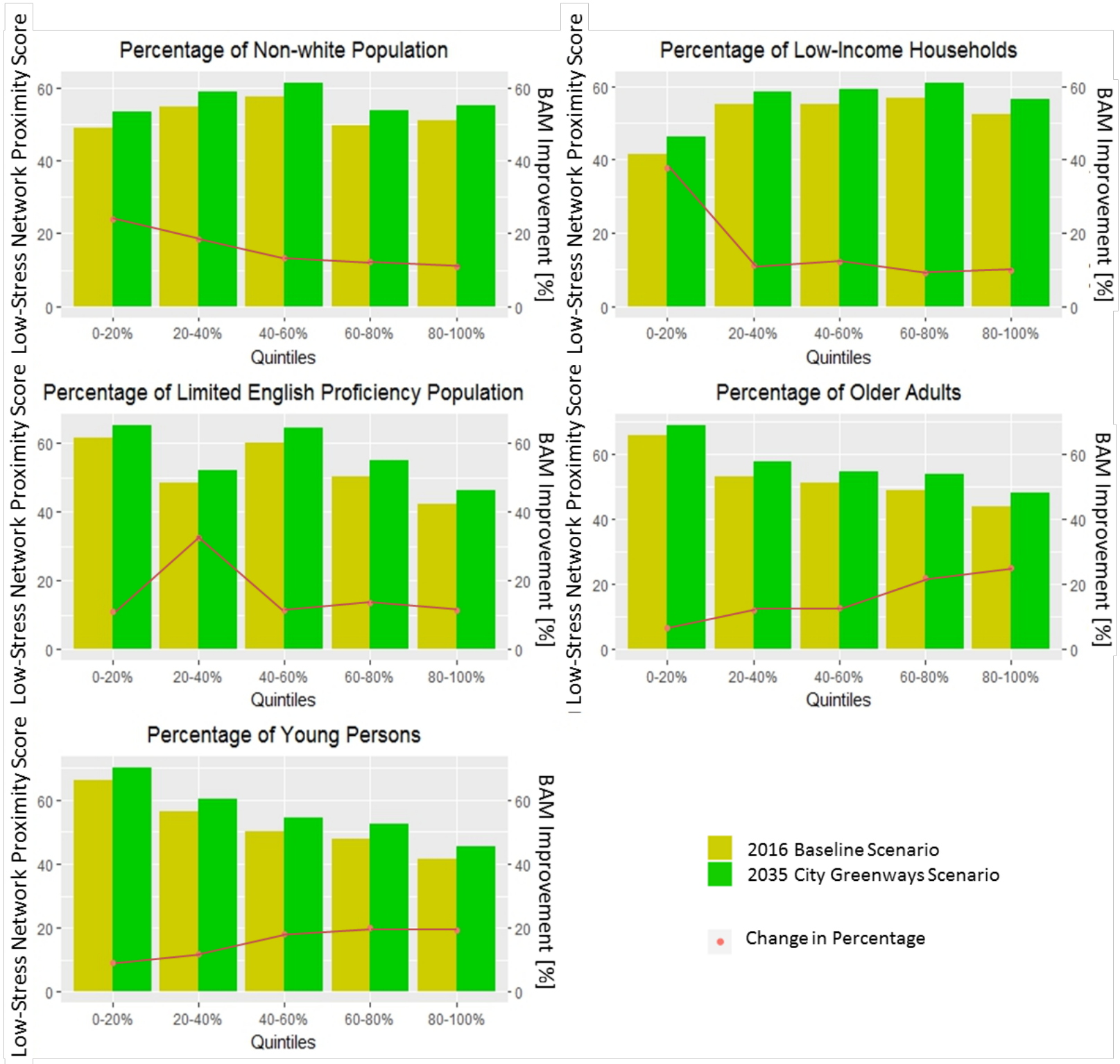

Figure 16. Low-Stress Network Proximity BAM Score across Environmental Justice Indicator Quintiles (by census block groups) 

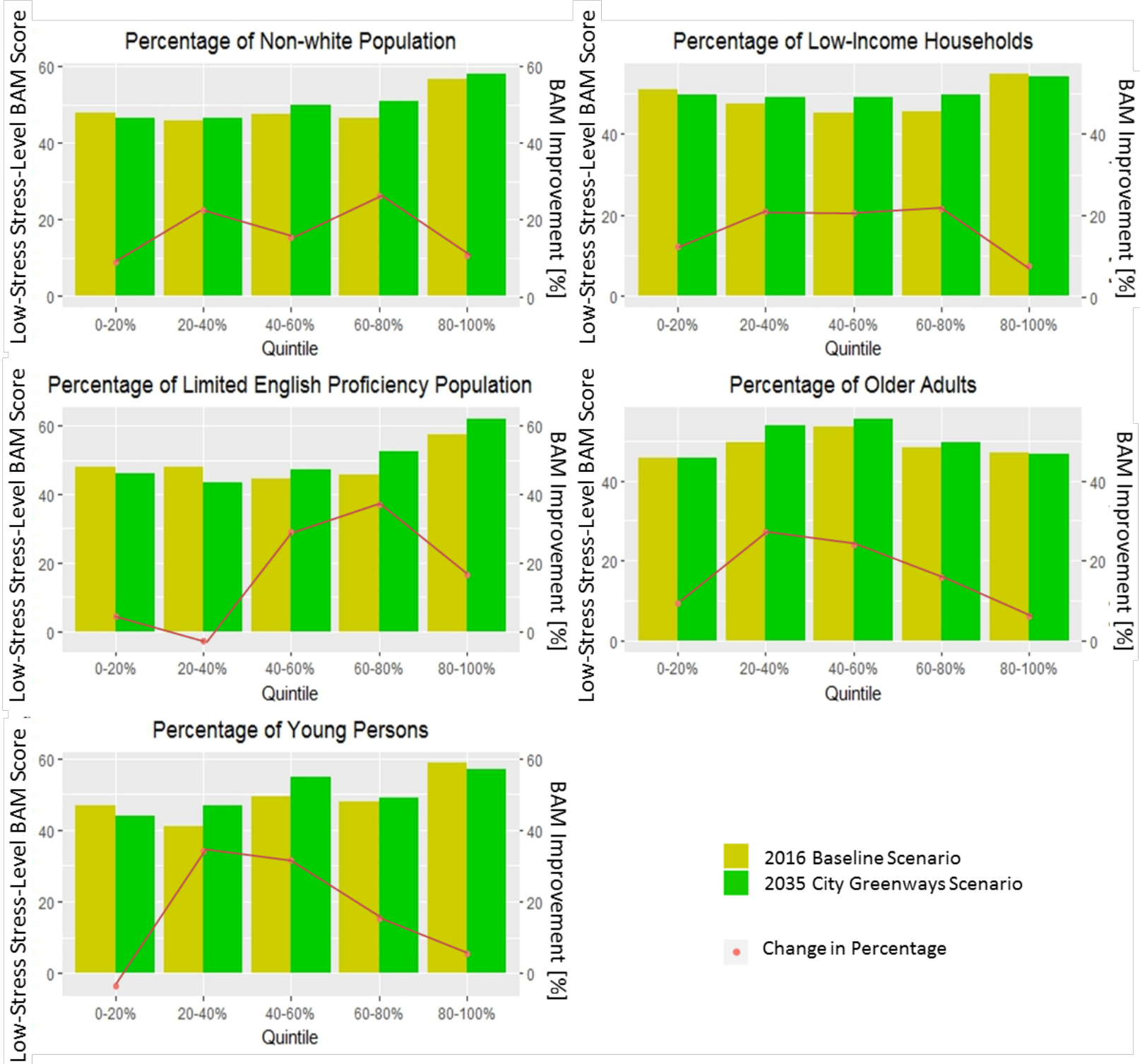

2016 Baseline Scenario

2035 City Greenways Scenario

- Change in Percentage

Figure 17. Low-Stress Network Stress Level BAM Score across Environmental Justice Indicator Quintiles (by census block groups)

\subsection{HISTORICALLY MARGINALIZED COMMUNITIES}

Next, we further investigated the changes in BAM scores for the most transportation disadvantaged communities in both the current 2016 baseline and the 2035 City Greenways scenarios. First, block groups (BGs) that fulfill any of the EJ indicator criteria for historically marginalized communities as defined by Metro (2017) are separately identified in 
Table 18. Tier I and II communities encompass all BGs that fit at least one criteria, as defined in Section 3.3. Then we compare BAMs of these most disadvantaged block groups with other nondesignated block groups, using a statistical t-test (a statistical test to assess whether the means between groups are statistically different from each other) to examine whether these EJ indicator communities experience significant transportation disadvantages. For example, in the first half row of Table 16, Portland has 173 block groups belonging to Tier I people of color, historically marginalized communities, and the distance-based BAM score in 2016 is significantly less than the rest 274 (=447-173) block groups (labeled as “_” sign), which are not people of color but are historically marginalized communities. However, after urban greenway improvement in 2035, the distance-based BAM score between those two groups are not statistically different. In addition, the change of each EJ disadvantaged block groups before and after urban greenway improvement were tested. For Tier I (people of color, historically marginalized communities), the distance-based BAM score has significantly increased (labeled as “^” sign) after urban greenways were installed.

Using the distance-based BAM (shown in the top part of Table 18), we can conclude that almost all disadvantaged communities identified using the broader Tier I criteria currently experience statistically significant worse bicycle access in Portland. The proposed city greenways significantly improve bicycle accessibility (as measured by proximity) to people of color, lowincome and limited English proficiency groups. Older adults tend to have worse bicycle accessibility in both scenarios, possibly due to their preference for less dense locations with lower general transportation. When the focus is on high population-density, historically marginalized communities (Tier II), people of color and low-income populations experience more bicycle accessibility improvement with city greenways when compared to other communities.

Using the low-stress-based BAM that takes route stress and accessibility to destinations into account, accessibility improvements from the proposed city greenways within disadvantaged communities are not as significant. As for proximity score, Tier II low-income block groups, mostly concentrated in downtown locations with better transportation accessibility in general, are the only communities that experience better bicycle accessibility than their higher-income counterparts. All other disadvantaged groups suffer from lower bicycle accessibility compared to the rest of the city, both under the existing bicycle infrastructure and the proposed city greenways. Low-stress-based BAM is an indicator reflecting bicycle route comfortableness. It includes route facilities-level and traffic-volume conditions. In general, all disadvantaged communities have improved stress levels after urban greenways. For Tier I, LEP and youngperson concentrated block groups experienced less stress level; however, other disadvantaged communities have similar stress levels compared to their counterparts.

Compared with distance-based BAM score, there are less increases after urban greenway installation among disadvantaged block groups, especially for Tier II (focused historically marginalized communities). These results are indicative that although bicycle infrastructure may appear to be built evenly across the city, the destinations or services that communities are able to access may still be unevenly distributed. Furthermore, the findings from these various analysis methods further underscore the importance of integrating land use factors (destinations) into 
transportation accessibility measures, particularly in the context of equal access to opportunities for all groups.

Table 18. BAM Changes by Environmental Justice Indicators

\begin{tabular}{|c|c|c|c|c|c|c|c|c|}
\hline & \multicolumn{4}{|c|}{$\begin{array}{c}\text { Tier I - } \\
\text { Historically Marginalized } \\
\text { Communities }\end{array}$} & \multicolumn{4}{|c|}{$\begin{array}{c}\text { Tier II - } \\
\text { Focused Historically } \\
\text { Marginalized Communities }\end{array}$} \\
\hline & $\begin{array}{l}\# \text { of } \\
\text { BGs }\end{array}$ & 2016 & 2035 & Change & $\begin{array}{l}\text { \# of } \\
\text { BGs }\end{array}$ & 2016 & 2035 & Change \\
\hline \multicolumn{9}{|c|}{ Distance-based BAM Score } \\
\hline $\begin{array}{l}\text { People of } \\
\text { color }\end{array}$ & 173 & - & & 1 & 77 & & + & 1 \\
\hline Low-income & 192 & . & + & A & 95 & & + & A \\
\hline LEP & 137 & - & & 1 & 48 & - & & 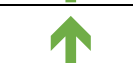 \\
\hline Older adults & 182 & - & - & A & & & & \\
\hline $\begin{array}{l}\text { Young } \\
\text { persons }\end{array}$ & 200 & - & - & A & & & & \\
\hline Overall & 388 & - & - & 1 & 114 & & + & 1 \\
\hline \multicolumn{9}{|c|}{ Low-stress-based Proximity BAM Score } \\
\hline $\begin{array}{l}\text { People of } \\
\text { color }\end{array}$ & 173 & & & & 77 & + & + & \\
\hline Low-income & 192 & + & + & 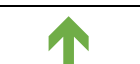 & 95 & + & + & \\
\hline LEP & 137 & - & - & A & 48 & - & - & \\
\hline Older adults & 182 & - & - & & & & & \\
\hline $\begin{array}{l}\text { Young } \\
\text { persons }\end{array}$ & 200 & - & - & & & & & \\
\hline Overall & 388 & - & - & A & 114 & + & + & \\
\hline \multicolumn{9}{|c|}{ Low-stress-based Stress Level BAM Score } \\
\hline $\begin{array}{l}\text { People of } \\
\text { color }\end{array}$ & 173 & & + & 1 & 77 & & & 1 \\
\hline Low-income & 192 & & & A & 95 & & & A \\
\hline LEP & 137 & + & + & 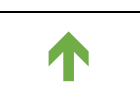 & 48 & & & A \\
\hline Older adults & 182 & & & A & & & & \\
\hline $\begin{array}{l}\text { Young } \\
\text { persons }\end{array}$ & 200 & + & + & A & & & & \\
\hline Overall & 388 & + & & 1 & 114 & - & & 1 \\
\hline
\end{tabular}

Note: “+” indicates that Historically Marginalized Community (both Tier I and II) block groups have significantly better bicycle accessibility than non-designated block groups; “-” indicates that Historically Marginalized Community block groups have significantly worse bicycle accessibility than non-designated block groups; blank spaces indicates that the differences in bicycle accessibility is not statistically significant at the 0.05 level. 


\subsection{DISCUSSION \& CONCLUSION}

\subsection{DISCUSSION}

This study developed three approaches to characterize and measure bicycle network accessibility: (1) distance-based BAM, (2) destination-based BAM, and (3) low-stress network BAM, which incorporated different components of active transportation network characteristics defined by FHWA (2016). In particular, the latter two measures both involved identification of important destinations for access to employment, retail, services and park/recreation. Each of the identified important destinations are weighted by its attractiveness through either job density or acreage of park. Some of these analytical choices are due to data availability, but future studies of these bicycle network accessibility measures may be improved by incorporating regional travel demand models that integrate active transportation modes or bicycle ridership data to more accurately capture the actual active transportation travel demand. Moreover, additional k-factors ${ }^{8}$ might be incorporated to calibrate nuances in actual travel behavior to destinations.

While this report presents several bicycle accessibility measures that incorporate different levels of data and computational requirements to advance the measurement of urban greenway networks, we hope to expand upon this research in the future by incorporating additional active transportation characteristics. In particular, we would like to explore additional applications and specifications of the low-stress network BAM, as our research results show the potential for this type of network performance metric. Given the importance of including access to important destination in these types of metrics, additional geo-cluster analysis can be integrated to further identify the true hot spot destinations that attract the largest number of trips of different types. In addition, we hope to also integrate additional low-stress route identification variables such as usage patterns of bicyclists and pedestrians, existence of on-street parking, lane width, and other road infrastructure characteristics (HCM 2014). It is also plausible to imagine that different types of urban greenway facilities will contribute differently to active transportation behavior (e.g., commuting bicycling versus recreational bicycling) and, thus, economic outcomes. Integration of the urban greenway network with other components of the transportation network, such as the public transportation network or bicycle sharing network, will be another important area of research that will allow for a more comprehensive understanding of how the entire transportation network contributes to accessibility.

In order to test whether BAMs are sensitive to different infrastructure and network changes, we applied two scenarios: baseline 2016 scenario and hypothetical 2035 future scenario. The purpose of these two scenarios is to aid in the examination of changes to bicycle network accessibility using a realistic hypothetical scenario. It should not be taken as an evaluation or forecast of the economic and social equity outcomes in 2035.

Not surprisingly, with improvements to the bicycle network infrastructure, bicycle accessibility increases across the city. However, BAM improvements are not equally distributed, both

\footnotetext{
${ }^{8} \mathrm{~K}$-factors are parameters that adjusts trip distribution between origins and destinations, often accounting for factors that cannot be incorporated into a model.
} 
spatially and demographically. In particular, the different BAMs reflect differences in the improvement of various aspects of the bicycle network. By definition, the distance-based BAM has the lowest data requirements, but this measure will improve with the majority of investments into the bicycle network infrastructure. As we found in the results, while residents may be better able to access the urban greenway network as more bicycle infrastructure is built, it does not necessarily translate into better access to important destinations or access via low-stress active transportation routes, especially for those within disadvantaged communities. These results underscore the importance of complementary economic development and land use policies that takes into account the spatial distribution of important destinations while investing in urban greenway infrastructure or other transportation network improvements.

\subsection{CONCLUSION}

“City Greenways” is a concept proposed as a part of Portland’s 2035 Comprehensive Plan, which calls for a citywide network of park-like pedestrian and bicycle-friendly streets crisscrossing the city at roughly three-mile intervals. This research establishes several approaches to evaluating the transportation outcomes of the "City Greenways” network, and defines several bicycle accessibility measures (BAMs) that characterize urban greenway networks for this purpose. In addition, we relate these network measures with economic and social equity characteristics to investigate the corresponding outcomes. We laid out our research questions and objectives at the beginning of this report as follows:

- What are the ways that we can characterize and measure the accessibility of the urban greenway network?

o Which urban greenway network accessibility measures are more sensitive to various types of active transportation infrastructure investments scenarios, particularly those aimed at improving the network?

o How do urban greenway network accessibility measures relate to economic outcomes?

o How do urban greenway network accessibility measures correspond to equity outcome in the context of providing equitable access to both the urban greenway network itself, as well as providing connections to employment, service and recreational opportunities via the network?

Past research has shown that changes, improvements and additions to urban greenways, defined as bicycle- and pedestrian-oriented infrastructure located in both on- and off-street settings, can result in multiple types of economic impacts, such as decreases in overall travel costs through lower congestion levels, growth in economic activities (including local business revenues, employment generation, and property values), and changes in the distribution of access to opportunities.

FHWA (2016) uses a six-principle framework to define a complete urban greenway network, including cohesion, directness, accessibility, alternatives, safety and security, and comfort. Several measures of urban greenway networks are reviewed, including distance-based, destination-based, topology-based and walkability/bikeability, based on this framework, and we derive three sets of bicycle accessibility measures (BAMs) based this field of research. 
In addition to the direct transportation accessibility impacts of urban greenway networks, we reviewed literature that characterizes indirect economic impacts of the active transportation network through impacts on economic output, business vitality, and property values. Most studies indicate positive linkage between active transportation investments and economic prosperity, but some negative impacts have also been found in some cases.

Finally, we review the literature on the equitable spatial and demographical distribution of active transportation infrastructure and find that studies show severe accessibility challenges to active transportation infrastructure for disadvantaged communities, and, correspondingly, challenges in accessing economic benefits, services and destinations served by the infrastructure network.

Building upon the existing research, we first construct three sets of bicycle accessibility measures (BAMs) to examine the transportation accessibility impact of urban greenway networks. The three sets of BAMs are distance-based BAM, destination-based BAM, and lowstress network-based BAM.

- The distance-based BAM measures accessibility of the active transportation infrastructure via a proximity measurement;

- $\quad$ The destination-based BAM measures the ease of access to closest five important employment, retail, service and parks/recreation destinations; and

- The low-stress network-based BAM measures the comfort levels and willingness to use an active transportation mode as a travel option. It incorporates bicycle level of stress factors (level of service (LOS) of urban greenways), such as link stress, link slope and turn factor to determine the overall accessibility of the urban greenway network.

After we constructed the various BAMs, the relationship between these bicycle accessibility measurements and economic and equity indicators were examined. We measured the economic impact of greenways through correlation analysis between BAMs and employment, and hedonic pricing regression analysis between BAMs and property values. In addition, we examined the equity impact through spatial analysis of BAMs within several definitions of disadvantaged populations in Portland.

Comparing the urban greenway network in the 2016 and proposed 2035 scenarios, we found that after the implementation of Portland's “City Greenway” network, all three sets of BAMs show improvements in accessibility compared to the existing network, although at varying degrees. The improvements in the distance-based BAM indicates more proximity to the urban greenway network for the general public.

Additionally, the added urban greenway facilities will increase the ease of access to all four types of important destinations, including employment, retail, service and parks/recreation destinations. When high-quality urban greenways are connected to existing bicycle facilities, they contribute to a well-formed and low-stress active transportation network for the city. The improved urban greenway network not only decreases the travel costs of active transportation due to a well-connected network and higher comfort and safety levels of cycling, it will also provide increased accessibility to important destinations at lower stress levels within the same distances. 
When we explored the relationship between the bicycle accessibility levels of the urban greenway network and economic indicators, we find a positive correlation between two BAMs (distance-based BAM and low-stress network-based BAM) with the number of jobs that are located in each census block. The low-stress network-based proximity BAM appears to be the more preferred measure, due to the statistical significant positive correlations that we found. In addition, the hedonic price model indicates that higher BAM scores are associated with higher property values, particularly for multifamily homes. In general, better BAMs are associated with higher levels of economic activities.

The spatial equity analysis examines the how bicycle accessibility is distributed across the metropolitan area and amongst identified, historically marginalized communities (including communities with higher populations of people of color, low-income limited English proficiency [LEP] residents, older adults and younger persons), and how the proposed 2035 City Greenways plan might impact these communities differently. We found that the 2035 City Greenways plan, as measured through BAM, slightly favor the communities with higher percentages of people of color, more low-income residents and people with language isolation. While the distance-based BAM showed significant improvements in accessibility for many of the transportation disadvantaged communities, the low-stress network-based BAMs showed tempered improvement in these communities.

This research utilizes Portland as an urban laboratory for the transportation, economic and social equity impacts of urban greenway networks. We hope to be able to replicate this methodology in other metropolitan areas gearing up to invest in urban greenway networks to validate and construct a most robust and practice-oriented measurement framework for bicycle accessibility. 


\subsection{REFERENCES}

Apparicio, Philippe, Mohamed Abdelmajid, Mylène Riva, and Richard Shearmur. 2008. "Comparing Alternative Approaches to Measuring the Geographical Accessibility of Urban Health Services: Distance Types and Aggregation-Error Issues.” International Journal of Health Geographics 7 (1): 7. https://doi.org/10.1186/1476-072X-7-7.

Asabere, Paul K., and Forrest E. Huffman. 2009. “The Relative Impacts of Trails and Greenbelts on Home Price.” The Journal of Real Estate Finance and Economics 38 (4): 408-19. https://doi.org/10.1007/s11146-007-9089-8.

Bent, Elizabeth, and Krute Singa. 2009. "Modal Choices and Spending Patterns of Travelers to Downtown San Francisco, California: Impacts of Congestion Pricing on Retail Trade.” Transportation Research Record: Journal of the Transportation Research Board 2115 (December): 66-74. https://doi.org/10.3141/2115-09.

Brander, Luke M., and Mark J. Koetse. 2011. "The Value of Urban Open Space: Meta-Analyses of Contingent Valuation and Hedonic Pricing Results.” Journal of Environmental Management 92 (10): 2763-73. https://doi.org/10.1016/j.jenvman.2011.06.019.

Broach, Joseph, Jennifer Dill, and John Gliebe. 2012. "Where Do Cyclists Ride? A Route Choice Model Developed with Revealed Preference GPS Data.” Transportation Research Part A: Policy and Practice 46 (10): 1730-40. https://doi.org/10.1016/j.tra.2012.07.005.

Clifton, Kelly, Christopher Muhs, Sara Morrissey, Tomas Morrissey, Kristina Currans, and Chiloe Ritter. 2012. “Customer Behavior and Travel Mode Choice.” Oregon Transportation Research and Education Consortium. http://kellyjclifton.com/Research/EconImpactsofBicycling/OTRECReportConsBehavTravelChoices_Nov2012.pdf.

Conway, Delores, Christina Q. Li, Jennifer Wolch, Christopher Kahle, and Michael Jerrett. 2010. "A Spatial Autocorrelation Approach for Examining the Effects of Urban Greenspace on Residential Property Values.” The Journal of Real Estate Finance and Economics 41 (2): 150-69. https://doi.org/10.1007/s11146-008-9159-6.

Cortright, Joe. 2009. "Walking the Walk: How Walkability Raises Home Values in US Cities.” http://www.citeulike.org/group/11305/article/5541951.

Dai, Dajun. 2011. "Racial/ethnic and Socioeconomic Disparities in Urban Green Space Accessibility: Where to Intervene?” Landscape and Urban Planning 102 (4): 234-44. https://doi.org/10.1016/j.landurbplan.2011.05.002.

Deng, Taotao. 2013. "Impacts of Transport Infrastructure on Productivity and Economic Growth: Recent Advances and Research Challenges.” Transport Reviews 33 (6): 686-99. https://doi.org/10.1080/01441647.2013.851745.

Dill, Jennifer. 2004. “Measuring Network Connectivity for Bicycling and Walking.” In 83rd Annual Meeting of the Transportation Research Board, Washington, DC, 11-15.

Dill, Jennifer, and Nathan McNeil. 2013. "Four Types of Cyclists?: Examination of Typology for Better Understanding of Bicycling Behavior and Potential.” Transportation Research Record: Journal of the Transportation Research Board 2387 (December): 129-38. https://doi.org/10.3141/2387-15. 
Drennen, Emily. 2003. "Economic Effects of Traffic Calming on Urban Small Businesses.” Department of Public Administration San Francisco State University. https://www.sfbike.org/download/bikeplan/bikelanes.pdf.

FHWA. 2016. "Noteworthy Local Policies That Support Safe and Complete Pedestrian and Bicycle Networks."

Flusche, Darren. 2012. "Bicycling Means Business: The Economic Benefits of Bicycle Infrastructure.” League of American Bicyclists. http://www.advocacyadvance.org/site_images/content/Final_Econ_Update(small).pdf.

Foth, Nicole, Kevin Manaugh, and Ahmed M. El-Geneidy. 2013. “Towards Equitable Transit: Examining Transit Accessibility and Social Need in Toronto, Canada, 1996-2006.” Journal of Transport Geography 29 (May): 1-10. https://doi.org/10.1016/j.jtrangeo.2012.12.008.

Golub, Aaron, Melody L. Hoffmann, Adonia E. Lugo, and Gerardo F. Sandoval. 2016. Bicycle Justice and Urban Transformation: Biking for All? Routledge.

Gotschi, Thomas. 2011. "Costs and Benefits of Bicycling Investments in Portland, Oregon.” Journal of Physical Activity and Health 8 (Suppl 1): S49-58.

Guo, Jessica Y., and Sasanka Gandavarapu. 2010. “An Economic Evaluation of HealthPromotive Built Environment Changes.” Preventive Medicine 50 (January): S44-49. https://doi.org/10.1016/j.ypmed.2009.08.019.

Hansen, Walter G. 1959. "How Accessibility Shapes Land Use.” Journal of the American Institute of Planners 25 (2): 73-76. https://doi.org/10.1080/01944365908978307.

Hood, Jeffrey, Elizabeth Sall, and Billy Charlton. 2011. "A GPS-Based Bicycle Route Choice Model for San Francisco, California.” Transportation Letters 3 (1): 63-75. https://doi.org/10.3328/TL.2011.03.01.63-75.

Huff, Herbie, and Robin S. Liggett. 2014. “The Highway Capacity Manual's Method for Calculating Bicycle and Pedestrian Levels of Service: The Ultimate White Paper.” Lewis Center for Regional Policy Studies and Institute of Transportation Studies, University of California.

Iacono, Michael, Kevin J. Krizek, and Ahmed El-Geneidy. 2010. “Measuring Non-Motorized Accessibility: Issues, Alternatives, and Execution.” Journal of Transport Geography 18 (1): 133-40. https://doi.org/10.1016/j.jtrangeo.2009.02.002.

Jaffe, Eric. 2015. “The Complete Business Case for Converting Street Parking Into Bike Lanes.” 2015. http://www.citylab.com/cityfixer/2015/03/the-complete-business-case-for-convertingstreet-parking-into-bike-lanes/387595/.

Krizek, Kevin. 2006a. Guidelines for Analysis of Investments in Bicycle Facilities (No. 522). Washington, D.C: Transportation Research Board. . 2006b. “Two Approaches to Valuing Some of Bicycle Facilities’ Presumed Benefits:” Journal of the American Planning Association 72 (3): 309-20. https://doi.org/10.1080/01944360608976753.

—. 2007. "Economic Benefits of Bicycling and Bicycle Facilities: An Interpretive Review and Proposed Methods.” In Essays on Transportation Economics, 219-48.

Landry, Shawn M, and Jayajit Chakraborty. 2009. "Street Trees and Equity: Evaluating the Spatial Distribution of an Urban Amenity.” Environment and Planning A 41 (11): 2651-70. https://doi.org/10.1068/a41236.

Lindsey, Greg, Joyce Man, Seth Payton, and Kelly Dickson. 2004. "Property Values, Recreation Values, and Urban Greenways.” Journal of Park and Recreation Administration 22 (3): 6990. 
Lindsey, Greg, Maltie Maraj, and SonCheong Kuan. 2001. “Access, Equity, and Urban Greenways: An Exploratory Investigation.” The Professional Geographer 53 (3): 332-46. https://doi.org/10.1111/0033-0124.00288.

Litman, Todd. 2017. "Evaluating Transportation Equity: Guidance For Incorporating Distributional Impacts in Transportation Planning.” Victoria Transport Policy Institute. http://www.vtpi.org/equity.pdf.

Liu, Jenny H., and Jeff Renfro. 2014. "Oregon Property Tax Capitalization: Evidence from Portland.” Northwest Economic Research Center. http://www.pdx.edu/nerc/proptax2014.

Liu, Jenny H., and Wei Shi. 2017. "Impact of Bike Facilities on Residential Property Prices." Transportation Research Record: Journal of the Transportation Research Board 2662: 5058.

Lowry, Michael B., Peter Furth, and Tracy Hadden-Loh. 2016. "Prioritizing New Bicycle Facilities to Improve Low-Stress Network Connectivity.” Transportation Research Part A: Policy and Practice 86 (April): 124-40. https://doi.org/10.1016/j.tra.2016.02.003.

Lowry, Michael, Daniel Callister, Maureen Gresham, and Brandon Moore. 2012. "Assessment of Communitywide Bikeability with Bicycle Level of Service.” Transportation Research Record: Journal of the Transportation Research Board 2314 (December): 41-48. https://doi.org/10.3141/2314-06.

Lubitow, Amy, Jennifer Rainer, and Sasha Bassett. n.d. "Exclusion and Vulnerability on Public Transit: Experiences of Transit Dependent Riders in Portland, Oregon.” Mobilities, 1-14.

Lucas, Karen. 2012. “Transport and Social Exclusion: Where Are We Now?” Transport Policy 20 (March): 105-13. https://doi.org/10.1016/j.tranpol.2012.01.013.

Lundberg, Benjamin. 2012. "Accessibility and University Populations: Local Effects on NonMotorized Transportation in the Tuscaloosa-Northport Area.” University of Alabama Libraries.

McNeil, Nathan. 2011. "Bikeability and the 20-Min Neighborhood: How Infrastructure and Destinations Influence Bicycle Accessibility.” Transportation Research Record: Journal of the Transportation Research Board 2247 (December): 53-63. https://doi.org/10.3141/224707.

New York City Department of Transportation. 2012. "The Economic Benefits of Sustainable Streets.” New York City Department of Transportation. http://www.nyc.gov/html/dot/downloads/pdf/dot-economic-benefits-of-sustainablestreets.pdf.

Nicholls, Sarah, John L. Crompton, and others. 2005. "The Impact of Greenways on Property Values: Evidence from Austin, Texas.” Journal of Leisure Research 37 (3): 321-41.

O’Connor, David, James Nix, Simon Bradshaw, and Enda Shiel. 2011. "Report on Shopper Travel Behaviour in Dublin City Centre.” In . University of College Cork, Cork. http://arrow.dit.ie/comlinkoth/10/.

Pivo, Gary, and Jeffrey D. Fisher. 2011. "The Walkability Premium in Commercial Real Estate Investments: The Walkability Premium in Commercial Real Estate Investments.” Real Estate Economics 39 (2): 185-219. https://doi.org/10.1111/j.1540-6229.2010.00296.x. Popovich, Natalie, and Susan Handy. 2014. "Bicyclists as Consumers: Mode Choice and Spending Behavior in Downtown Davis, California.” Transportation Research Record: Journal of the Transportation Research Board 2468 (December): 47-54. https://doi.org/10.3141/2468-06. 
Portland Metro. 2017. "2018-2021 Metropolitan Transportation Improvement Program (MTIP) (Adoption Draft).” http://www.oregonmetro.gov/sites/default/files/MTIP-2018-21-PublicReview-Draft-20170421.pdf.

Resource Systems Group, Inc., Economic and Policy Resources, Inc., and Local Motion. 2012. "Economic Impact of Bicycling and Walking in Vermont." http://vtransengineering.vermont.gov/sites/aot_program_development/files/documents/ltf/Bi kePedFinal\%20Report\%20Econ\%20Impact\%20Walking\%20and\%20Biking2012.pdf.

Rosen, Sherwin. 1974. "Hedonic Prices and Implicit Markets: Product Differentiation in Pure Competition.” Journal of Political Economy 82 (1): 34-55.

Rowangould, Dana, Alex Karner, and Jonathan London. 2016. "Identifying Environmental Justice Communities for Transportation Analysis.” Transportation Research Part A: Policy and Practice 88 (June): 151-62. https://doi.org/10.1016/j.tra.2016.04.002.

Rowe, Kyle. 2013. "Measuring the Economic Impact of Bicycle Facilities on Neighborhood Business Districts.” http://bikewalkkc.org/wp-content/uploads/2016/03/Bikenomics_v4.pdf.

Sandt, Laura, Tabitha Combs, and Jesse Cohn. 2016. "Pursuing Equity in Pedestrian and Bicycle Planning.” Federal Highway Administration.

http://www.pedbikeinfo.org/cms/downloads/PBIC_WhitePaper_Equity.pdf.

Schlosberg, David. 2009. Defining Environmental Justice: Theories, Movements, and Nature. Oxford University Press.

Silva, Cecilia, and Paulo Pinho. 2010. “The Structural Accessibility Layer (SAL): Revealing How Urban Structure Constrains Travel Choice.” Environment and Planning A 42 (11): 2735-52. https://doi.org/10.1068/a42477.

Stantec Consulting. 2011. "Vancouver Separated Bicycle Lanes Business Impact Study.” Stantec Consulting Ltd. http://www.peoplepoweredmovement.org/site/images/uploads/penv3BusinessImpactStudyReportDowntownSeparatedBicycleLanes-StantecReport.pdf.

Turrell, Gavin, Michele Haynes, Lee-Ann Wilson, and Billie Giles-Corti. 2013. "Can the Built Environment Reduce Health Inequalities? A Study of Neighbourhood Socioeconomic Disadvantage and Walking for Transport.” Health \& Place 19 (January): 89-98. https://doi.org/10.1016/j.healthplace.2012.10.008.

Vale, David S., Miguel Saraiva, and Mauro Pereira. 2016. "Active Accessibility: A Review of Operational Measures of Walking and Cycling Accessibility.” Journal of Transport and Land Use, June. https://doi.org/10.5198/jtlu.2015.593.

Williams, Kristine, and Aaron Golub. 2017. "Evaluating the Distributional Effects of Regional Transportation Plans and Projects.” National Institute for Transportation and Communities. http://pdxscholar.library.pdx.edu/trec_reports/139/.

Winters, Meghan, Michael Brauer, Eleanor M Setton, and Kay Teschke. 2013. "Mapping Bikeability: A Spatial Tool to Support Sustainable Travel.” Environment and Planning B: Planning and Design 40 (5): 865-83. https://doi.org/10.1068/b38185.

Wolch, Jennifer R., Jason Byrne, and Joshua P. Newell. 2014. "Urban Green Space, Public Health, and Environmental Justice: The Challenge of Making Cities 'just Green Enough.'” Landscape and Urban Planning 125 (May): 234-44. https://doi.org/10.1016/j.landurbplan.2014.01.017.

Wolch, Jennifer, John P. Wilson, and Jed Fehrenbach. 2005. "Parks and Park Funding in Los Angeles: An Equity-Mapping Analysis.” Urban Geography 26 (1): 4-35. https://doi.org/10.2747/0272-3638.26.1.4. 


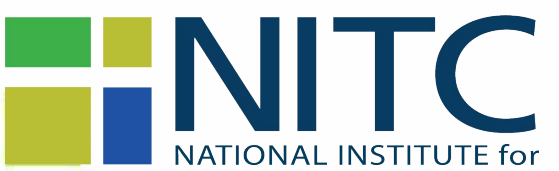

TRANSPORTATION and COMMUNITIES

Transportation Research and Education Center

Portland State University

1900 S.W. Fourth Ave., Suite 175

Portland, OR 97201 